\title{
Quality assurance and accreditation for the development and improvement of public health education
}

Citation for published version (APA):

Goodman, J. D. (2017). Quality assurance and accreditation for the development and improvement of public health education. [Doctoral Thesis, Maastricht University]. Datawyse / Universitaire Pers Maastricht. https://doi.org/10.26481/dis.20170503jg

Document status and date:

Published: 01/01/2017

DOI:

10.26481/dis.20170503jg

Document Version:

Publisher's PDF, also known as Version of record

\section{Please check the document version of this publication:}

- A submitted manuscript is the version of the article upon submission and before peer-review. There can be important differences between the submitted version and the official published version of record. People interested in the research are advised to contact the author for the final version of the publication, or visit the DOI to the publisher's website.

- The final author version and the galley proof are versions of the publication after peer review.

- The final published version features the final layout of the paper including the volume, issue and page numbers.

Link to publication

\footnotetext{
General rights rights.

- You may freely distribute the URL identifying the publication in the public portal. please follow below link for the End User Agreement:

www.umlib.nl/taverne-license

Take down policy

If you believe that this document breaches copyright please contact us at:

repository@maastrichtuniversity.nl

providing details and we will investigate your claim.
}

Copyright and moral rights for the publications made accessible in the public portal are retained by the authors and/or other copyright owners and it is a condition of accessing publications that users recognise and abide by the legal requirements associated with these

- Users may download and print one copy of any publication from the public portal for the purpose of private study or research.

- You may not further distribute the material or use it for any profit-making activity or commercial gain

If the publication is distributed under the terms of Article $25 \mathrm{fa}$ of the Dutch Copyright Act, indicated by the "Taverne" license above, 


\title{
Quality Assurance and Accreditation for the Development and Improvement of Public Health Education
}

\author{
Julien Goodman
}




\title{
Quality Assurance and Accreditation for the Development and Improvement of Public Health Education
}

\author{
Dissertation
}

to obtain the degree of Doctor at Maastricht University, on the authority of the Rector Magnificus, Prof. Dr. Rianne M. Letschert in accordance with the decision of the Board of the Deans, to be defended in public on Wednesday, May 3rd 2017 at 12.00 Hours

by

Julien Goodman 


\section{Supervisor:}

Professor Wim Groot

\section{Assessment Committee:}

Professor Kristof De Witte (Maastricht University, Chair)

Professor Harm Hospers (Maastricht University)

Professor Henriëtte Maassen van den Brink (Maastricht University)

Professor Selena Gray (University of the West of England)

Professor Theodore Tulchinsky (Braun School Public Health and Community Medicine)

\section{Dedication}

M.D. \& Z R i L

\section{Acknowledgement of funding:}

Three of the following chapters $(4,5$ and 6$)$ were funded through a project supported by Erasmus Lifelong Learning Programme, Accompanying Measures Reference: 527903-LLP1-2012-1-BE-ERASMUS-EAM. Project Name: Public health Education Reform For Equity in Quality of Training. 


\section{Contents}

Chapter 1. General Introduction. $\quad 9$

Chapter 2. The Role of the Third Sector in the Development and Improvement of Public Health Education.

Chapter 3. The History of Public Health Education Accreditation.

Chapter 4. European Accreditation and the Future Public Health Workforce.

Chapter 5. Harmonisation in European Public Health Education: A Question of Looking in the Right Places?

Chapter 6. The Use of Quality Assurance Indicators as a Framework for Developing New Schools and Programmes.

References.

Appendices.

Summary.

Curriculum Vitae.

Acknowledgements. 


\section{List of Tables}

Table 1: Definitions of quality assurance including accreditation. 13

Table 2: Definitions of common elements of QA and accreditation processes. 13

$\begin{array}{ll}\text { Table 3: The evolution of public health. } & 15\end{array}$

Table 4: The definition of Public Health used in this document. 18

Table 5: The definition of public health education used in this document. 18

Table 6: "Areas of knowledge basic to public health" in US public health curricula content.

Table 7: A working definition of a School Public Health integrating social accountability. 21

Table 8: A "core" definition of accountability. 21

Table 9: SPH missions from around the globe. 26

Table 10: ENQA Membership. Institutional and programme focus, ECTS and public health content.

Table 11: Example criteria of development spectrum used by Finnish Education Evaluation $\begin{array}{ll}\text { Centre (FINEEC). } & 35\end{array}$

Table 12: Academic institutions of participating schools and programs. 45

Table 13: Changes in American accreditation compulsory curricula contents 1946 to 2014.

Table 14: Example Criterion from APHEA accreditation scheme (2011 version). $\quad 65$

Table 15: Criterion 5 broken down into individual questions. 65

Table 16: Comparison of APHEA sub-categories with 6 other agency accreditation standards.

$\begin{array}{ll}\text { Table 17: Pilot testing feedback and changes made. } & 70\end{array}$

$\begin{array}{ll}\text { Table 18: Regional distribution and collection of survey. } & 72\end{array}$

Table 19: Average compliance with the overarching criteria in the four European regions.73

Table 20: The three least complied sub-criteria in the four European regions. 74

Table 21: School name types from the survey. $\quad 82$

Table 22: Programme name types from the survey. $\quad 82$

Table 23: Temporal and spatial establishment of schools and programmes. 83

$\begin{array}{ll}\text { Table 24: On site review interviewee list. } & 91\end{array}$

Table 25: Estimation of the time needed (in minutes) for the questions proposed. 92 


\section{List of Figures}

Figure 1: Distribution of health workers by level of health expenditure and burden of disease by WHO region.

Figure 2: Mapping Africa's advanced public health education capacity: AfriHealth project.11

Figure 3: Infant mortality rate (IMR) by GNI/capita in US\$.

Figure 4: Burke's academic (accountability) triangle.

Figure 5: Systems framework according to Lancet Commission.

Figure 6: Westley and Antadze's systemic view of social innovation.

Figure 7: European development of Schools of Public Health.

Figure 8: Accredited American SPHs by decade.

Figure 9: Percentage compliance to 23 selected accreditation criteria.

Figure 10: New accountability axes proposed for international accreditation scheme.

120 


\section{List of Abbreviations and Acronyms}

\begin{tabular}{|c|c|}
\hline APHA & American Public Health Association \\
\hline APHEA & Agency for Public Health Education Accreditation \\
\hline AQA & Agency For Quality Assurance and Accreditation Austria \\
\hline ASPHER & Association of Schools of Public Health in the European Region \\
\hline ASPPH & Association the Schools and Programs of Public Health (former ASPH) \\
\hline CAQA & Serbian Commission for Accreditation and Quality Assurance \\
\hline $\mathrm{CEE} / \mathrm{NE} / \mathrm{SE} / \mathrm{WE}$ & Central Eastern/Northern/Southern/Western - Europe \\
\hline $\mathrm{CEPH}$ & Council on Education for Public Health \\
\hline CIS & Commonwealth of Independent States \\
\hline CPD & Continuous Professional Development \\
\hline $\mathrm{CPH}$ & Center for Public Health \\
\hline EAPAA & European Association for Public Administration Accreditation \\
\hline ECTS & European Credit Transfer System \\
\hline EHEA & European Higher Education Area \\
\hline EHMA & European Health Management Association \\
\hline EMPH & European Masters of Public Health \\
\hline ENQA & European Association for Quality Assurance in Higher Education \\
\hline EPAS & European Programme Accreditation System \\
\hline EPHA & European Public Health Alliance \\
\hline EPHO & Essential Public Health Operations \\
\hline EQAR & European Quality Assurance register \\
\hline EQUIS & European Quality Improvement System \\
\hline ESG & European Standards and Guidelines \\
\hline ETC-PH & European Training Consortium in Public Health \\
\hline EUPHA & European Public Health Association \\
\hline FINEEC & Finnish Education Evaluation Centre \\
\hline FOSIM & Foundation Open Society Institute Macedonia \\
\hline $\mathrm{FPH}$ & Faculty of Public Health \\
\hline GNI & Gross National income \\
\hline HFA & Health For All \\
\hline IANPHI & International Association of Public Health Institutes \\
\hline IMR & Infant Mortality Rate \\
\hline IUHPE & International Union for Health Promotion and Education \\
\hline LCQAHE & Lithuanian Center for Quality Assessment in Higher Education \\
\hline MPH & Master of Public Health \\
\hline NAFTA & North American Free Trade Area \\
\hline NaUKMA & National University of Kiev-Mohyla Academy \\
\hline NGO & Non-Governmental Organisation \\
\hline NVAO & Accreditation Organisation of the Netherlands and Flanders \\
\hline OAQ & Swiss Center of Accreditation and Quality Assurance in Higher Education \\
\hline OECD & Organisation for Economic Cooperation and Development \\
\hline $\mathrm{OSI} / \mathrm{F}$ & Open Society Institute / Foundations \\
\hline PAHO & Pan American Health Organization \\
\hline
\end{tabular}


PEER

PERFEQT

QA

QAA

QIDS

QUANGO

San-Epid

SPH

TTIP

UK

US

USSR

WASC

WFME

WFPHA

WHO
Public health Education European Review

Public health Education Reform For Equity in Quality of Training

Quality Assurance

Quality Assurance Agency for Higher Education

Quality Improvements and Development Service

Quasi-autonomous-non-governmental organisations

Sanitary-Epidemiology

School of Public Health

Transatlantic Trade and Investment Partnership

United Kingdom

United States of America

Union of Soviet Socialist Republics

Western Association of Schools and Colleges

World Federation of Medical Education

World Federation of Public Health Associations

World Health Organization 

Chapter 1. General Introduction 
In 1985 there were an estimated 101 schools of public health on the planet (2). Within a quarter of a century this number had more than quadrupled to 467 (3). On the face of it, this four-fold increase seems impressive but it still only represents one school per 15 million people and more importantly the distribution abides by the "inverse care law" (4) where areas in most need are least served $(5,6)$. Figure 1 demonstrates this law with health workers who are defined as "all people primarily engaged in actions with the primary intent of enhancing health" (5).

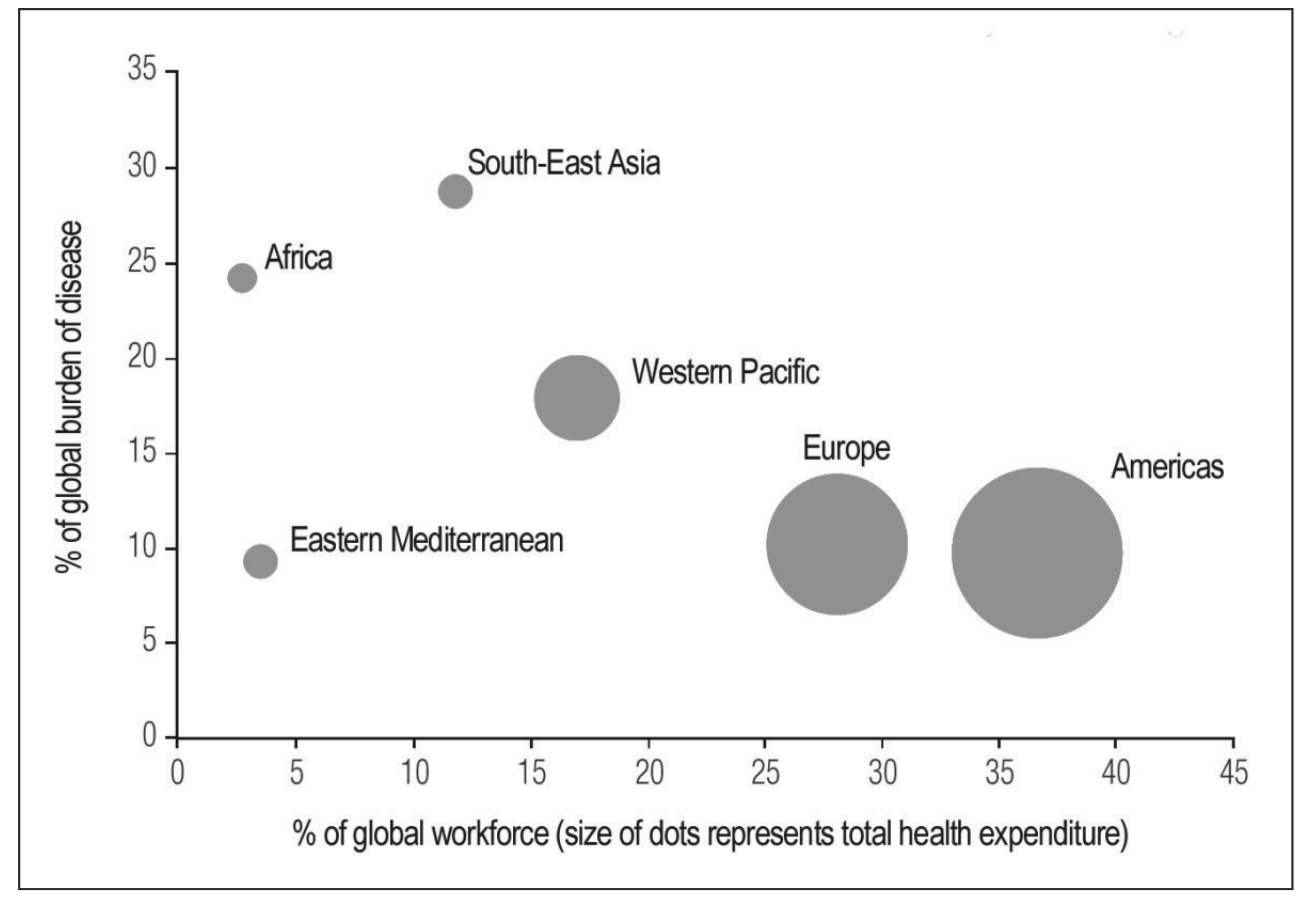

Figure 1: Distribution of health workers by level of health expenditure and burden of disease by WHO region. Source (5)

In the United States of America (US) the school / population ratio is 1 to just under 5.5 million people whereas in Africa the ratio is 1 to every 17.4 million (1) (see Figure 2) and in India there is only 1 school for every 307 million people (3). Hence the growth in schools of public health continues to be restricted to wealthier countries (7). In 2012 it was estimated that there was a shortfall of 7.2 million professional health workers which is expected to rise to 12.9 million over the next decades (8). Although this figure may embrace a broader workforce definition, educated and trained public health workers have been shown to be lacking throughout the globe (9-13). 


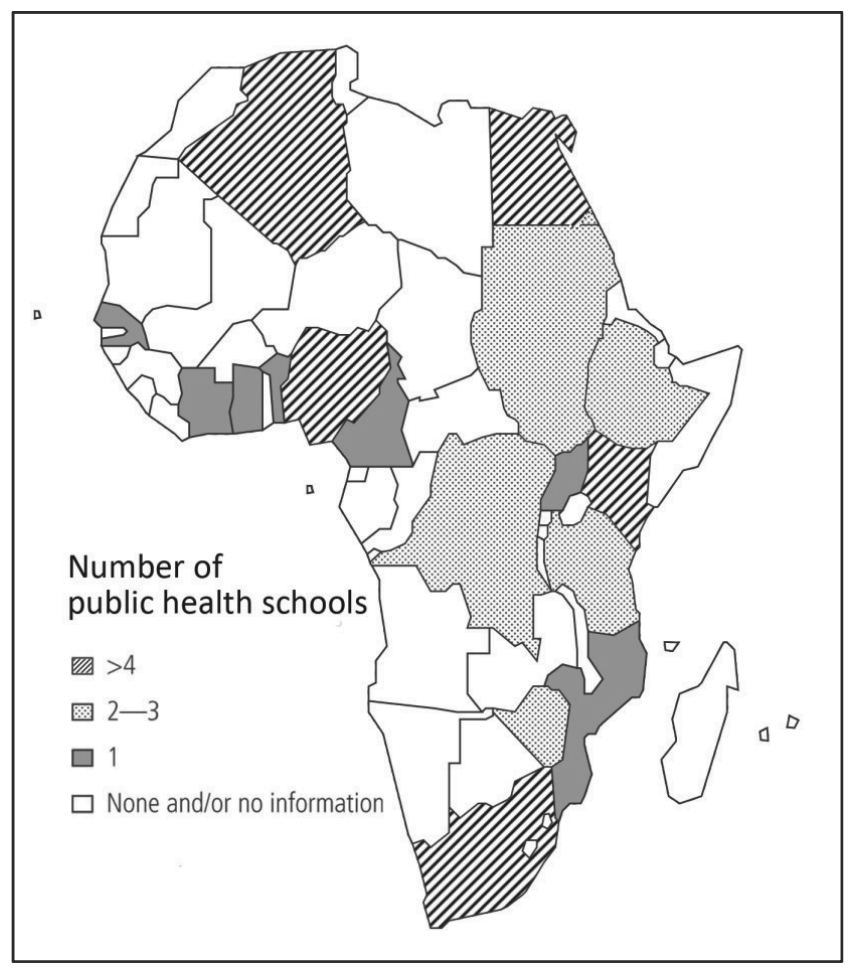

Figure 2: Mapping Africa's advanced public health education capacity: AfriHealth project. Source (1)

To redress this situation and the low production of graduates, the World Health Organization had earlier stated that "shortfalls will require building new institutions and ensuring a more appropriate mix of training opportunities - for example, more schools of public health are needed" (5). But what is a school of public health? There are no universally agreed definitions (6). Figure 2 (on the African Schools) is a case in point. Here the authors mention "number of public health schools" but this map actually shows the "number of institutions with post graduate public health programmes" (1). How then should these "schools" develop without a clear definition of what they are? What models should they adopt or follow? It has been suggested that accreditation could act in a stewardship role in shaping the development of schools and programmes in public health $(2,14-16)$. This leads to the central research question:

Can accreditation be used for the development and improvement of public health education and, if so, how? 


\subsection{Definitional Ambiguity}

Accreditation shares many similarities with public health and public health education, such as a lack of or confusing definitions, changing roles within nation states and societies, emerging global developments, competition and, most of all, being in an ever changing state of flux. An appropriate starting point is to explore the differences in the definitions that exist in accreditation, public health and public health education which will help highlight the complexity of the field of enquiry, clarify the different prescribed usages and adopt a consistent terminology for the subsequent text.

\subsubsection{Quality Assurance}

"Quality is like love. Everybody talks about it and everybody knows what he or she is talking about. Everybody knows and feels when there is love. Everybody recognises it. But when we try to give a definition of it, we are left standing with empty hands." (17)

Accreditation can be seen to sit within the framework of quality assurance (QA) (18) but discerning the two is often perilous as QA is a generic term which lacks any specific and accepted definition (19-21). The terms are often used synonymously (20, 22, 23). A general description of QA would involve activities aimed at maintaining and enhancing quality (24, 25 ) but this too is covered by varying definitions of accreditation: "accreditation... is about quality assurance and quality improvement" (26) or accreditation "focuses heavily on institutional development and improvement" (27). Westerheijden states that "the discussion on definitions is in principle tedious since we can define terms as we like" (28). Existing alongside accreditation under the QA umbrella are other terms and titles such as audit, assessment, external examining. Here, too, there are blurred definitional lines in the object, focus, rationale, and methods of these different processes (29-31). Some authors have attempted to draw a line in the sand by delimiting their definitions: "we generally use 'quality assessment' to describe the first more limited set of processes - evaluation, review, audit, monitoring" (32) or "accreditation refers to a process resulting in a decision that warrants an institution or programme; audit explores internal processes; assessment passes a judgement; external examination checks standards"(33). However, all of these aspects can be found to some degree in the varying systems of QA $(26,34,35)$. In the given version of accreditation above, the word "warrant" conjures up a new layer of societal power relations in which education is deemed accountable: "quality assurance is about ensuring accountability" (36, 37). The "who" education is accountable to invariably influences the role and ultimately the definition.

Table 1 identifies both a definition of quality assurance and associated processes and Table 2 addresses the basic ingredients or methods thereof $(21,38)$. Both tables draw on Lee Harvey's thorough analysis of terms associated with quality assurance in which Harvey synthesises a plethora of diverse designations (39). 


\begin{tabular}{|l|l|}
\hline $\begin{array}{l}\text { Quality } \\
\text { Assurance }\end{array}$ & $\begin{array}{l}\text { "Assurance of quality in higher education is a process of establishing } \\
\text { stakeholder confidence that provision (input, process, and outcomes) fulfils } \\
\text { expectations or measures up to threshold minimum requirements." }\end{array}$ \\
\hline Accreditation & $\begin{array}{l}\text { "The establishment of the status, legitimacy or appropriateness of an } \\
\text { institution, programme or module of study." }\end{array}$ \\
\hline Audit & $\begin{array}{l}\text { "Audit, in the context of quality in higher education, is a process for checking } \\
\text { that procedures are in place to assure quality, integrity, or standards of } \\
\text { provision and outcomes." }\end{array}$ \\
\hline Assessment & $\begin{array}{l}\text { "A general term that embraces all methods used to judge the performance of an } \\
\text { individual, group or organisation." }\end{array}$ \\
\hline
\end{tabular}

Table 1: Definitions of quality assurance including accreditation. Source (39)

Some elements which are more constant or common refer to the "ingredients" of QA and accreditation processes and are based around transparency and agreed standards and criteria which tend to include the activities isolated in Table 2 below.

\begin{tabular}{|l|l|}
\hline $\begin{array}{l}\text { Self-study / evaluation / } \\
\text { assessment }\end{array}$ & $\begin{array}{l}\text { "Self-assessment is the process of critically reviewing the quality of } \\
\text { one's own performance and provision." (39, 40) } \\
\text { "The review and evaluation of the quality and effectiveness of an } \\
\text { institution's own academic programmes, staffing, and structure, based } \\
\text { on standards set by an outside quality assurance body, carried out by } \\
\text { the institution itself. Self-studies are usually undertaken in } \\
\text { preparation for a quality assurance site visit by an outside team of } \\
\text { specialists. Results in a self-study report." (41) }\end{array}$ \\
\hline Peer review / Site visit & $\begin{array}{l}\text { "Peer review is the process of evaluating the provision, work process, } \\
\text { or output of an individual or collective that is operating in the same } \\
\text { milieu as that of the reviewer(s). Peer review is a long-established } \\
\text { tradition in academia and is conducted by academics in the same } \\
\text { discipline" (42). "A site visit is when an external evaluation team goes } \\
\text { to an institution to evaluate verbal, written, and visual evidence" (39, } \\
\text { 40). }\end{array}$ \\
\hline Report & $\begin{array}{l}\text { "Report made of the results of and experience with the methods used } \\
\text { during the site visit, with options for applicant responses." (34, 43) }\end{array}$ \\
\hline $\begin{array}{l}\text { Judgment by accrediting } \\
\text { organisation }\end{array}$ & $\begin{array}{l}\text { "Decision-making bodies (commissions) affirm /reaffirm / deny } \\
\text { accreditation for institutions and programmes." (26) }\end{array}$ \\
\hline Periodic review & $\begin{array}{l}\text { "An evaluation of an institution or its programmes on an agreed } \\
\text { regular timeline, for example once every 6 years." (39) "Often used to } \\
\text { check compliance with previously made recommendations." (44) }\end{array}$ \\
\hline
\end{tabular}

Table 2: Definitions of common elements of QA and accreditation processes (sources indicated in brackets).

\subsubsection{Public Health}

Before analysing public health education, public health as a discipline requires examination to provide a context for the education of the sector. Definitions of public health (and with them public health education) are bound in time and space and are intrinsic to the societal relationship of the individual and the society (45) and can often only be identified by current practices. 
In his History of Public Health, George Rosen examined the North American and European history of public health up to the (r)evolution of the bacteriological epoch (46). Out of many potential starting points, be they urbanisation, sanitation or the Broad Street pump, this is perhaps the point in time where modern (Western) public health began. The advent of bacteriology replaced the underlying theories and understanding of health, most notably miasma theory, which believed disease to be a result of bad or "mal" air. The dominance of the older miasma theories did not die out immediately and continued for some time (47, 48). Indeed, so slow were the earlier systems to change that meteorology remained on the curriculum in one school for over 50 years after the advent and acceptance of bacteriology (47). Students were still expected to read a barometer in order to predict the prevailing air patterns! The protracted time required for change, along with its sibling "stasis," remains a constant theme throughout the history of public health and public health education and continues to this day. For example, a government interviewee in a recent WHO selfassessment report for the Essential Public Health Operations (EPHOs) stated the following in 2011:

"Public health is considered as SanEpi ${ }^{1}$ services only, and that the only public health structure that we have is State Hygiene and Anti-epidemic Inspectorate. I think this is not right. In fact there is a problem with the perception, definition and functions of public health. The public health structure cannot be limited to inspection. It should be broader. I think we have problems with the perception of public health at all levels, from higher to lower." (49)

By the early twentieth century, the term "new public health" was coined. One of its earliest proponents wrote in 1913 (rather inversely by modern interpretations): "The old public health was concerned with the environment; the new is concerned with the individual" (50). The period was also seen as moving away from the dominance of the untrained amateur to the scientifically trained professional (51).

One of the difficulties in pinpointing "public health" as a definition is due to the range of interpretation given to the term (52) and its capacity to change across time and space. As the World Health Organization noted in 1985, "subjects included in the curricula differ from institution to institution, from course to course, and from one year to another...which have occurred because of historical, political, and cultural developments" (2).

Table 3 below highlights a potential for 6 phases (eras) in public health paradigms as seen by one author over the last two centuries and how remnants of the former periods remain in present use. Other authors have opted for more reductionism: "The first public health revolution addressed sanitary conditions and fought infectious diseases; the second public health revolution focused on the contribution of individual behaviours to noncommunicable diseases and premature death. The third public health revolution recognizes health as a key dimension of quality of life" (53).

\footnotetext{
${ }^{1}$ This term is identified as 'San-Epid' throughout the following text.
} 
However, understanding the ebb and flow in the definition of public health is incredibly difficult and often takes a "leap of faith" in considering what is to be defined as public health. In many respects, for contemporary eyes it is like viewing the world through a Marxian camera obscura (54). In the late 19th and early 20th century public health was part of a utilitarian "fit for work and war" ethos $(55,56)$, where the focus of attention lay in getting people into factories or on the front line. Earlier, as an extension of European foreign policy, public health can be seen within a history of colonisation $(1,57)$ and the attempts to protect one's own army and civilians in what became to be referred in Africa as the "white man's grave" $(58,59)$. Perhaps most pertinent is the relationship of the rich and poor. Only when the middle classes (the rich) were affected by the diseases of the poor was any action taken (60).

\begin{tabular}{|c|c|c|}
\hline Public Health Era & Dominant Paradigm & Contemporary Public Health \\
\hline $\begin{array}{l}\text { 1. Health } \\
\text { Protection } \\
\text { (antiquity-1830s) }\end{array}$ & $\begin{array}{l}\text { Diseases may be prevented by } \\
\text { enforced regulation of human } \\
\text { behaviour, mediated through } \\
\text { societies' social structures. }\end{array}$ & $\begin{array}{l}\text { Quarantine of illegal migrants; enforcement of } \\
\text { some environmental protection laws; aspects of } \\
\text { spirituality in prevention and coping with } \\
\text { disease; some occupational and transport } \\
\text { safety. }\end{array}$ \\
\hline $\begin{array}{l}\text { 2. Miasma Control } \\
(1840 \mathrm{~s}-1870 \mathrm{~s})\end{array}$ & $\begin{array}{l}\text { Addressing unsanitary } \\
\text { environmental conditions may } \\
\text { prevent diseases. }\end{array}$ & $\begin{array}{l}\text { Aspects of Healthy Cities initiatives; potable } \\
\text { water and sanitation programmes; legal } \\
\text { framework for implementing public health } \\
\text { activities; foundations of modern epidemiology } \\
\text { and surveillance. }\end{array}$ \\
\hline $\begin{array}{l}\text { 3. Contagion } \\
\text { Control }(1880 \mathrm{~s}- \\
1930 \mathrm{~s})\end{array}$ & $\begin{array}{l}\text { Germ Theory: positivist } \\
\text { approach to demonstration of } \\
\text { infectious origins of diseases. }\end{array}$ & $\begin{array}{l}\text { Evidence-based public health practice; ethical } \\
\text { vaccination practices; foundations for } \\
\text { international cooperation in health; foundations } \\
\text { for modern chemotherapy. }\end{array}$ \\
\hline $\begin{array}{l}\text { 4. Preventive } \\
\text { Medicine (1940s- } \\
1960 s)\end{array}$ & $\begin{array}{l}\text { Improvements in public health } \\
\text { through focus on the } \\
\text { prevention and cure of diseases } \\
\text { in "high-risk groups." }\end{array}$ & $\begin{array}{l}\text { Focus on "high-risk groups" in the planning and } \\
\text { implementation of public health programmes; } \\
\text { improved understanding of the pathogenesis of } \\
\text { communicable and non-communicable diseases. }\end{array}$ \\
\hline $\begin{array}{l}\text { 5. Primary Health } \\
\text { Care (1970s- } \\
1980 \text { s) }\end{array}$ & $\begin{array}{l}\text { Health for All: effective health } \\
\text { care geared toward the } \\
\text { community, for the community, } \\
\text { and by the community. }\end{array}$ & $\begin{array}{l}\text { Concepts underpinning multicultural health and } \\
\text { Healthy Cities initiatives, health inequalities, } \\
\text { and community participation in health } \\
\text { promotion activities. }\end{array}$ \\
\hline $\begin{array}{l}\text { 6. Health } \\
\text { Promotion (1990s- } \\
\text { present) }\end{array}$ & $\begin{array}{l}\text { Advocacy for health; enabling } \\
\text { individuals and communities to } \\
\text { attain optimal health. }\end{array}$ & \\
\hline
\end{tabular}

Table 3: The evolution of public health. Source (63)

The relationship between the rich and the poor provides for several theories on public health, including the notion that societal inequalities negatively affect the health of those societies (61). Other theories tend to look at the wealth of a society and the relationship of wealth with the burden of disease. Social medicine and, later, epidemiological transition theory placed a large emphasis on the social and economic conditions of a society $(59,62)$. Under these theories the wealthier a society becomes the more the burden of disease 
changes from infectious to non-infectious disease (health transition). The socioeconomic development of a society acts as a catalyst with the most important factor for improved health being a rising standard of living (59).

The economic and social development of a country affects the overall mortality rates of a population and most notably in infants (59) (see Figure 3). In the 1970s it was argued that in developed countries "infectious disease is relatively unimportant accounting for less than $1 \%$ of deaths. In the developing countries of Africa, Southeast Asia and Latin America the pattern is reversed" (59).

Other commentators have argued that health transition is influenced by a broader scope, including not only social and economic but also political and cultural factors (64). This view would allow for an interpretation in which governments in poorer countries can focus on public health interventions as a route to economic development and thus reversing the trend seen in previously developing countries: "the history of public health development in low and middle income countries shows that important breakthroughs in public health interventions have led to great improvements in economic development" and "Health is a cause rather than an effect of economic development" (65). Such a view would seem to reinforce the importance of the WHO's call for new schools of public health, especially in poorer regions, as it places an emphasis on the economic utility of public health in the same way that the "fit for work" ethos did for earlier public health progress in the now developed countries.

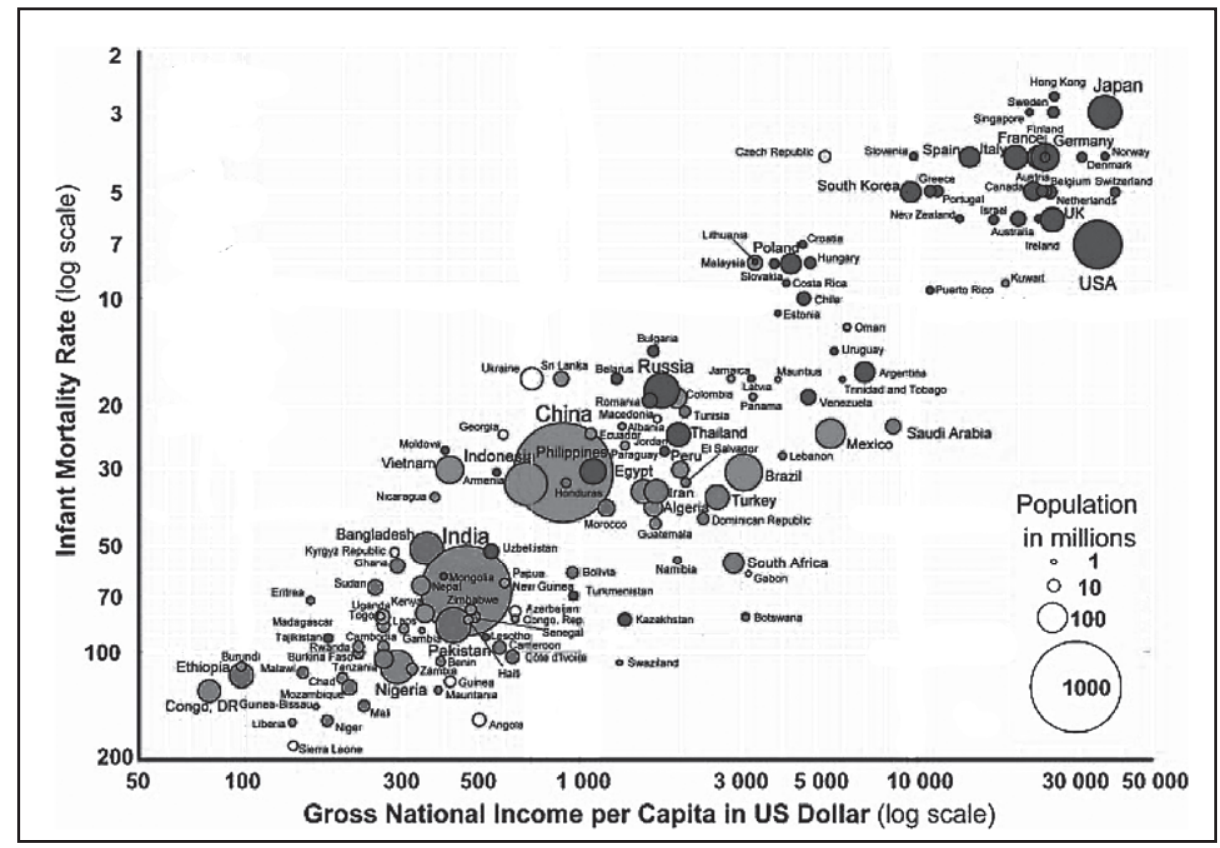

Figure 3: Infant mortality rate (IMR) by GNI/capita in US\$ (both variables are on a logarithmic scale). Source (66) 
The above descriptions paint a picture with a very broad brush as they tend to view societies as mono economic entities, poor, rich, etc. Societies do not consist of one particular wealth group but often see a co-existence of wealth, poverty and disease $(67,68)$. These inequalities are summed up thus: "life expectancy is shorter and most diseases are more common further down the social ladder in each society" (64). In development terms, as countries socially and economically transit, the approach to disease often remains rooted in previous infectious disease control paradigms in the same way as reading the barometer (69). This means that those systems, and the understanding and perceptions within those systems, can often go unchanged and remain outmoded, with dire consequences for the health of those nations $(49,70)$.

\subsubsection{New Public Health}

The interaction of social, economic, political and cultural factors within developing societies along with the changes in the burden of disease may explain why wealthier countries began focusing more closely on (reacting to) non-infectious disease control which required a wider societal response than medicine alone. What distinguishes public health from medicine is that the latter is seen primarily as a reaction to individual health whereas public health takes a preventative and promotional route to the health of a population (71). A modern and accepted view of public health was established in the late 1970s by the World Health Organization's 38 "health for all" targets and the integration of these targets into practice which became known as the "New Public Health"2 (72). This concept is an ever developing term embracing all of the elements highlighted in Table 3 along with a recognition of global inequalities and the "newer" issues of environmental and ecological damage (73). In this sense, it is less a definition than a philosophy aiming to tackle the (population level) causes rather than the (individual level) symptoms. Ashton and Seymour summed this up with an anecdote about health workers as lifesavers standing beside a fast flowing river:

"Every so often a drowning person is swept alongside. The lifesaver dives into the rescue, retrieves the 'patient' and resuscitates them. Just as they have finished another casualty appears alongside. So busy and involved are the lifesavers in all of this rescue work that they have no time to walk upstream and see why it is that so many people are falling in the river." (72)

One of the most popular definitions of public health derives from 1920. It is defined thus: "the science and the art of preventing disease, prolonging life, and promoting physical health and efficiency through organized community efforts" (74). The author, C-E.A. Winslow, saw the inclusion of various professional types; physician, epidemiologist, nurse, engineer, bacteriologist, statistician, social worker, sanitary inspectors, administrator (74). This definition was repeated with slight changes by Acheson in 1988 (75). This was the same year that the Institute of Medicine delivered their "landmark" definition of public health (71): "Public health is what we, as a society, do collectively to assure the conditions

\footnotetext{
2 There was actually nothing new about the term "New Public Health" which appeared in 1913 (Hibbert Hill) and 1923 (C-E A Winslow). Even on its own, the newer usage of the term is 27 years old which strains the concept of "new."
} 
in which people can be healthy" (76). This definition nevertheless is seen as ideologically loaded by some; for example, the Royal College of Physicians of Edinburgh argue that: "we prefer the Acheson definition to the Institute of Medicine definition. The Institute of Medicine definition is couched in free market terms, or the 'minimal state'" (77). The definition of public health used in this document is based on Winslow's definition without the utilitarian "health and efficiency." One potential weakness in this definition, however, is that it does not specifically refer to a multi-agency approach to re-enforce that public health is not uniquely a medical endeavour. A more modern approach which may work as a political sound-bite is seen by the author as "a multi-agency response to population health needs."

"the science and art of preventing disease, prolonging life, and promoting health through organised community efforts."

Table 4: The definition of Public Health used in this document

\subsubsection{Public Health Education}

"It's what you do that defines you"

Batman

Both of the existing accreditation agencies in Public Health education, the Council on Education for Public Health (CEPH) and the Agency for Public Health Education Accreditation (APHEA) are referenced as "public health education" but cover both educational and institutional accreditations which have a wider scope than "education" alone. In these accreditation systems, "education" is used as a broad term which covers education, research and service activities (outputs) as well as institutional structures and processes of schools, programmes and courses. This usage may be due to the difficulties in defining, identifying or naming the structures most commonly associated with a "school of public health." For example, the term "School" is not widespread in Europe, with education being conducted through "departments" or "faculties" (78). This is the same semantic situation in Africa although schools tend to be referred to as community health or community medicine (1). In the American model, historically a range of names was used, including school, faculty or council (79) whereas presently "school" and "college" are the two main modern institutional terms (80).

A broad term covering education, research and service activities of schools, programmes and courses focused on public health as well as their institutional structures and processes.

Table 5: The definition of public health education used in this document

In May 1915 a report by William Welch and Wycliffe Rose was presented to the Rockefeller foundation outlining proposals for the development of schools of public health in which public health was to be separated from medical schools. The creation of schools and the move to separate public health from medicine created "outright hostility" from the medical professions (81) and has been noted as marking "the formal institutionalization of what has been called the schism" (82). This schism may also been seen between European and US 
approaches to public health and to public health education as witnessed by the statement from the physicians in Edinburgh. The autonomy and independence of schools of public health from medical schools is a fundamental tenet of the US public health education and accreditation system whereas in Europe (and its former colonies) the situation is quite different with a history firmly rooted and interwoven with medical education $(1,14,83$, 84).

The stipulation for independence is solely a US phenomenon and may be traced back to only one sentence in the Welch Rose report:

"The profession of the sanitarian or public health worker not being identical with that of the practitioner of medicine, the institute of hygiene, as the essential part of a school of hygiene, should have an independent existence and should not be regarded merely as a department of a medical school" (85).

However, the proposition recommended that schools should maintain a connection: "the school of hygiene should be closely related to a medical school of high standard in such way that the facilities of each should be open to the students of both" (85). This report was delivered to the Rockefeller General Education Board whose assistant secretary (later head) was Abraham Flexner (86). His seminal report only 5 years earlier had recommended the closure of 120 out of 155 medical schools (87). Why would Rockefeller, with Flexner on board, advocate attaching schools of public health to medical schools which, for the most part, should be scrapped? This separation was not a universal prerequisite, as Harvard School, established with Rockefeller funds in 1922, was not initially independent (81). The loss of accreditation in 1945 was used to leverage its re-organisation and independence (88) which is the first recorded instance of public health accreditation being used as a transformational tool.

This independence has been used to help describe a school of public health in the American system (89) and has led to rather vague descriptions, such as "the school of public health is best understood as a community of health specialists in a university setting" (90), or "schools of public health are part of our total health system and share with other units the job of moving toward our overall objective - the health of our people" (91). But descriptions are not definitions.

Schools of Public Health, by and large, remain undefined although there are clear areas of remit which include education, research, and service which are seen as the key ingredients of what constitutes a school $(92,93)$, as well as departments, faculties and programmes. Even these terms, seemingly benign, can be fraught with differences in interpretation and application. Within the US system of accreditation, a school of public health must deliver a minimum of five pre-determined Master level courses in "areas of knowledge basic to public health" (see Table 6) (84) to be both accredited and gain entrance to the Association of Schools and Programs of Public Health (ASPPH - formerly known as ASPH) (94). The areas highlighted in Table 6 have changed over the years, coinciding with the changes in the interpretation of public health, and express a mixture of educational and practical competences (95). For example, parasitology was initially considered a "basic" area but had been dropped by $1974(79,95)$ (See Table 13). 


\begin{tabular}{|l|l|}
\hline Biostatistics & $\begin{array}{l}\text { collection, storage, retrieval, analysis and interpretation of health data; } \\
\text { design and analysis of health-related surveys and experiments; and } \\
\text { concepts and practice of statistical data analysis. }\end{array}$ \\
\hline Epidemiology & $\begin{array}{l}\text { distributions and determinants of disease, disabilities and death in } \\
\text { human populations; the characteristics and dynamics of human } \\
\text { populations; and the natural history of disease and the biologic basis of } \\
\text { health. }\end{array}$ \\
\hline $\begin{array}{l}\text { Environmental health } \\
\text { sciences }\end{array}$ & $\begin{array}{l}\text { environmental factors including biological, physical and chemical factors } \\
\text { that affect the health of a community. }\end{array}$ \\
\hline $\begin{array}{l}\text { Health services } \\
\text { administration }\end{array}$ & $\begin{array}{l}\text { planning, organization, administration, management, evaluation and } \\
\text { policy analysis of health and public health programs. }\end{array}$ \\
\hline $\begin{array}{l}\text { Social and } \\
\text { behavioural sciences }\end{array}$ & $\begin{array}{l}\text { concepts and methods of social and behavioural sciences relevant to the } \\
\text { identification and solution of public health problems. }\end{array}$ \\
\hline
\end{tabular}

Table 6: "Areas of knowledge basic to public health" in US public health curricula content. Source (84)

In the European system there is no prescribed number of programmes which adorns an institution with the title "school." Examples exist of single programme schools (96), and within the membership of the Association of Schools of Public Health in the European Region (ASPHER) there are examples of members offering a sole bachelor programme (97).

A working group of the World Health Organization in 1961 defined a School of Public Health as an institution which, "in addition to research in public health and service to the community, provides a full-time course lasting not less than one academic year" (98). This definition also appears at a time when short training or continuous professional development was in its infancy and when there was hence a lack of integration of this aspect of modern training (99). Later efforts to map global schools of public health saw the WHO adopt an inclusive definition, but still potentially lacking the prospect of continuous professional training:

"institutions that provide full-time postgraduate courses lasting at least one academic year. Other institutions, such as schools of medicine, that have a department of public health, community health, or the like, offering postgraduate programmes in public health, are also included" (2).

The paucity of globally accepted definitions of Schools of Public Health recently led to the curtailment of a global mapping exercise, "because of definitional ambiguity, [our] estimation of public health institutions was incomplete" (3). "Counting" schools, however, may be considered a lower concern than the demonstrative lack of global unity in focus and application which may act to further fragment the sector (100). The following embracing definition of a school of public health uses the WHO term "social accountability" referring to education, research and service and also utilises "educational unit" in denoting an "institution with a recognised duty to prepare the workforce that society needs" (101) but allowing for the scope to cover programmes and departments. 
An educational unit with an obligation to direct education, research and service activities towards addressing the priority health concerns of the community, region, and/or nation it has a mandate to serve.

Table 7: A working definition of a School Public Health integrating social accountability (102)

\subsection{Accountability}

Quality assurance and accreditation are instruments of accountability $(100,103)$ which were brought about in many countries through an ideological change in the relationship between governments and public institutions under the neo-liberal banner associated with "new public management" $(37,38,104-106)$. This relationship change is fundamental to understanding the context and rise of quality assurance in education.

Accountability is the requirement, when undertaking an activity, to expressly address the concerns, requirements or perspectives of others.

Table 8: A "core" definition of accountability Source (39)

\subsubsection{Accountability in Education}

Burton Clark considered educational accountability in his "triangle of coordination" which placed national higher education systems in a triangle of authority between, state, market and academic oligarchies (self-regulation) (45). In this model, different countries exhibit different "pulls" on their education systems according to the three societal areas of authority as (subjectively) viewed by Clark. However, Clark's analysis is based on an ideological perspective over the interaction of the private market, state and the public which stresses a traditionally more American viewpoint than that historically seen in Europe. For example, Clark's definition of market is that "in the broad meaning of market, it is synonymous with nongovernmental, nonregulated." Most countries' education systems do not subscribe to this laissez-faire approach, and Clark seems reminiscent of a "cold-war" viewpoint which literally sees the USSR at the (negative) end of a line, and America at the other (positive) end of the same line.

The arrival of new public management places emphasis on cost control, transparency, market creation and enhancement of accountability to the customers for the quality of services $(107,108)$. As an example, Van Vught and Westerheijden point out that "in the Netherlands [accreditation] final reports, including the 'local reports,' have been made public. The argument for doing so is the accountability objective" (34). These societal conditions are most notably seen in America through a stress on markets above state planning which incorporate "performance measurement, monitoring and management systems, with a growth of audit systems rather than tacit or self regulation" (109). Amaral and Maassen argue that, "new public management approaches have reduced the power of the academic professionals; and one may argue that the use of quality assurance in new public management has led to micromanagement techniques that have been used at the 
local level to control the behaviour of academics in an intrusive way" (110). An example of this micro-management control can be seen in the criteria of an ENQA member, the Serbian Commission for Accreditation and Quality Assurance (CAQA), which stipulates "the maximum work load of the teacher cannot be more than 12 contact hours a week" and "for the performance of study program an adequate space shall be provided with at least $5 \mathrm{~m}^{2}$ net per student" (111).

Joseph Burke adapted Clark's triangle to incorporate and demonstrate the different functionality in the range of quality assurance mechanisms but slightly altered the terminology of the state and academic axis (112). Burke's model is again reflective of the ideological predispositions of Clark's model when considering the position of accreditation within the triangle. In the US, accreditation, as mentioned, is a non-governmental activity, but in Europe, for example, there is a closer bond of accreditation with some agencies sitting within the Ministries of Education $(36,113)$. For example, only four countries in Europe (Austria, Iceland, Switzerland and Cyprus) allow universities to choose their accreditation mechanisms, whereas in the Netherlands only privately funded programmes can do the same (114). This would see the position of European accreditation systems closer toward the axis of state priorities within Burke's model.

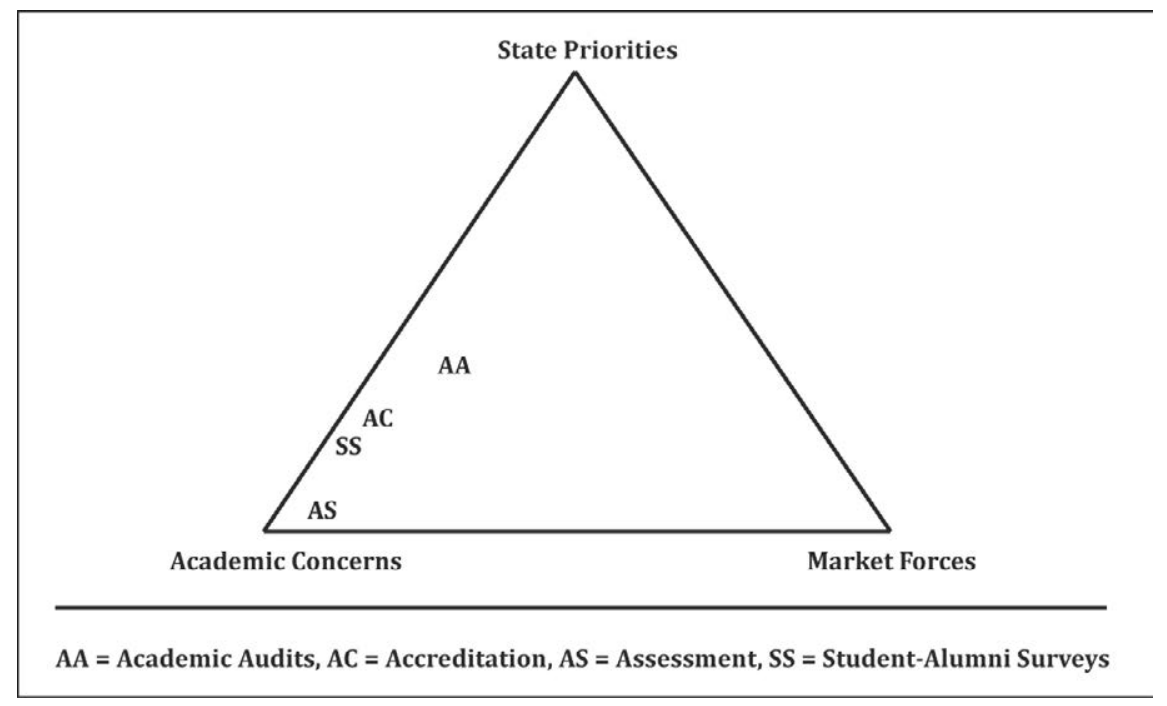

Figure 4: Burke's academic (accountability) triangle. Source (112)

Burke also incorporated varying existent measures of accountability which encompassed a client / stakeholder focus (115-117). As earlier noted by Ball, Vincent and Radnor, there was often a "confusion about who the customer/client actually is" (117). On the other hand, a stakeholder is defined as "organizations and individuals that are involved in a specific activity because they participate in producing, consuming, managing, regulating, or evaluating the activity" (118). This becomes important as it enriches the notion of accountability for funds or money received which, along with concerns such as "value for 
money," dominate the literature on accountability $(17,21,25,36)$. But should monetary value be the sole measure of accountability in education? As Malcolm Frazer writes:

"In summary, quality in higher education is important because universities must be accountable to society, to employers, to students, and to each other. The accountability is not merely financial. Universities exist to generate new knowledge, to disseminate knowledge and to safeguard and transmit a cultural heritage." (24)

Within the American system of accreditation there are financial benefits of successfully achieving accreditation. Most schools gain federal funds through varying federal grants (119). These funds began through the Hill-Rhodes Act instigated in 1958 which initiated a $\$ 1$ million grant system for accredited schools. By 1961 this had risen to $€ 2.5 \mathrm{~m}$ (55) and by 1969 the 18 accredited schools were receiving over $\$ 44 \mathrm{~m}$ from federal sources (120). Federal support was further enshrined in the Health Professions Education Act of 1998 where only accredited schools were eligible for grants under the public health workforce section: "The Secretary may make grants or contracts for the operation of public health training centers" ... "a public health training center shall be an accredited school of public health" (121). In 2012 the 49 accredited schools of public health received over $\$ 1.5 \mathrm{bn}$ in federal grant assistance. To put this into context, the same schools received just over $\$ 400 \mathrm{~m}$ in tuition and fees (122).

\subsubsection{Social Accountability in Public Health Education}

Boelen and Woollard argue that "as globalisation is reassessed for its social impact, societies will seek to justify their investments with more solid evidence of their impact on the public good" and that "there is an urgent need to foster the adaptation of accreditation standards and norms that reflect social accountability" (123). This was echoed by the authors of the aforementioned Lancet mapping exercise who further noted accountability through accreditation:

"The imposition of greater social accountability into accreditation could be instrumental in production of a professional workforce that is well aligned with societal health goals." (3)

These latter authors believe that the supply of health workforce exists in a perpetual cycle with demand (see Figure 5). The interaction of the education and health systems through the labour market, as seen in Figure 5, is represented by two arrowed lines at the top of the diagram. The upper line may reinforce the view that the most direct route to the workforce is obtaining a degree from a school of public health (76). This could be considered as the educative function of a school of public health for producing undergraduate, graduate and postgraduate students ready for inclusion in the workforce. The second lower line is rather more problematic as it seems to imply that there is some form of coherent workforce which requires education. 


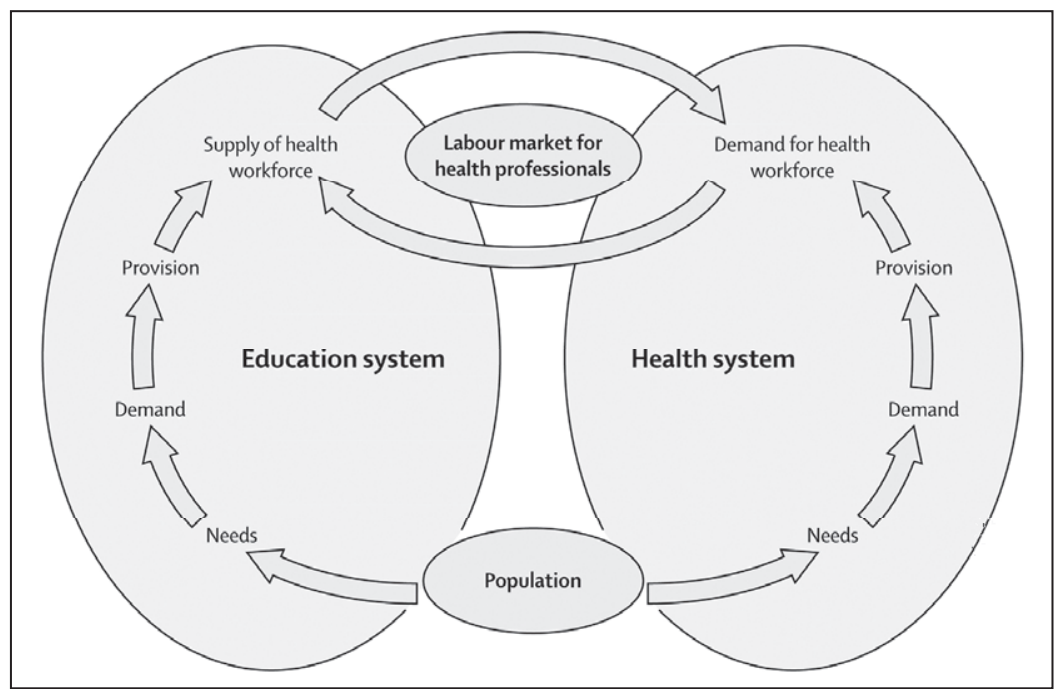

Figure 5: Systems framework according to Lancet Commission. Source (3)

Even in the most developed nations, defining a public health workforce is challenging (124) and is often so broadly inclusive as to lack any firm demarcation $(125,126)$. Furthermore, even if there was a clearly defined public health workforce, is it educated in schools of public health or even educated in public health? In keeping with global experiences (10-12), a recent survey in Switzerland (one of the wealthiest countries on the planet) found that over two-thirds of their public health workforce lacked a public health education (13). Even if the workforce is educated through schools of public health there may also be a mismatch of the skills and competences taught compared to the health needs of the population (127). Therefore, an element of continuous education or training of the workforce is not only an essential need within society but also falls under the scope of public health education. Understanding where it fits within the function of a school of public health is more problematic. Although there are moves to combine education and training, there remains the dichotomy of one being considered as academic or science based, and the other being professionally based $(128,129)$. For educationalists such as Malcolm Tight, the division between education and training is easily reconciled by housing them both under the broader heading of "learning" (130).

In previous American accreditation criteria, workforce training fell under the service function of a school. According to the $2002 \mathrm{CEPH}$ accreditation criteria, the service function of a school was both ill defined and broad, accepting professional education as a constituent part:

"the term service is often ill-defined and covers a wide range of activities including contributions of professional expertise, professional practice, continuing or outreach education, and membership on university committees." (131) 
In the later (now present) 2011 revisions of the criteria, the CEPH added a new criterion headed "workforce development" which is delineated from both the education and service functions of a school of public health:

"Although the primary educational function of a school of public health is the preparation of qualified professionals, a school should also address the needs of the large numbers of personnel engaged in public health practice without formal training and previously trained professionals who seek to maintain and advance their knowledge and skills." (132)

In Europe, the "service" element incorporated into these concepts has been recently replaced by the term "innovation" within a "knowledge triangle": education, research and innovation $(133,134)$. Under this banner, innovation is seen "as the engine of economic development and education as a necessary investment in human capital" (134). To the World Health Organization, "Health professional education has not escaped the trends of international economies. It has become a business, seen as both an investment and an export commodity" (135).

A potential issue arises when considering the economic or "market" demands and how these shape the outputs and focus of public health education. In many countries there exists a very poor understanding of modern comprehensive public health. Governments (policy setters) and stakeholders in these countries continue to understand public health through outdated models of public health (49). This often sees public health falling within medicalised surveillance of infectious diseases and sanitary issues and taught in medical universities as a specialisation $(1,136,137)$. Orientating school activity solely to meet the demands of a market containing such perspectives of public health runs the real risk of exacerbating those perspectives rather than broadening them.

\subsubsection{Social Accountability as Part of a School's Mission}

When addressing the impact of service, Boelen and the WHO highlight four areas: dissemination, advocacy, expansion (scaling-up) and effects. Although a series of actions are provided, there is no clearer understanding of the concept "service." Table 9 identifies a range of mission statements deriving from schools of public health around the globe. No mission statement explicitly expresses the term "service" as an outright activity as was historically the case (98), but most do express additional elements to education and research, including communication, advocacy, policy, outreach, promotion and the translation of knowledge into practice.

These additional elements fit neatly under a newer term, "social innovation." This term covers the previous elements of service as applied to public health education, as the OECD points out: "social innovation seeks new answers to social problems by identifying and delivering new services that improve the quality of life of individuals and communities" (138). Addressing a population level is also fundamental in this new term: "any novel and useful solution to a social need or problem, that is better than existing approaches (i.e., more effective, efficient, sustainable, or just) and for which the value created (benefits) accrues primarily to society as a whole rather than private individuals" (139). Furthermore, 
social innovation embraces multidisciplinarity which is central to new public health: "a diverse background provides a more robust basis for learning, knowledge diversity also facilitates the innovative process by enabling the individual to make novel associations and linkages" (140). Finally, reflective of Ashton and Seymour's definition of new public health, the end objective of social innovation is to address not only the symptoms but also the causes of societal problems (141).

1. The overarching mission of the Harvard T.H. Chan School of Public Health is to advance the public's health through learning, discovery, and communication.

Harvard T.H. Chan School of Public Health. US (142)

2. Our mission is to improve health and health equity in the UK and worldwide; working in partnership to achieve excellence in public and global health research, education and translation of knowledge into policy and practice.

London School of Hygiene and Tropical Medicine, UK (143)

3. To train public health practitioners who will be leaders and change agents for health development in Ghana in particular and in the wider African context.

University of Ghana, School of Public Health, Ghana (144)

4. In pursuing recognition and excellence in its core functions of research, teaching and learning, and integrating engagement with society and communities into these, the University of Pretoria will use quality, relevance, diversity and sustainability as its navigational markers.

Faculty of Health Sciences, University of Pretoria, South Africa (145)

5. The School is committed to protecting and improving health for all people, through the synthesis of state-of-the-science research, the dissemination of knowledge in education and training, and the application of the public health sciences.

School of Public Health, University of Hong Kong (146)

6. To create innovative public health leaders and solutions through cutting-edge, experiential Education, Training, Research and Advocacy.

The James P Grant School of Public Health, Dhaka, Bangladesh (147)

7. Produce, disseminate and share knowledge and technologies aimed at the strengthening and consolidation of the Unified Health System (SUS) and contribute to the promotion of health and quality of life of the population. Besides the reduction of social inequalities and the national dynamics of innovation, with the defense of the right to health and full citizenship as central values.

Escola Nacional de Saude Publica Sergio Arouca at the Oswaldo Cruz Foundation, Rio de Laneiro, Brazil (148)

Table 9: SPH missions from around the globe (Sources indicated in brackets)

The concept of social innovation is progressive and proactive by emphasising a requirement to scan for future needs (149). Westley and Antadze envisage the concept's flexibility in usage through an inter-linkage from the individual through to the organisation and, further, the system: "social entrepreneurship focuses on an individual and social enterprise addresses organizations, social innovation strives to change the way a system operates" (see Figure 6) (141). As such, the integration of social innovation can be envisaged to exist along a spectrum, from the skills and "mindset" encouraged in the individual 
student, faculty or change agent, to how the schools engender a spirit of entrepreneurship and innovation inside their own walls and finally through to how the schools interact with and affect the wider institutional fabric of their societies.

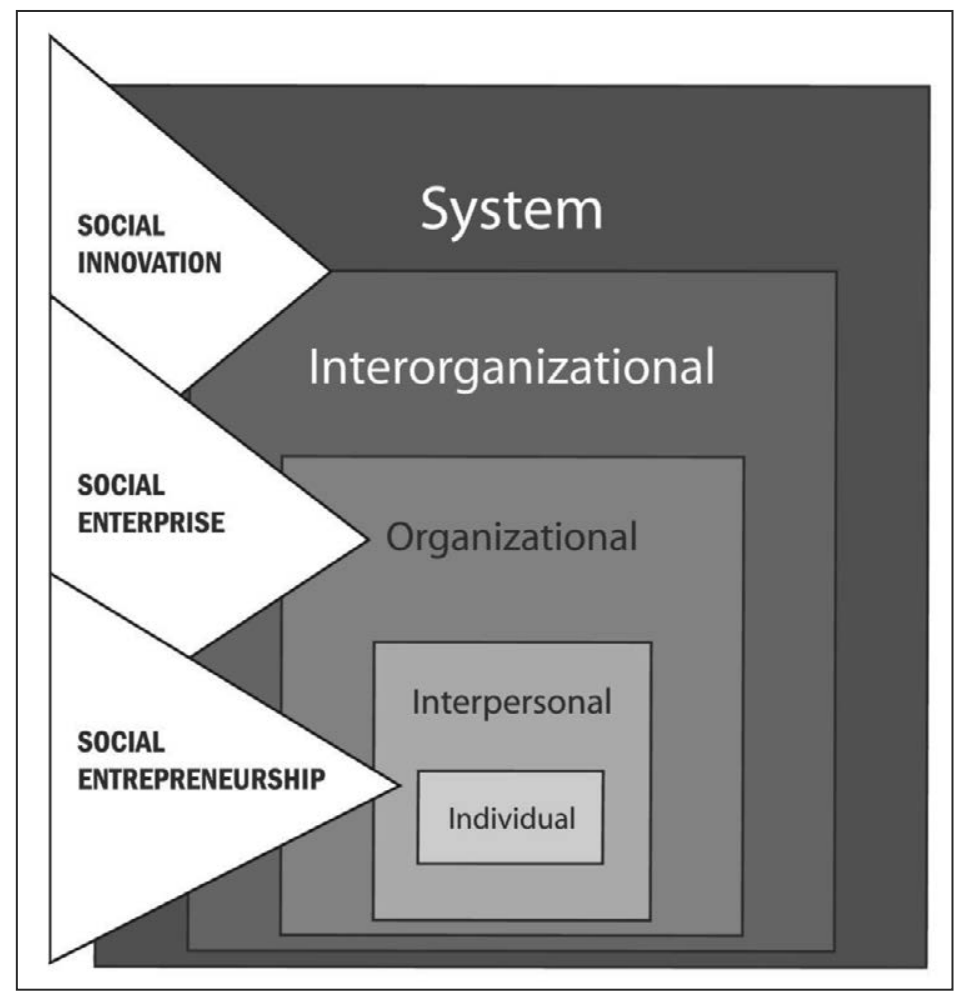

Figure 6: Westley and Antadze's systemic view of social innovation. Source (141)

\subsection{The Increasingly International Remit of Accreditation}

Although Europe becomes progressively more economically and socially united, there is still a major inhibiting influence from political history (103) which is not the case for the US. In the US, education is not a responsibility of the federal government $(112,150,151)$. Within this governmental "laissez-faire" approach, the first state to provide accreditation was New York in 1787 (23), although accreditation of higher education programmes and institutions began in earnest in the mid to late 19th century $(152,153)$. This was realised through the substitution of governmental responsibility to a dependence for academic quality through the use of non-governmental institutional accreditation bodies (26) or the so-called "third sector." Accreditation in the US is for the private sector and is designed to exclude the state $(27,154)$. The first public health education accreditation took place in 1946 (79).

This is quite the reverse situation to the origins of European mass education which was used as a tool to reinforce the legitimacy of national identities between competing and 
often warring European nation states (155). But as the walls fell in Europe, nations faced an opening up to competition in the education markets, with a direct result seen in the introduction of the first large-scale accreditation in the post communist Central and Eastern European region (156). Unlike the American model, the early European approaches to quality in the higher education sector designated a central role for national governments in the control of institutions and the design of programmes (36). The predominance of accreditation in many European countries remained as state control $(21,29,33,34)$. As Skolnik writes:

"Quality assurance agencies often have the formal or effective power to confer or deny the authority that is necessary for an academic programme to be offered or to be successful, and in the course of exercising that power they can practically dictate how the programme is to be designed." (157)

Westerheijden maintains that this period represents the "first generation" of European accreditation which was seen as "control" both in terms of bureaucratic and academic central control but also in market control by protecting the system against alternative providers of education (158). The conclusion of this period was, to Westerheijden, "mainly negative."

The "second generation" according to Westerheijden is characterised by the Bologna arrangements aimed at more transparency, but where national control over the higher education system remained one of the most important principles (158). To combine the joint purposes of European identity with national subsidiarity, a range of nongovernmental (NGO) and quasi-autonomous-non-governmental organisations (QUANGOS) began to appear. One such organisation was the European Association for Quality Assurance in Higher Education (ENQA) which was established to drive the "development of quality assurance across all the Bologna signatory countries" (159). However, there are no specifics to this "quality assurance" within the European Standards and Guidelines (ESG) which ENQA use as their gate keeping application process (18). Instead, under the heading of "fit for purpose," they refer to "fitness" to achieve aims and objectives: "It is of the first importance that agencies should operate procedures which are fit for their own defined and published purposes" (160). This rather leaves the door ajar with no firm commitment. Some commentators go further: "phrases such as 'fitness for purpose'... are without any solid theoretical framework. Fitness for purpose, even if linked to a fitness of purpose, thus implying a non-trivial purpose, still fails to evoke the core concept of the concept of quality" (21).

ENQA may provide a semblance of trust in that it operates based on the ESG. These, according to Kohoutek, are "the most significant outcome of the Bologna Process quality assurance agenda to date" (161). Maassen and Stensaker argue that:

"With the acknowledgement of the European Standards and Guidelines for quality assurance, and the set-up of a new register for quality assurance agencies agreed upon at the ministerial Bologna meeting in London in 2007, one can argue that a major step towards greater standardisation of quality assurance structures has been made." (134) 
Closer examination may bring this into question, not only for educators but also for stakeholders such as students and employers who may want more specificity in the academic and skill competences of their training. As Westerheijden claims, "as for process, nothing more is set than an expectation that 'normally' the four step process is followed outlined already over a decade ago"(28) (see Table 2).

Two European groups operate using the ESG as gate-keeping: ENQA and the European Quality Assurance Register (EQAR). ENQA is, with a couple of exceptions, comprised solely of government-related accreditation agencies. A small scoping exercise found in Table 10 provides information deriving from the standards and criteria used by the national accreditation agencies who are members of ENQA. The analysis centres on the institutional or programme focus of the accreditation systems, on the implementation of the European Credit Transfer System (ECTS) which is central to the Bologna process, and a public health sector focus.

\begin{tabular}{|c|c|c|c|c|c|c|c|c|c|c|c|c|c|c|c|c|c|}
\hline Country & 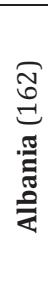 & 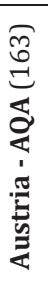 & 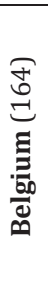 & 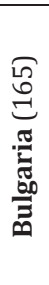 & 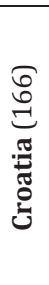 & 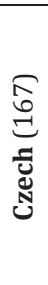 & 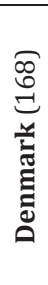 & 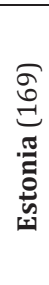 & 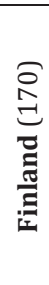 & 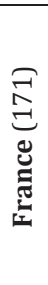 & 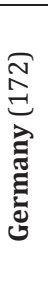 & 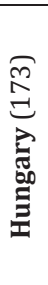 & 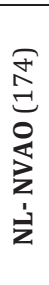 & 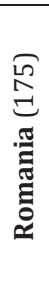 & 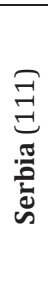 & 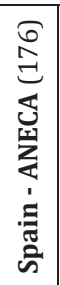 & 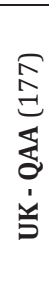 \\
\hline Focus & $a$ & $a$ & $a$ & $a$ & 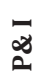 & $a$ & $a$ & $\bar{\alpha}$ & $\bar{\alpha}$ & $a$ & $a$ & $a$ & $a$ & 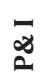 & 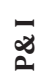 & $a$ & 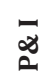 \\
\hline ECTS & $\mathrm{y}$ & $\mathrm{y}$ & $\mathrm{y}$ & $\mathrm{n}$ & $\mathrm{y}$ & $\mathrm{n}$ & $\mathrm{y}$ & $\mathrm{n}$ & $\mathrm{n}$ & $\mathrm{y}$ & $\mathrm{y}$ & $\mathrm{n}$ & $\mathrm{y}$ & $\mathrm{y}$ & $\mathrm{y}$ & $\mathrm{n}$ & $\mathrm{n}$ \\
\hline Public Health & $\mathrm{n}$ & $\mathrm{n}$ & $\mathrm{n}$ & $\mathrm{n}$ & $\mathrm{n}$ & $\mathrm{n}$ & $\mathrm{n}$ & $\mathrm{n}$ & $\mathrm{n}$ & $\mathrm{n}$ & $\mathrm{n}$ & $\mathrm{n}$ & $\mathrm{n}$ & $\mathrm{n}$ & $\mathrm{n}$ & $\mathrm{n}$ & $\mathrm{n}$ \\
\hline
\end{tabular}

Key: $P=$ Programme. $P \& I=$ Programme and Institution. $y=$ Yes. $n=$ No

Table 10: ENQA Membership. Institutional and programme focus, ECTS and public health content. (Sources indicated in brackets)

The majority of accreditations (over 64\%) only focus on programmes, which to some is more "validation" than accreditation (178). This is very different from the US model which looks at both institutions and programmes $(26,36,179,180)$. Next, the agencies identified are national-based accreditation agencies whose governments have signed the Bologna declaration which includes the European Credit Transfer System (ECTS) as a key element to encourage international transparency and mobility (20). Just over half (58\%) of the agencies monitored ECTS as part of their criteria. This goes directly against the notion that quality assurance can be a tool for the implementation of the Bologna Process (38). As a European University Association report stated:

"Many higher education systems are currently being held back from Bologna implementation - and thus from offering improved services to students and society by national QA systems that are costly, offer no evidence of overall quality improvement, and stifle institutions' capacity to respond creatively to the demands of evolving European knowledge society." (182) 
In keeping with other findings, there is no commonality between the European accreditation systems (183), which fortifies the argument that countries integrate "individualised versions" of Bologna for self or nationally defined purposes (28), resulting in a jungle of approaches (156). Finally, public health content is not systematically monitored by any national agency. Previous studies indicated external international members on external committees but these were neither compulsory nor necessarily subject specialists $(184,185)$. This has entailed occasions where the expertise of the visitors did not align to the discipline being reviewed. One commentator noted an Art \& Design specialist served on an evaluation visit to a music conservatoire (186). Such mismatches can be harmful, as was witnessed by the author when a dentist was contracted by a national accrediting agency in Lithuania to review a Faculty of Public Health. The review was entirely negative, did not follow its own procedures and resulted in the faculty being faced with truncating admission of new students. It is therefore a realistic potential that poorer countries wishing to include international expertise may not be able to afford discipline-based quality reviewers and will settle for reviewers outside the discipline. Equally, it may be a question of knowing or having access to the right type of people. In any case, the evidence provided in this section would indicate that national agencies are "generically" focused. How this will benefit the student or stakeholder at a graduate or more specialised level is not apparent. This returns to Woodhouse's notion that professional sectors are their own best judges (22).

In 2013 the WHO stated that "more than half the countries of the world appear to lack a credible, transparent and comprehensive accreditation system" (135). This situation may be slowly changing. The World Bank is the "largest single source of external financing for education in developing countries" (187) and, beginning in the 1970s, it has been a vociferous advocate for the establishment of accreditation and QA agencies throughout the developing world (including the aforementioned CEE region) (188), along with other elements, such as the liberalisation of education sectors, student loans and the adoption of academic credit systems (central to Bologna). The establishment of accreditation systems are a key objective of the World Bank's global education policy (189).

\subsection{Development and Improvement of Public Health Education}

The role of the World Bank sits within an international context of funded development across many sectors, including public health education. Starting in the early 1990s, the World Bank provided funding to begin and develop public health education in the CEE region. Clear examples can be found in Croatia, Estonia, Hungary, Kazakhstan (136) and Romania (113) as part of their education modernisation programmes. Earlier in the century, the Rockefeller Foundation was paramount for the establishment of schools, whereas at the end of the century, other actors, such as George Soros, played a part in the transition countries under the ethos of "open societies." 


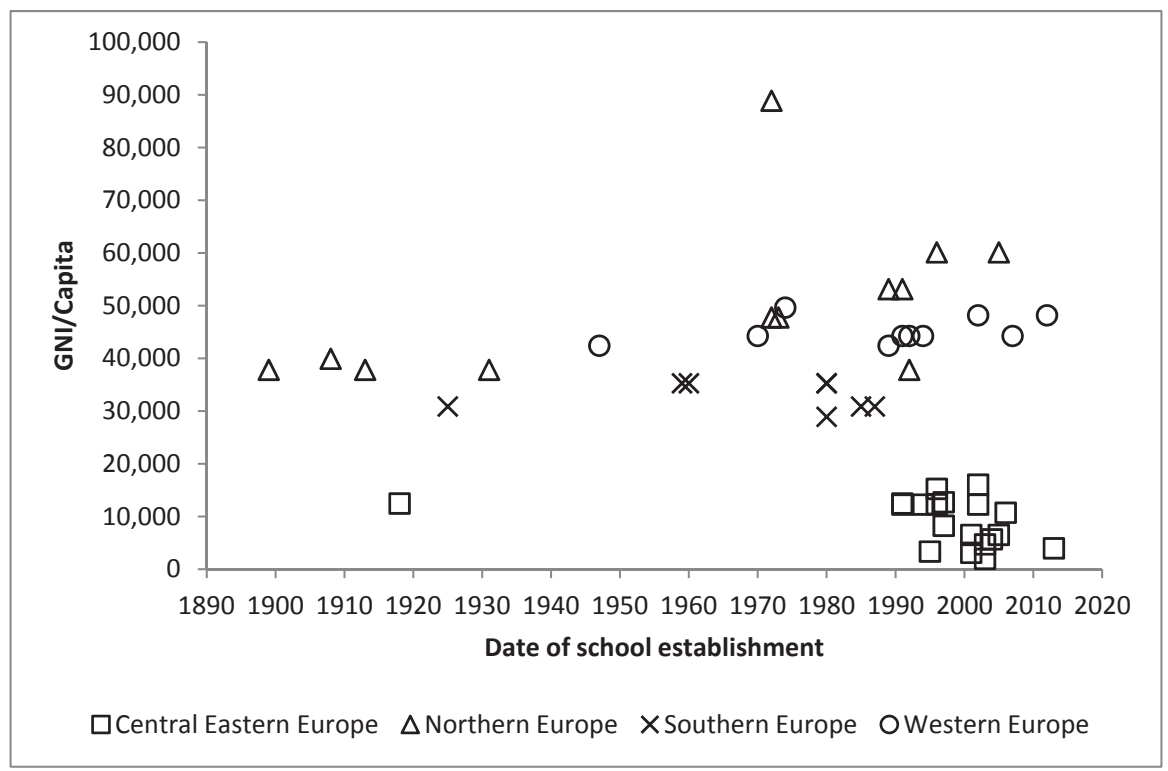

Figure 7: European development of Schools of Public Health. Source (190)

Plotting the development of schools of public health across the EHEA can be seen in Figure 7 which demonstrates that, within 51 surveyed as part of chapters 4 and 5, all schools of public health in the CEE, apart from one school in Poland (191), ${ }^{3}$ began in the years directly following the restructuring of the region. The primary reason we know this is that the schools provided information on their date of establishment during the above-mentioned survey, and the CEE members were themselves "encouraged" to join a European level association of schools as part of a Soros funded project (113). This raises questions about the impetus behind restructuring. Both accreditation processes and public health education seem heavily and directly influenced by external NGO funders: would these changes have occurred without that funding?

The relationship between improvement and quality assurance is one of continual debate and often hinges on the practicability of combining the two $(17,21,192)$. However, most commentators argue that quality assurance is entrenched in quality improvement $(17,21$, $22,24,26,193,194)$, to such a point that a question was raised: "is quality enhancement the new quality assurance?" (195). As Harvey points out: "it is not helpful to represent quality assurance practice only in terms of accountability. Quality assurance is an important driver for quality enhancement" (196). Moreover, generally governments would prefer not to close down poor quality institutions but rather seek their improvement (197).

The main focus of improvement tends to centre on the process of internal self evaluation $(185,198,199)$ which provides the basis of information for an external peer review visit $(34,40,185)$. As Kis highlights, "there are a number of studies indicating that institutional self-evaluation processes taken on as a part of an self-evaluation processes are very useful

${ }^{3}$ The SPH in Zagreb began in 1927 with Rockefeller funds but did not provide data for this analysis. 
processes for higher education institutions" (44). Lee Harvey goes further to express that even if there were no funding conditionality to accreditation, the two interrelated processes are a worthwhile exercise, as one of his respondents noted:

"I think the self-study provides an opportunity for the institution to conduct a formative evaluation and identify both strengths and areas for improvement. The accrediting team can offer a more summative evaluation and an objective external perspective that can potentially strengthen the institution." (29)

In this sense, the role of the self-evaluation with the associated peer review can fit within a total quality management approach through a process of institutionalising reflection and providing a framework to alternatively reflect on existing thinking and practices (200). However, the defining feature of accreditation is the decision making (see Table 2). This provides a "threshold" decision and, although not always referenced as a common element, accreditation tends to implement a periodic review process in which changes implemented from the previous review can be monitored (see Table 2) (44). Due to the "authority" of an accreditation there is an observed tendency for institutions to adopt a "what gets rewarded gets done" or "what gets measured gets done" approach and to steer self-reflection only around the requirements of the self evaluation / obligations of the reviewer (38). The problem with this is, as Sursock writes, "a quality assurance system that is perceived as creating work instead of creating quality will not yield the anticipated results. It induces compliance and window dressing" (201). The problem with compliance is that the aim of the applicant may only be to meet the criteria regardless if they are suitable (34).

In this sense, improvement (the formative function) becomes only a side effect of the accreditation process which is summative in nature (39). Therefore, the impetus is on the ability of the self-evaluation to ask the "right questions." Most of the commentators on the subject wrote at a time during the ascendency of state-based accreditation. Many of these agencies are members of ENQA and, as Table 10 demonstrates, they do not focus on either the accreditation or improvement of public health education as a discipline.

The present ability of national accreditation systems may be seen as more geared toward accountability than steering the development of schools and programmes of public health. As Amaral and Maassen note, "The balance between these potentially conflicting objectives (quality improvement and accountability) shifts towards improvement when academics have a strong voice, and towards accountability when the will of the government's predominates" (110). Furthermore, Sursock argues that "power relationships can shift in favour of an improvement orientation, provided the sector is organised to speak with a single voice" (100). Internationally, however, the idea of a "single voice" in the sector may be driven more from the developed countries whose systems may have been operational for many years and do not face the challenges faced when establishing SPHs within "traditional" medical settings $(81,113)$. In these "developed" countries accreditation has been implied as a form of "luxury goods, affordable only at a later stage of higher education development" (103). 
If accreditation is to be used for stewardship of new schools and programmes of public health, it will need to assimilate the full developmental range from establishment and development, as well as the "luxury good" market. One group which is attempting to do this is the World Federation of Medical Education (WFME) which has produced its Postgraduate Medical Education "Global Standards for Quality Improvement" (202). For the WFME, "quality assurance of medical education must emphasise the need for improvement and provide guidance for achieving it" (202). To this end, the standards indicate both quality assurance termed "basic standards" which include "must" (summative) statements and quality improvement termed "quality development standards" which use "should" (formative) statements. Although representing the varying needs of education along the developmental spectrum, the WFME is quite clear: "WFME is not an accrediting authority or agency. Accreditation of medical education is normally carried out by national governments, or by national agencies receiving their authority from government" (203). Therefore, although pertinent and useful, their adoption / encouragement / enforcement is questionable and will rely instead on the voluntary adoption by national agencies.

Another accreditation which uses standards addressing a spectrum of development is the Finnish Higher Education Evaluation Council's audit system (see Table 11). This system also relies on a self evaluation and site visit but is interesting for two reasons. Firstly, it focuses solely on internal quality management systems and states that its system is "based on the principles of enhancement-led evaluation." No other system in the ENQA membership was found to operate in this way. Secondly, the Council uses a form of "maturity matrix" incorporating four stages of a developmental spectrum: "absent, emerging, developing and advanced." To successfully pass, applicants require only to pass above the "absent" category. Other systems, such as the Dutch NVAO, utilise a gradated decision categorisation but do not use terminology associated with the development process (174). The NVAO, for example, use the term "unsatisfactory" which could be extremely harmful in the development of burgeoning systems in hostile environments (174).

In terms of public health accreditation, there are only two systems: the CEPH in the US, and APHEA in the European region. APHEA was established in 2011 and initially set at a European Regional level. In 2015 the agency adopted an international remit. At the heart of the APHEA accreditation is the legacy of a previous quality improvement instrument entitled PEER Review (204).

The PEER Review was established as a quality check for schools which could be deemed in the luxury good end of the market but was later used as a framework for the establishment and early stage development of schools and programmes in the CEE region (see chapter 2). There was no formal decision, as the process did not issue the "window dressing" stamp of approval and the applicants were all members of the regional association of schools of public health whose membership conducted the visits. Integral to the PEER Review was the use of standards and evidence which was continued within the accreditation process. As part of the developmental processes in the CEE region, the standards provided a framework to enquire into the individual elements of a school/programme which led to recommendations for change. These were turned into measurable project deliverables 
using financed project money from Soros (113). Although the PEER standards were redevised for accreditation (205), the most distinct change came from an additional decisionmaking process which utilises a consortium of European and international stakeholders to garner independence in the face of conflicts of interest (204). 


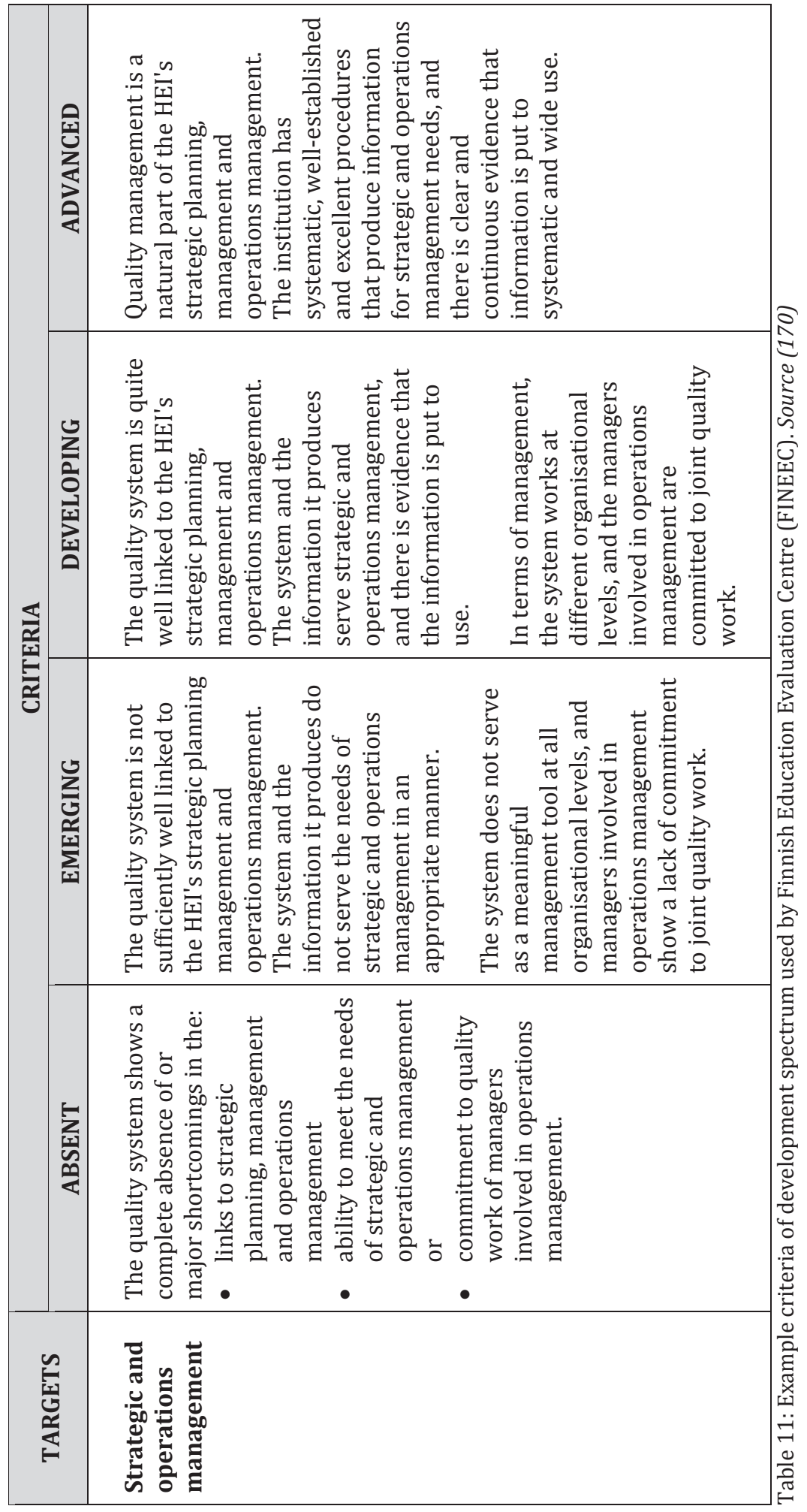




\subsection{Research aims, objectives and dissertation outline}

The call from the World Health Organization for more schools of public health (5) and the focus on accreditation for achieving the development and improvement of schools and programmes of public health forms the basis of this enquiry.

The central research question is: Can accreditation be used for the development and improvement of schools and programmes and courses of public health, and, if so, how?

The central research question is approached in this dissertation through a series of five main research aims highlighted below in italics which refer to the individual chapters. Each of these aims is then supplemented by a succession of objectives for each of the chapters which are then integrated and synthesised within the final concluding chapter of the dissertation.

To review the historical background and provide a context for public health education accreditation through an examination of the inter-connected areas of public health, public health education and accreditation.

The aim of the preceding chapter was to use a cross-cutting literature review based on the main themes associated with public health education accreditation which include accreditation and quality assurance, accountability, developments in public health and its education, internationalisation as well as examples of the historical foundations, development and improvement in public health education. The objective was to make an extended historical examination of the disparate fields of enquiry which fall under the scope of the central research question.

To study the history of the development and improvement of public health education with a focus on the third (or non-governmental) sector.

The aim of chapter 2 is to view public health accreditation in the context of developmental activity in public health education which exists outside the scope of direct governmental involvement. The development of modern public health education in America arose from the funding provided by Rockefeller which steered both the definition of a school of public health and the country's antecedent accreditation processes. Within the European region, the arrival of public health accreditation was predicated on the Association of Schools of Public Health in the European Region's (ASPHER's) quality improvement tool entitled Public health Education European Review (PEER). This tool was a peer review based instrument which, although originally aimed at schools and programmes in a later stage of development, formed the backbone of a funded project entitled "Quality Development of Public Health Teaching Programmes in Central and Eastern Europe" 2000-2005 (113). As part of this development project, the PEER Review provided a framework to assess, recommend and monitor the implementation of various developmental activities. The initial aim of the chapter is to highlight the work of the third sector outside the role of government, whereas the objective is to demonstrate that the utility of peer review 
processes, which formed an integral part of accreditation, can be broadened to include education at varying stages of development.

How and why did public health education accreditation emerge and are there lessons for the future?

Accreditation as a process began in earnest in America in the late 19th century and was followed in Europe in the early 1990s with its introduction into the Central and Eastern European region during the period of transition from communism. European public health education accreditation arrived 65 years later than the US based accreditation which began in the 1940s. The origins of US public health education accreditation can be traced back to attempts to control and standardise the widely varying standards in public health education, whereas European public health education accreditation can be seen as a response to the difficulties of implementing cross-country educational activities. In chapter 3 , through the use of a literature review, we aim to examine the historical development of this form of accreditation with the objective of understanding whether there is a potential that the history and present operations can help shape the future activity.

What are the strengths and weaknesses of public health education within the European Higher Education Area (EHEA)?

The development of public health education has taken place at different times and in different places throughout the EHEA. For example, chapter 1 highlights how many countries in the Central and Eastern European region developed their public health education systems after the fall of the Berlin wall. We examine whether this differing development over the region has led to variation in compliance to the European public health accreditation standards. The objective is to understand whether compliance to accreditation standards can highlight comparative strengths and weaknesses (areas for improvement) across the region and to understand what effects these might have on the continuing development of accreditation in the sector. We investigate both the level of compliance to the European public health education accreditation criteria and examine, first of all, the areas of least compliance or divergence (chapter 4) as well as, secondly, the areas of greatest compliance or convergence (chapter 5 ).

Can individual elements of accreditation be used for improvement, and, if so, how?

Examples in the preceding paragraphs demonstrate how individual elements of the accreditation processes, such as a peer review, self-evaluation study and decisions or judgements, may be viewed within a formative assessment approach. However, as a complete accreditation process, improvement is not central to the overall accreditation process, and examples are also provided of how accreditation works as a summative-based control mechanism. The objective of the research contained in chapter 6 is to understand if or how individual or stand-alone parts of accreditation (highlighted in Table 2) can be used in a formative manner. In Chapter 6 we provide an investigation of the use of a site visit review by academic peers as a stand-alone activity in three countries of the EHEA at differing levels of institutional development. 
The dissertation is finalised in chapter 7 whose aim is to integrate and synthesise the research from the preceding chapters with the objective of positing conclusions and recommendations on the future direction of an accreditation scheme capable of including the varying stages of development. The secondary objective is to discern the areas for further research, as well as to identify policy recommendations for any such a scheme. 


\section{Chapter 2. The Role of the Third Sector in the Development and Improvement of Public Health Education.}

\section{Based upon:}

Overall JW, Goodman J. The role of non-governmental organizations in development of schools of public health: an example from Eastern Europe and Central Asia. Public Health Reviews. 2011;33(1):168-89. 


\subsection{Introduction}

Non-governmental organisations (NGOs) in the health sphere have gained strength, momentum and numbers over time. The Director General of WH0,1973-1988, recognised the ability of NGOs to influence policy makers, as noted by Narayan, Wise, and Ghebrehiwet: "Dr. Mahler, Director General of WHO at the time, publicly states that it was the non-governmental organizations (NGOs) who pressed WHO strongly to move beyond a disease-focused, expert-dependent, techno-management approach, based on the dominant system of medicine, to one wherein community participation, inter-sectoral coordination and appropriate technology were important" (206). A recent (2010) acknowledgement by Laaser and Epstein of the power of NGOs in the health arena states that the fourth phase of the internationalization of health "is characterized by the growing influence of healthrelated, non-governmental organizations (NGOs)" (207) which include those in the arena of public health, such as the World Federation of Public Health Associations (WFPHA), the International Union for Health Promotion and Education (IUHPE), the International Association of National Public Health Institutes (IANPHI), national and regional public health associations, and national and regional associations of schools of public health.

Discussions of development of schools of public health (SPHs) almost uniformly include the 1915 Welch-Rose report (85) and the resulting funding of the development of SPHs in the United States and abroad by the Rockefeller Foundation in particular. On a national scale, the development of schools by the Rockefeller Foundation sought to provide trained professionals for public health service (81). On an international scale, the Foundation implanted schools and institutes around the world creating a movement of professionals in which new ideas and techniques could be shared (208). Direct funding for establishment and capacity building of SPHs remains an issue in many parts of the world, but other aspects of their growth and development, such as the determination of competences needed by public health professionals and the quality (and its measurement) of the educational programmes to be taught in SPHs are crucial as well.

In 2010 a Global Independent Commission on the Education of Health Professionals for the $21^{\text {st }}$ Century called for a global social movement of all stakeholders, including NGOs, to propel action to promote a new century of transformative health professional education (3). Although the report shows the dearth of information about health professionals' education in general, its findings highlight the continuing lack of information about public health professional education per se:

1. of the 11,054 publications found in the Commission's search for publications about health professions education, only two percent were about public health;

2. although there are an estimated 467 schools and departments of public health globally, the estimation of public health institutions was incomplete because of definitional ambiguity/variability in definition; and

3. the Commission could not estimate the number of public health graduates because of data and definitional restrictions (3).

In a separate article, Evans notes that it is surprising how little research has been done to assess the role of SPHs in contributing to population health as well as the lack of research on the strengths and weaknesses of the different models of SPHs (6). Although efforts have 
begun to identify and map public health professional education institutions (e.g., AfriHealth (1)), and originally the data were to be included in a global database of health professions educational institutions (Avicenna Directories) (209), the information available at the site to date is about medical education only. Databases about member schools and programmes exist and are being updated within national and regional associations of SPHs, but many schools or programmes are not association members.

Beaglehole, Sanders, and Dal Poz noted years earlier (2003), in regard to the public health workforce and public health education, that "Despite the importance of the public health workforce, surprisingly little is known about it strengths, disposition or performance...there is lack of data on the extent and composition of the public health workforce...there is limited effectiveness of public health training and practice...there is need for an evidence base on the size and structure of the public health workforce and to complete mapping of public health postgraduate training in sub-Saharan Africa" (210). Since that time, much the same has continued to be reported about the global public health workforce. Petrakova and Sadana (127) noted that The World Health Report 2006 demonstrated that data were available about the distribution in the health workforce of clinicians (physicians, nurses, midwives, dentists), but little was known about workers addressing population health, including public and environmental health workers, community health workers, or health managers (127). In 2009, a report on the public health workforce in 17 countries of Latin America and the Caribbean documented much the same (12).

Information in reports can appear contradictory. One message is that more SPHs and members of the public health workforce are needed, while a simultaneous message is that there is no clear identification of the public health workforce (and therefore the competences needed) or of the existing SPHs. For example, some reports state: there is a shortage of public health specialists and critical skills (including health policy and management); SPHs do not graduate enough people each year; more SPHs are needed; and graduates' competences should meet local profiles of health needs to carry out essential public health functions and services (5). Other information, however, reveals that, as a result of the paucity of data about the public health workforce and its education institutions and training processes, several things are not known for sure: how many SPH graduates there are; who the specific members of the professional public health workforce are; how many of them there are (excluding doctors and other clinicians); or specifically what many of them do. What some of them do is sometimes described generally as to "improve, promote, protect, and restore" population health (211). Others, again in general terms, may support and manage health programmes and services: identify, monitor and manage population health problems; inform, evaluate and advocate for appropriate health and inter-sectoral policies; or plan and manage the health system and services in response to population health needs (212).

Questions arise from the reports. One is why there continues to be so little reliable data about public health professional education, practice, and workforce. A second is what can be done, by whom, to rectify this in a more specific, expedient manner. Until this issue is adequately addressed, it will continue to be difficult, if not impossible, to determine 
specific public health workforce and professional education needs (numbers and competences).

A third question is what SPHs are expected to teach in this context - one in which they should meet international criteria of curriculum content and ensure that graduates are capable of carrying out geographically-articulated essential public health functions (PAHO) $(213,214)$ / services (US) (215) / operations (WHO European Region, proposed) (49) to meet the health needs of the local population while being influenced more and more by a global environment. They must also adhere to the realities of the labour market, financial and human resources, and national laws.

\subsection{Specific Roles of NGOs in Development OF SPHs}

NGOs are important in the employment of SPH graduates and are well positioned to identify at least part of the professional public health workforce. This includes adding to the data about practitioners, identification of skills and competences needed for particular jobs and specialties, and providing feedback to SPHs. This can augment government planning for workforce needs (including competences), aid in the development of workforce performance standards, and support the need for governments and licensing bodies formally to recognize and regulate public health practice as a specialty. In addition to being potential employers of SPH graduates, NGOs are also potential sources of students, adjunct lecturers, and practicum sites for SPHs.

A critical issue for some associations of SPHs is their work with partners to promote workforce-competences development in curricula of varying levels, including bachelor, master and doctorate, of public health professional education $(216,217)$. The American Association of Schools of Public Health (ASPH) is one example. The Association of Schools of Public Health in the European Region (ASPHER) is another; its Working Group on Public Health Core Competencies faces the task of determining and promoting competences in a vast geographic area that includes Member States of the European Union, Council of Europe, and European Region of WHO. At the global level, the WFPHA, in collaboration with WHO Headquarters, established a working group on public health education in 2010; one item in its action plan is fostering the development of a global harmonization of the various articulations of public health essential functions and competences based upon local practice needs (218), including coordination of efforts of governments and international organizations.

In regard to quality standards for programmes taught in SPHs, there is collaboration among ASPH and ASPHER, for example, and their respective national/regional public health associations and accrediting agencies. The Council on Education for Public Health (CEPH) (219) is an independent, non-profit agency in the US that accredits schools and programmes in public health; its two corporate members are the American Public Health Association (APHA) and ASPH. The Open Society Institute (OSI) ASPHER initiatives, described below, included Public health Education European Review (PEER) review of some SPHs in the European Region and provided a strong base for efforts to establish the 
European Agency for Public Health Education Accreditation (APHEA) (220), an independent, non-profit organisation in association with ASPHER, the European Public Health Association (EUPHA), and several other prominent European public health organizations.

Advocacy for the value of SPHs and the public health workforce is an important and necessary role, one that can best be played by actors actually working "on the ground," many of which are NGOs. Of those NGOs, the associations of SPHs, the national and regional public health associations, and a few global organizations (such as WFPHA and IANPHI) are best positioned to lead the movement to fill in the gaps in the data regarding the identification of the public health workforce, the numbers and competences needed, and their true corresponding educational needs. Those associations, and their individual members, are the organizations who must lead in proving in some countries or regions that public health professional education and the public health professional workforce are as valuable as medical education and the clinical health care workforce in protecting health at the population level.

The reality is that severe underfunding continues for direct capacity building in public health education and training. Direct financial support of the Rockefeller Foundation in the establishment of SPHs was crucial in the early development of public health education and more recently in developing the Public Health Schools Without Walls model in the early 1990s, in Africa and then Asia $(52,221,222)$. A few other organizations have provided direct funding recently for the development and capacity building of SPHs, although there often is a need for additional funding partners for particular aspects of a school. One welldocumented example is BRAC (formerly Bangladesh Rural Advancement Committee), the largest NGO in the world, $(223,224)$ and the establishment of the James P. Grant School of Public Health in 2004. The Atlantic Philanthropies Foundation funded direct capacity building in SPHs in South Africa (University of Western Cape School of Public Health) and Vietnam (Hanoi School of Public Health) in particular (225). Another example is the Wellcome Trust's capacity building award in 2010 to link the Public Health Foundation of India (PHFI) with a consortium of UK SPHs that will provide Master of Science and PhD training (226).

An example of flexible, direct funding for a regional program of capacity building in schools and programmes of public health in the 2000's is described in the section below. It was a broad, collaborative development program of two NGOs: funding by the Public Health Program of OSI, now the Open Society Foundations (OSF), and technical implementation by ASPHER, through faculty of its member schools. The flexibility available for use of the funds and the dedication and work of the individual faculty members of ASPHER schools as consultants to existing schools and mentors to new ones, along with the determination and focus of in-country faculty and other major stakeholders, were major keys to the individual successful projects within the initiatives. 


\section{3. "Quality Development of Public Health Teaching Programmes in Central and}

Eastern Europe" And Parallel Projects, 2000-2007

As the World Health Report 2006 notes, the education of the health workforce requires attention to organisation, curriculum, teaching methods, training of teaching staff, research and service (5). In addition, it notes that more SPHs are needed. These issues also comprise the themes of the OSI ASPHER workforce development program entitled "Quality Development of Public Health Teaching Programmes in Central and Eastern Europe," 2000-2005 (113), along with parallel projects in Central and Eastern Europe (CEE) and Central Asia that ended in 2007.

Designed with the understanding that a professional, qualified and multidisciplinary workforce, in sufficient numbers, is vital to the organisation and management of effective public health systems in Europe and around the world, this was an initiative, along with parallel ones, to build public health workforce capacity by strengthening and developing public health schools and teaching programmes in twenty countries (Table 12) (113). The initiatives included the development of one new SPH or the further development of an existing one in each country (with the exception of Russia, in which there were four), while at the same time fostering regional networking. Although funding, evaluation, and participation in initial planning were provided by OSI, the specific content and implementation were determined and carried out primarily by individual faculty members of the regional association of schools and programmes in collaboration with the faculty members and administration of the individual project schools.

These initiatives took place during a time of tremendous social, political and economic changes in the region, including the revamping of European university education standards (the Bologna Declaration and Process) (227) that had to be taken into consideration. Several countries of the initiatives were in the process of EU accession and harmonizing many of their laws and sectors. Geographically, these schools and programmes are located in a region where the model of public health often has been one that is largely infectious disease-focused and hospital-oriented (113).

In many countries there was pervasive dialogue about the merits of the SanitaryEpidemiology (San-Epid) system/service and that of the New Public Health, described by Tulchinsky and Varivakova as "a contemporary application of a broad range of evidencebased scientific, technological, and management systems implementing measures to improve the health of individuals and populations" (228). Not all of the countries in the region, however, had adopted the San-Epid system, particularly those of the former Yugoslavia (229). Djubuti, Gotsadze, Mataradze, and Menabde described the San-Epid service in the former Soviet Union: it was a highly-centralized network, as part of the health system, focusing on environmental and epidemiological health; it was highly successful in areas such as immunizations and communicable disease control; employees were graduates of a five-year course in San-Epid faculties in medical academies or universities that included some basic medical education and some clinical training, in addition to the major focus on environmental health and infectious disease epidemiology and control; graduates obtained 
the degree of medical doctor, with specialization in epidemiology, environmental health, nutrition, etc (137).

\begin{tabular}{|c|c|}
\hline Country & School of Public Health \\
\hline Albania & $\begin{array}{l}\text { Institute of Public Health and Department of Public Health, Faculty of Medicine, } \\
\text { University of Tirana (programme changed since the end of the project) }\end{array}$ \\
\hline Armenia & College of Health Sciences, American University of Armenia \\
\hline Azerbaijan & Project closed \\
\hline Bulgaria & Faculty of Public Health, Medical University of Varna \\
\hline Croatia & Andrija Stampar School of Public Health, Medical Faculty, University of Zagreb \\
\hline Estonia & Department of Public Health, Faculty of Medicine, University of Tartu \\
\hline Georgia & $\begin{array}{l}\text { Faculty of Medicine, Tbilisi State Medical Academy (project was closed during OSI } \\
\text { ASPHER project; later successfully opened as SPH at TSMU) }\end{array}$ \\
\hline Hungary & $\begin{array}{l}\text { School of Public Health, Medical School and Health Science Center, University of } \\
\text { Debrecen }\end{array}$ \\
\hline Kazakhstan & $\begin{array}{l}\text { Ministry of Health, Republic of Kazakhstan; OSI support in the form of grants for } \\
\text { staff development and e-learning rather than technical assistance }\end{array}$ \\
\hline Latvia & $\begin{array}{l}\text { Faculty of Public Health and School of Public Health, Medical Academy of Latvia } \\
\text { (renamed Riga Stradins University; SPH later closed with programmes incorporated } \\
\text { into the Faculty of Public Health) }\end{array}$ \\
\hline Lithuania & Faculty of Public Health, Kaunas University of Medicine \\
\hline Macedonia & Center for Public Health, Faculty of Medicine, University of Saints Cyril and Methodius \\
\hline Moldova & $\begin{array}{l}\text { School of Public Health Management, State University of Medicine and Pharmacy } \\
\text { "Nicolae Testemitanu" }\end{array}$ \\
\hline Mongolia & School of Public Health, Health Sciences University of Mongolia \\
\hline Poland & School of Public Health, Nofer Institute of Occupational Medicine \\
\hline Romania & $\begin{array}{l}\text { Department of Public Health and Management, University of Medicine and Pharmacy, } \\
\text { "Carol Davila" and the National Institute for Research and Development in Health } \\
\text { (NIRD later changed to the National School of Public Health) }\end{array}$ \\
\hline $\begin{array}{l}\text { Russian } \\
\text { Federation }\end{array}$ & $\begin{array}{l}\text { 1. Chelyabinsk: Ural State Medical Academy of Postgraduate Education; } \\
\text { 2. Moscow: Faculty of Public Health Management, I.M. Sechenov Moscow Medical } \\
\text { Academy (named changed in } 2010 \text { to I.M Sechenov First Moscow State Medical } \\
\text { University); } \\
\text { 3. St. Petersburg: College of Public Health, Medical Academy of Post-graduate } \\
\text { Studies; } \\
\text { 4. Tver: Faculty of Postgraduate Studies, Tver State Medical Academy }\end{array}$ \\
\hline Tajikistan & Faculty of Public Health, Tajik State Medical University \\
\hline Ukraine & School of Public Health, National University of Kiev-Mohyla Academy \\
\hline Uzbekistan & $\begin{array}{l}\text { Second Tashkent State Medical Institute (Presidential Order of } 2005 \text { merged. 1st and } \\
\text { 2nd TSMI into Tashkent Medical Academy; programme now is housed in the } \\
\text { Department of Public Health and Health Management, Tashkent Medical Academy) }\end{array}$ \\
\hline
\end{tabular}

Table 12: Academic institutions of participating schools and programmes 
The San-Epid systems retain a strong influence today in many countries in the European region (defined here as the European Region of WHO), though they may have altered forms in different countries (230). It is imperative that those who work to build or expand schools and programmes of public health, as consultants or as funding organizations, for example, take the time to understand thoroughly any existing systems with corresponding educational programs, particularly when the system/service/network is as pervasive as the San-Epid system in the former Soviet Union. Otherwise, it is difficult at best, if not impossible, to have the full depth of discussion needed regarding the reasons and merits for adding to or changing the existing system/service and its corresponding education.

\subsection{Methods}

The goals of the OSI ASPHER initiatives included: growth of selected, existing schools, programmes and curricula; establishment of new ones within the framework of national and international standards and within existing academic institutions; and addressing the training needs of each country's public health workforce and stakeholders. Examples of initiatives to develop standards of education/accreditation for SPHs in the region include the ASPHER PEER funded by OSI (2001-2005) and the EU Leonardo da Vinci Programme (2004-2007) $(231,232)$, which have evolved into APHEA to be operational and further developed during the 2011-2012 academic year (233).

As the accrediting agency did not exist at the time of the OSI ASPHER initiatives, the ASPHER PEER was the standard used. Primary methods of implementation included: systematic peer review (ASPHER PEER Review) of existing teaching programmes and curricula; "twinning"/ partnerships with Western European SPHs; short-and long-term faculty training at established European SPHs; in-country lectures and workshops; and site visits by consulting faculty from the regional association of schools. In response to requests from across the countries, two Faculty Development Pedagogic Institutes were added (2005), in collaboration with the John E. Fogarty International Center (US National Institutes of Health). The topics were Epidemiology and Health Management, as those were the two most consistently requested ones.

\subsection{Other Activities for Faculty and Potential Faculty of Participating Schools}

There were special conferences and workshops for faculty members of the initiatives to share information and to provide continuing networking opportunities (Israel 2002; Lithuania 2003; Armenia 2003; Ukraine 2004; Macedonia 2006). During annual conferences, there were special sessions devoted to the OSI ASPHER initiatives (20012006). Additionally, OSI funded and the Braun School of Public Health, Jerusalem, implemented a series of Visiting Faculty Programs for mid-level faculty from CEE countries, Russia and Central Asia developing new SPHs. For potential junior faculty, OSI funded scholarships from 2001-2006 to the Braun International MPH programme and to other SPHs on individual bases. OSI continues to provide support in 2010-2011 to the SPHs in Georgia, Kazakhstan, Mongolia, and Ukraine through its International Higher Education Support Program (HESP). 
There were widespread challenges; reflecting prior discussion, there were no clear definitions of "public health," "public health workforce," or public health skills and competences. Therefore, it is not surprising that there were differences of opinion over whether public health professional education should be part of medical training or a separate multidisciplinary field taught by multidisciplinary faculty. If in a medical faculty, corresponding issues included whether a public health faculty or programme should be housed and taught as part of basic medical education or higher level or taught at a postgraduate institute, along with whether the Bologna Declaration applies to medical education.

Another challenge was the need for faculty development in specific subject matter as well as teaching/research methodology. In many instances, there was lack of materials at the outset; simply providing copies or translations of materials from other countries was not sufficient, even though important. The same was true for curriculum expansion, revision, or development. A lack of defined employment for graduates was often problematic, while there was need for both short-and long-term training for the existing workforce. The need for health management training and the determination of how to balance health management with other core courses was a common theme. Differences in meaning and interpretation of terminology, such as "public health specialist," "master's," and "postgraduate" caused difficulties. There were issues regarding Bologna Declaration levels, conversion to the European Credit Transfer and Accumulation System (ECTS), and compatibility of national accrediting standards and international ones (113).

All of these were challenging, but the issues of the relationships, interactions, and lines of authority between Ministries of Health and Ministries of Education over public health teaching programmes and curricula, along with the need for more careful examination of national laws, orders, regulations, and standards caused additional problems and delays at times. Another factor that must be noted is that, if one of the goals is employment in the government sector, other ministries, such as Labour, Finance, and Social Affairs, (names vary by country) must also be included and consulted.

There was a major, consistent complaint from the field: the three-year window per individual school project was too short, particularly for the newly-established schools. Continued growth and success of new schools in particular therefore often are reflections of the determination, leadership and vision of "idea champions" in those schools plus commitments of the ASPHER partner schools and individual faculty members to continue to provide mentorship, lectures, collaboration, and, at least upon one occasion, additional funds.

\subsection{Results}

Though not all of the individual projects succeeded, much was accomplished from 2000-2007. In the larger OSI-ASPHER initiative, six of a possible seven PEER Reviews were conducted (Armenia, Bulgaria, Estonia, Hungary, Lithuania, Poland). In the combined initiatives, several newer programmes that were started or supported then continued, sometimes with 
revisions, after the initiatives ended (Albania, Latvia expanded master program, Macedonia, Moldova, Mongolia, Romania, Russia, Tajikistan, Ukraine, Uzbekistan). Three research forums were established (Albania, Macedonia, Mongolia). It is impossible to describe here all of the individual school projects. However, in order to provide more in-depth information and insight about the initiatives, three specific examples are included below.

\subsubsection{Kiev, Ukraine: Partnerships and Twinning}

The start-up and development of a SPH at the National University of Kiev-Mohyla Academy (NaUKMA) contains many issues described above: where to house the SPH; whether a programme of health management is appropriate as a programme of public health; the importance of collaboration with the medical community and the Ministry of Health; the interaction of Ministries of Health and Education; how and where to train faculty; innovative teaching and research methods; and national licensing and accreditation.

Although one of the most successful "twinning" partnerships of the initiatives, the collaboration of NaUKMA and Maastricht University, the Netherlands (the ASPHER partner), almost did not happen at all due to differences of opinion regarding the placement of the SPH in a university rather than a medical academy of postgraduate studies. The project was delayed for almost a year as a result of disagreement, as it would have been difficult and high risk to establish a SPH without support, or at least acceptance by, the medical establishment (113). Final resolution was to include four Ukrainian partners: the Ministry of Health, Kiev Medical Academy of Postgraduate Education (KMAPE), NaUKMA, and the Ministry of Education at the outset.

The Master of Health Care Management programme finally opened at NaUKMA in 2004 with a multidisciplinary student body of medical and social workers, economists, lawyers, and foreign students. Problem-based Learning (PBL), a hallmark of Maastricht University teaching, was used from the outset, with NaUKMA faculty members being trained in PBL methods at Maastricht. The first students, accustomed to more didactic teaching, were less receptive to PBL methods than the second class that followed. Licensing of the programme was another hurdle: there was resistance from both the medical profession and the professional council on management in addition to inaction by the Minister of Education, partly due to the fact that this is a very different and unique programme based on European quality standards with content oriented to Ukraine's needs.

Support from a member of Parliament (later the Minister of Health) was key to successful licensing in 2005. The first cohort graduated in 2006, with national programme accreditation awarded in 2007 as Master of Management of Organizations (Health Care Management); the Master of Public Health (MPH) did not exist in Ukraine. The partnership continues, with the addition of Kiev-Mohyla Business School; Maastricht professors continued to lecture at the school; and some NaUKMA students have studied at Maastricht University for several months. The SPH offers two concentrations in the regular master level programme of Public Health and Healthcare Management, a Master of Healthcare Management for Executives, and a PhD program. The commitment of Maastricht University and its individual faculty consultants (e.g., training of Ukraine SPH faculty members in PBL 
teaching methodology at Maastricht, assisting in individual teaching-unit development, lecturing at the new SPH) was, and continues to be, along with the NaUKMA SPH Dean's clear vision for the school and the flexibility provided for development by the university, one of the strongest commitments in the initiatives and one of the key reasons for the new SPH success.

\subsubsection{Kaunas, Lithuania: Need to Harmonize Accreditation/Assessment Criteria}

By the time of the OSI ASPHER initiative, the Faculty of Public Health (FPH) at Kaunas University of Medicine already offered four programs: Bachelor of Public Health, MPH, Master of Public Health Management (MPHM), and continuing MPHM. The OSI ASPHER initiative enabled the FPH to move toward systematic evaluation and quality improvement by undergoing the PEER Review and implementing its procedures. What happened during the process was important both within the context of the Bologna Declaration goal to develop a common European Higher Education Area (with harmonized academic regulations on accreditation of teaching programmes and recognition of university degrees) and that of the development of the Lithuanian system of accreditation of university teaching programs.

In 2002-2003, in addition to the PEER Review, the FPH also went through a national accreditation review by the Lithuanian Center for Quality Assessment in Higher Education (LCQAHE). The national accreditation and international PEER criteria were different, as were the results of the two reviews: the LCQAHE viewed the international and European dimension in teaching negatively; the PEER Review evaluation considered it to be very positive. According to FPH Dean Ramune Kalediene, "This is why it is evident that this is a challenge for national and international experts and accreditation bodies to harmonize assessment criteria." (113)

Later, in 2007, the MPH programme at Kaunas FPH and the University of Sheffield (UK) were chosen as candidates for pilot accreditation in the EU-funded project, European Accreditation of Public Health Education (PH-ACCR). Lessons learned from that experience, as well as from the PEER Review, were transferred to the creation of APHEA, the new European accrediting body created by ASPHER and sister organizations. The OSI ASPHER PEER project was an important piece in the development of the agency and its processes, as it provided basic ideas, precedent and tools. The new agency was established on April 1, 2011.

\subsubsection{Skopje, Macedonia: Unifying Departments; Amending Bylaws; Creating a Market.}

The Center for Public Health (CPH), Faculty of Medicine of Saints Cyril and Methodius University, is an example of a new entity created from already-existing departments of a faculty of medicine (Epidemiology and Biostatistics, Social Medicine, Hygiene, Occupational Health, Microbiology) (234). It is also an example of the need for creating an awareness of the importance of public health and graduate level training within the academic and professional communities and in the community at large. Implementation and development 
of the CPH was no simple task. The process from initial planning for the CPH until final accreditation of a revised master programme and a PhD programme lasted ten years.

The CPH was established to provide postgraduate training for a multidisciplinary group of professionals (medicine, dentistry, nursing, economics, law, social sciences, business administration, and engineering). A modular format was chosen in order to allow enrolment of students already working in the health sector. Planning and assistance from ASPHER faculty consultants began in 2001. However, implementation of the CPH was dependent upon revision of the Statute of the Faculty of Medicine, which did not occur until May of 2003. The CPH master programme began in December of that year.

The CPH was possible due to the strong and continuous support from the Faculty of Medicine, the University, and the Ministry of Health, in addition to the OSI funding and the intensive technical assistance and mentoring from faculty of two member schools from the regional association of schools of public health. Key areas of technical assistance included curriculum design and materials preparation and the design and implementation of a research forum for students and junior faculty, in addition to meetings with officials of the University and the Ministries of Health and Education to promote the CPH.

OSI and the local national foundation (FOISM) supported the following: training for trainers conducted by international visiting faculty members; CPH faculty member study visits to well-established SPHs; participation of CPH faculty in international meetings; strengthening of infrastructure (e.g., teaching rooms, library, computer labs); writing/translation and publication of a glossary of public health terms; and translation of an international textbook, The New Public Health (Tulchinsky and Varavikova), (73) for use by CPH faculty and students. Most of the CPH faculty attended Visiting Faculty Programs at the Braun School of Public Health during the preparatory phase of development. At least one of the consultants continued to lecture in the programme after the OSI ASPHER initiative ended.

According to the members of the working group of the CPH project, some of the major problems included: merging the teaching capacities of different Medical Faculty departments into a unified academic course of modern public health; adjustment of current law and regulations for establishment of a SPH; insufficient public and professional awareness of the importance of public health and its education at different levels; and need for commitment from official authorities that graduates of the master programme would be integrated into the public health workforce. As a result, there was necessity for ongoing activities to create and promote the market for public health graduates. One reflection of the reality of the need and market for health management, for example, is the teaching, in agreement with the Ministry of Health, of a certificate course in Health Management and Leadership that now is required for health managers of health care facilities in Macedonia (e.g., 400 participants in a six-week training module during 2006-2007) (113). This is in addition to the regular teaching programmes of the CPH. In February 2011, according to the head of the $\mathrm{CPH}$, the National Accreditation Board at the Macedonian Ministry of Education and Science officially accredited the revised MPH programme and the new PhD in Public 
Health (three years, 180 ECTS, harmonized with Bologna Declaration principles and prepared according to the new Macedonia Law for Higher Education).

\subsection{Conclusions}

Great strides have been made over the last century to supply a trained public health workforce. Much of this work has been accomplished through direct involvement and funding by NGOs, but the lack of funding and initiative remain a global issue. In 2003, for example, the Committee on Educating Public Health Professionals for the $21^{\text {st }}$ Century acknowledged "the major contributions of philanthropic foundations to the development of public health education in the United States and emphasizes the renewed importance of foundation support to fund new initiatives and experiments in public health education" (119). In 2010, the Global Commission on Education of Health Professionals for the $21^{\text {st }}$ Century stressed the gross under-financing and sounded the call for donors to increase funding for health professional education as a significant share of development assistance" (3). Funding alone, however, is not sufficient.

Although it is estimated that there are over 400 SPHs throughout the world, a lack of data makes it hard to identify schools, the levels of their training programs, the quality of their graduates, or even the roles that graduates take after finishing their studies. Lack of public health workforce definition and data make it difficult to identify the competences to be addressed by programmes taught in SPHs. The early pioneers established schools on virgin territory with a modern notion of public health still in its infancy. With over a century of maturing, the paradigm of public health has become temporally and spatially scattered. The New Public Health of Hibbert Winslow Hill (50) in the early $20^{\text {th }}$ century contrasts the New Public Health of Ashton and Seymour (72) in the later $20^{\text {th }}$ century. The sphere of influence, until recently, of American and European public health was equalled or surpassed by the spheres of influence of the San-Epid systems in most of the region of the OSI ASPHER initiatives. The San-Epid systems still exist and retain varying roles across the region. Many would argue that American and European Public Health are distinct (77). There are geographically-articulated public health "essentials" (e.g., "functions," "services," and "operations"). Against such a changing and varied backdrop in the very basic understandings of public health, it becomes comprehensible how implementing new systems in third countries has become fraught with hurdles where the issue of funding is only one piece of the puzzle. Associations of SPHs have demonstrated an increasingly important and active role in developing new schools. The OSI ASPHER initiatives highlighted in this article demonstrate one example of how one such association (ASPHER), its member schools, and individual faculty members can substantially change the landscape of public health training through partnerships, networking, the sharing of experiences, the transfers of knowledge, and moral support. A European accreditation system for MPH programs, not available during the time of the OSI ASPHER initiatives, was developed in part based on the PEER Review experience and is being developed and operationalised with the initiative of ASPHER, EUPHA, and several other organizations during 2011-2012 as APHEA (220). 
Initiatives to adapt the training of public health workers to current and future health needs in Europe are reflective of the early attributes of the Rockefeller Foundation, et al. activities but with a major difference. Rather than seeking to build brand new infrastructures, the European (European Region of WHO) initiatives described here sought to change existing structures and practices in both sustainable and cost-efficient ways. More government and NGO funding is needed to continue establishment and expansion of schools and programmes of public health education. In order to achieve this, there is need for advocacy from professionals in the field of public health in some countries and regions to show the value of public health education and to press for more clear identification of the public health workforce and its competences.

When associations of SPHs help to establish new schools and programmes and include them in membership, it is part of the associations' responsibilities to foster and mentor their development, growth and maturity. Governments in their health and education roles bear the responsibility for training the professional public health workforce of the future and of promoting quality education in association with accreditation agencies within their countries and across national boundaries. The NGO efforts to promote fledgling new schools will require ongoing support to achieve the vital growth and sustainability to meet the challenges of public health in the coming decades. 


\section{Chapter 3. The History of Public Health Education Accreditation}

\section{Based upon:}

Goodman JD. The history of European public health education accreditation in perspective. South Eastern European Journal of Public Health. 2015 Dec 7;3(1). 


\subsection{Introduction}

The accreditation of higher education programmes and institutions has its roots in American higher education (152) and the history of accreditation of public health education is no exception. However histories do differ in the role of the state in education. In 18th and 19th century Europe, education was taken away from the church and placed under state control to reinforce the legitimacy of the emerging, and competing, European nation states (155). American political development differed from the European model and when the states came together to form the US, education was not among the functions specifically expressed as a federal responsibility (150). Europe continues to develop and embrace individual nation states with an increasing trend for laissez faire deregulation as a route to diminish barriers to free trade but it is yet unclear how this will affect the future of education and accreditation at a nation state level.

\subsection{Methods}

The research is based around a literature review and search of key websites including the American Journal of Public Health, Pubmed and google scholar. The reviews took place between July and October 2014 based upon the search terms of "public health education accreditation." The analysis of key themes highlighted mainly American development and this was complemented for European development, by the use of the physical archives from the Association of Schools of Public Health in the European Region (ASPHER). The searches delivered over 150 separate books and articles covering the subject to varying degrees of pertinence. From this set, information was retrieved to describe the history of public health accreditation in this chapter. Together these allowed for a demonstration and reflection of the origins of public health accreditation in both Europe and America.

\subsection{Results}

The American laissez faire approach of federal governmental responsibility toward education was not without its detractors especially when combined with a comparable economic approach. In 1910 Abraham Flexner criticised the free market nature of medical education in America, "over-production of ill trained men is due in the main to the existence of a very large number of commercial schools" (235) and that, "the schools were essentially private ventures, money-making in spirit and object" (236). As a result Flexner recommended that 120 of the 155 medical schools should close. Flexner was to become soon after the head of the general education board within the Rockefeller foundation (237). Five years after Flexner's report, Wycliffe Rose and William Welch submitted their views on the development of schools of public health to the Rockefeller foundation. Given the utter calamitous state of contemporary medical education it was no surprise that the authors recommended that schools of public health should not be part of medical schools. Apart from the notion that the public health worker was not identical with that of a practitioner of medicine no other reason for the independence of schools of public health was given in the report (85). 
Institutionally splitting public health from medical education did not however allay concerns about the quality of public health training. In 1920 the American Public health Association (APHA) established a committee on the standardisation of public health training and one year later it reported on what it saw: "the most serious defect in the whole system at present, however, lies in the fact that certain institutions give not only the Certificate in Public Health but even the Doctorate in Public Health for a course of a few weeks, while others require a period of almost three years, and it seems most desirable to effect some form of standardization in this field" (238). Similar to the findings of Flexner, there were also complaints of profit-making public health training programmes of questionable quality offering public health degrees (119). An editorial in the American Journal of public health in 1924 noted that, "as far as the medical end of this scandal goes the matter can be left to the strictly medical journals but unfortunately public health is also involved" (239). This situation continued for the next twenty years with some schools being recognised as, "merely seeking to attract students by deliberately and grossly misleading prospectuses" (240).

It took 26 years from the origins of the committee on standardisation until the adoption of an accreditation system in 1946 which coincided with the Committee for Professional Education within APHA taking on the responsibility for monitoring standards. This committee was headed by William Shepard who strove for the recognition of public health as a profession, "whether we fully realize it or not, public health has become a profession." (241) Accreditation would play a role in producing well trained individuals and supplying relevant data on the needs of the national public health, as Shepard noted, "to my knowledge this is the first occasion in modern times that a learned profession has kept its educational house in order as it developed. Since becoming a recognized profession, we have been spared the developmental blight of having our ranks flooded with pseudotrained people." (241)

In 1946 there were 11 criteria which comprised the minimum requirements of institutions to be accredited to the master of public health (79). The criteria had been developed by another associate of the Rockefeller board and pioneer of modern public health, CharlesEdward Winslow, who had deliberately kept the criteria flexible and small enough to allow time for schools to comply and maintained that too much standardisation was undesirable (241). The basis for Winslow's criteria came from the notion that "public health is not a branch of medicine or of engineering, but a profession dedicated to a community service which involves the cooperative effort of a dozen different disciplines" (242).

Accreditation at this point consisted of seven criteria which looked at the institution and a further four criteria which were course specific (79). Out of these latter four, one criteria stipulated the content, see Table 13. By 1974 when accreditation became housed within the Council on Education for Public Health (CEPH) (243) these criteria had evolved to express a mixture of educational and practical competences (95) which saw the retraction of elements such as economics and parasitology but the addition of health systems. These criteria are kept in place into the modern period (80), albeit more succinctly phrased as 
biostatistics and epidemiology were included as part of investigation, measurement, and evaluation (244). The one omission is focused on the biological features of the curriculum.

\begin{tabular}{|c|c|c|}
\hline $\begin{array}{l}\text { APHA } 1946 \\
\text { 1. The nature functioning of } \\
\text { human organisms; } \\
\text { 2. The nature behaviour of } \\
\text { various forms of parasitic } \\
\text { life; } \\
\text { 3. The physical environment; } \\
\text { 4. Social and economic } \\
\text { factors; } \\
\text { 5. The major source of } \\
\text { quantitative information } \\
\text { and its numerical } \\
\text { presentation and analysis. }\end{array}$ & \begin{tabular}{l}
\multicolumn{1}{c}{ CEPH 1974} \\
1. Biological, physical, and \\
social factors; \\
2. Social and behavioural \\
sciences; \\
3. Health service delivery \\
systems, \\
4. Community health needs; \\
5. Information collection, \\
storage, retrieval, analysis, \\
and dissemination; \\
6. Environmental \\
monitoring, analysis, and \\
management.
\end{tabular} & \begin{tabular}{ll} 
& \multicolumn{1}{c}{ CEPH 2014 } \\
1. & Biostatistics, \\
2. Epidemiology, \\
3. \\
Environmental health \\
sciences, \\
4. Health services \\
administration \\
5. Social and behavioural \\
sciences.
\end{tabular} \\
\hline
\end{tabular}

Table 13: Changes in American accreditation compulsory curricula contents 1946 to 2014

The history of American accreditation therefore took root at a time when public health was beginning to find its feet as a profession and against a laissez faire backdrop, which saw many schools geared toward profit making above quality and this is perhaps a situation which continues in a sense today with the growth of unrecognized, illegitimate degree and accreditation mills that "sell" (245). Against these developments, were the architects of an alternative and earnest public health movement based on the research focus of the German schools and the practical training methods on the English schools (246). This period of development can be seen as 1916 to 1946, from the first Rockefeller School of Public Health to the implementation of a fully functioning accreditation scheme. This period directly coincides with an epoch engrossed in war.

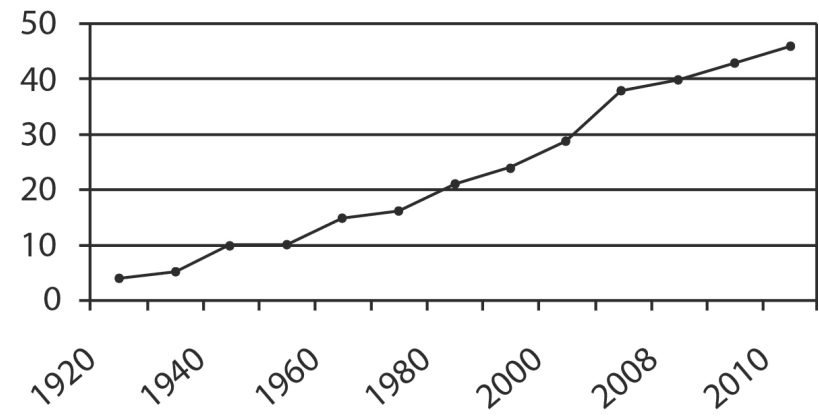

Figure 8: Accredited American SPHs by decade. Source (247)

Although initially the criteria had been kept flexible to allow more schools to participate, the arithmetic growth of accreditation in the U.S. was not overwhelming until around the turn of the twenty first century (247) see Figure 8. In 1946 there were 9 schools of public health accredited in America (79). Nearly 30 years later, in 1975 after the move to the CEPH 
there were 19 schools (248). This had risen to 27 in 2000 (249) and by 2014 there were over 50 schools accredited and over 100 programmes of public health accredited (80).

After the second world war, Europe began a process of reconciliation culminating in the present union enshrined through the 1992 Maastricht treaty where, under article 126, the role of union in education was to "encourage cooperation." It is in these post war collaborative movements where European accreditation, like its American counterpart, found its foothold. As one commentator phrased, "there was an intensified development of accreditation during the 1990s in various European countries. This trend is parallel with the rapid growth in international and trans-national organisations after the Second World War."(250) Moreover, the first large scale appearance of accreditation was a direct result of competition and the post communist transformation in the Central and Eastern European region where the markets were opened up to private and foreign providers (156).

This European movement of the 1980's and 90's was to create a fertile environment for international collaborations at a public health school level with examples being, The European Training Consortium in Public Health (ETC-PH)(251), BRIMHEALTH (252) and the European Masters of Public Health (EMPH). The latter of these, the EMPH was a collaboration between ASPHER and the World Health Organization (WHO) to develop a European master's degree in public health based on the WHO's 38 Health For All (HFA) principles (253). This followed from a drive in European Public Health created by the elaboration of these principals into practice which was given the title of "new public health" (72). Although this term was not new, it was first coined in 1913 as a bacteriological approach (50) and again in 1923 as health promotion (254), it did reflect the more comprehensive view of public health which still resounds today. The EMPH embraced three distinct areas: a) it should be concerned with the masters level, b) it should reflect the philosophy of the WHOs HFA and c) students should be exposed to a European perspective (255). It was enthusiastically anticipated that the EMPH would raise the standards of education and training across the European region and would provide a "gold standard" of which other schools and programmes would eagerly follow (256). Alas, attempts to realise the programme failed.

The failure of the EMPH was a product of several reasons: credit transfer mechanisms were poorly developed; systems didn't accept qualifications from other institutions; the programme was too inflexible and did not respect the diversity and traditions of the countries; European content didn't need to be all encompassing as it could be could be integrated into existing courses; and moreover, given the heterogeneity of public health training programmes in Europe it was not possible to introduce rigorous quality assessment and assurance (257). As a result of these failures the introduction of accreditation was seen as a necessary and fundamental step. However, accreditation was not introduced but rather a process of mutual recognition of courses, modules, programmes and institutions was established entitled the Public health Education European Review, more commonly known as the PEER Review (204). The three central principals of this review were a reflection of its EMPH foundations (256): 
- The course/module/programme/institution should be concerned with postgraduate training in public health.

- The course/module/programme should be based on the philosophy of the Health for All policy.

- The students should be exposed to a European perspective.

The PEER Review was established by 1994 but it differed from accreditation as it was devised primarily as a quality improvement tool conducted through academic peers in a collegial manner. Although the initial anticipation was for a multi-agency quality assurance approach this did not materialise until the advent of accreditation proper which was proposed and accepted in 2001.This was exactly the same time that ASPHER began to use the PEER Review for the establishment and quality improvement of new schools and programmes of public health in the Central and Eastern European region (113). This project gave valuable insights for accreditation $(205,258)$ and also showed how PEER could be used as a framework for development.

In 2011 the accreditation agency was established and consisted of ASPHER and four other public health based NGOs, European Public Health Association (EUPHA), European Public Health Alliance (EPHA), European Health Management Association (EHMA) and EuroHealthNet. At the time of its establishment European accreditation focused solely upon the accreditation of postgraduate (so-called second cycle) public health degrees. Similar to the American model, the processes also contained specific criteria on core curricula content: introduction, methods, population health and its determinants, Health Policy, economics and management, Health Education and promotion, cross-disciplinary themes and culminating experiences. These areas were based on the core subject domains developed through earlier ASPHER work on Public Health Core Competencies (129).

In 2014, following a two-year review of its processes, APHEA introduced two new aspects in addition to programme accreditation. The first was a curriculum validation process which replaced its initial eligibility criteria by ensuring that curricula contain the basic structure and core content expected from a modern comprehensive public health offering. The second addition was to focus on institutional accreditation which would assess the relationship of an institution, in terms of education, research and service, to the specific local, national, regional or international environments in which they serve, their so-called "social accountability" (123). This development represents a reversal of the American model which started with institutional accreditation followed by programme level accreditation.

\section{$\underline{\text { 3.4. Conclusions }}$}

So far the remit of APHEA was in keeping with the first and third central principals of the earlier PEER review. However, for future development, the postgraduate focus was also brought into question with proposals to develop accreditation for bachelor and $\mathrm{PhD}$ 
programmes, thus covering the whole spectrum of school based education in public health. APHEA also began consultations on the development of training accreditation which would cover smaller units from continuous personal development (CPD), MOOCs through to summer schools which can be delivered outside of school settings. Finally, the role of using the accreditation criteria as a framework for quality improvement and development also requires future scrutiny as the PEER Review had worked exceptionally well in this regard (113).

The second central principle of the previous PEER Review is based upon the health for all policies of the 1970s which has been superseded of late by the development of the WHOs Essential Public Health Operations (EPHOs) (259). An encompassing definition given for these is, "a set of fundamental actions that address determinants of health, and maintain and protect population health through organized efforts of society" (260). The potential therefore lies in the ability to change the older HFA targets for these later EPHOs, for example, by translating the operations into a series of competences and then assessing how these competences are integrated into the education of the workforce. However, care will need to be taken so that any system will be flexible enough to respect the diversity and traditions of different countries and thus, hopefully avoiding some of the reasons for the failure of the EMPH whilst learning the lessons from Charles-Edward Amory Winslow's introduction of accreditation in America.

All of these activities however are predicated on the future potential for sector based professional accreditation and there are two areas within the history of Public Health accreditation which may help determine its future trajectory. The first area is one of collaboration and second, the liberalisation of the education sector. The origins of both the American and European models of accreditation appeared as a result of interstate or supranational collaboration and an opening up of markets in education. The realisation of Europe has installed significant economic liberalisation, especially in the service markets. Many services in Europe are now no longer a state responsibility but rather a subject of the free market and how far this free market extends remains to be seen. For example, what will be the influence of the mooted agreements between the North American Free Trade Area (NAFTA) and the European Union on the liberalisation of the educational market (the TTIP negotiations)? In many ways perhaps the free movement of people already enshrined in the European project has created a quasi liberalised market with students being free to study in any country. This freedom of movement is often liberally extended to international students travelling the globe. Equally important for the forthcoming years will be the influence of technologies in teaching which allow for students to receive a foreign based education without the need or hindrance of travel. The result of these present and future changes is conceivably then one of burgeoning competition above that of collaboration where education systems both within and between states increasingly compete for students and their own subsequent economic survival. The origins of the Bologna declaration and the resultant European Higher Education Area is a cooperation based on mutual trust between education systems of the member states (261) but the reason why America had accreditation before Europe is because accreditation is not best suited to 
centralised governments (152). The question must then be raised, if collaboration turns into competition, will the national state accreditation agencies be seen as a credible guardian of trust or will they be seen as protective of their national systems, anticompetitive and riddled with conflicts of interest? 


\section{Chapter 4. European Accreditation and the Future Public Health Workforce}

\section{Based upon:}

Goodman JD, Muckelbauer R, Müller-Nordhorn J, Cavallo F, Kalediene R, Kuiper T, Otok R. European accreditation and the future public health workforce. The European Journal of Public Health. Volume 25, Issue 6, 1 December 2015 .1112-1116 


\subsection{Introduction}

In 2011 the Agency for Public Health Education Accreditation (APHEA) was established with the initial purpose to accredit master level public health programmes (205). The importance of this form of accreditation is seen to bring added value benefitting students and academics and to improve the quality of the Public Health workforce in Europe and its competitiveness globally (220). The advent of European accreditation represents nearly a quarter of a century of development in the field (190) and as such is reflective of the time taken to develop the American system of accreditation $(1921$ to 1946)(79, 238). In 1988 the Association of Schools of Public Health in the European Region (ASPHER), attempted to introduce an unified European masters programme entitled the European Master of Public Health (EMPH) based on the World Health Organization's (WHO's) Health for All principals (256) which followed from a momentum in European public health created by the elaboration of these principals into practice which was given the title of "new public health" (72). It quickly became apparent that national public health training programmes were very different which hindered mobility (257). To address these differences, there was an attempt to organise "a process of mutual recognition of courses, modules, programmes and even institutions"(204) which later became known as the PEER Review (Public health Education European Review)(255) system. Between 2001and 2006 this review was additionally used as a framework for public health capacity development through aiding both the establishment and development of Schools of Public Health within the Central and Eastern European region $(113,262)$ which highlighted the heterogeneous level of development across the EHEA and which provided the grounding for the theoretical framework of the research within this chapter.

\subsection{Theoretical framework}

The following chapters, 4, 5 and 6, form a central part of this dissertation and are based around a project funded by the European Commission's Lifelong Learning programme entitled "Public health Education Reform For Equity in Quality of Training" (190). The previous projects and research (highlighted above) demonstrated that second cycle public health education across the EHEA is not level and shows great disparities across many areas such as, governance, management, admissions, curriculum, pedagogy and quality systems. Not only does this raise questions over the quality of graduates entering into the national workforces but, as shown by the EMPH project, also hinders academic mobility between nations. An attempt to remedy this was a central objective for the introduction of the formal accreditation system which sought to increase transparency and ensure a recognised quality standard across the EHEA. But, given the existing disparities, it is anticipated that many programmes and institutions would not gain accreditation and therefore these inequalities may continue with an additional disparity: those programmes accredited and those not.

This research seeks to understand the levels of disparity and their impact on the range of reforms required by schools and programmes of public health in order to achieve accreditation. The research attempts to achieve this through investigating the compliance of programmes to the existent accreditation criteria and to identify heterogeneous areas 
that may require further strengthening (chapter 4) as well as homogeneous areas (chapter 5). A further concern is to understand if there are any variables, such as regional location or programme age, which can be seen to affect compliance.

The research then seeks to identify practicable actions which can be undertaken by the schools and programmes to realise these reforms (chapter 6). Understanding the changes needed is only part of the issue. The ability to reform is an issue which needs to be understood and any recommended actions will need to be grounded on the feasibility of their implementation.

\subsection{Methods}

We had decided at an early stage that a web-based survey, based on the accreditation criteria, would be the most appropriate given the geographical spread of potential participants. The survey would use three distinct sections (see appendix B). The first section (Part A: Introductory Questions) focused upon contextual variables; the details of the programme, the institution and their national contexts or environments including, the existence of other MPH programmes and the requirements for national accreditation. The second section (Part B: Accreditation Needs) consisted of an investigation of the compliance to selected accreditation criteria. We also included a tertiary section (Part C: Your needs for Improvement) which sought to investigate the programme's own perceived needs. Only the first two of these sections (parts A and B) are included to provide the methodology for chapters 4 and 5.

\subsubsection{Generation of Questions Part A: Introductory Questions (contextual identifiers)}

The first question we wished to ask concerned the country location of the programme. This question was chosen as it could be cross-referenced with both World Bank GNI/capita data and United Nations regional classifications to form additional variables based on "wealth" and regional location whilst retaining the anonymity of the respondent. Although initially deemed basic in nature it became clear that our survey would have benefitted from a more location specific question based on the city in which the programme is located to avoid confusion during the follow-up phases where several master programmes existed within a single country.

The survey questions subsequently requested the programme name, the programme establishment date along with the school establishment date. This was intended to enable variables, such as, the date of establishment and title to be used in the analysis of the data to understand if they bore any significance to compliance. However, during the verification of the data it was evident that the language used in the questions "programme established in" and "school established in" was perhaps too open for interpretation as several schools mentioned either their town or country which would entail a follow-up.

Following pilot phase feedback (see section 4.3.4. below) we issued a definition of an MPH or MPH type "programme" to be used in the survey: "includes all programmes which follow on at least from a first cycle degree education with a focus on public health, which are 
generally considered 'master' level" (see appendix B). The survey then enquired as to respondent school's knowledge of existing or competing programmes in their country: "Number of MPH or MPH type programmes in your country?" The question was designed with the objective to identify programmes and schools outside of the ASPHER network which could be contacted to avoid solely questioning those programmes within the membership of the association. However, alongside time constraints of the funded research, a lack of clarity into existing programmes hindered potential approaches to programmes outside of this selection group (see section 6.5.1. below for further elaboration). The Final questions of the first section then questioned the existence of formal national accreditation bodies involved in either the licensing and continued accreditation of the programmes. These agencies were then cross-referenced based on their membership or not of ENQA.

\subsubsection{Generation of Questions Part B: Accreditation Needs (compliance)}

The second section, Part B, focused upon the accreditation criteria based questions and required several stages of methodology to complete. These stages included a clarification of the existing criteria, a comparison with other external criteria, the selection of criteria to be used and the generation of a response scale. The initial intention was to use the accreditation criteria in a straightforward manner, by questioning the programmes over their compliance to individual criteria. The European accreditation criteria consisted of seven broad or "overarching" criteria (205): i, Governance and Organisation of the Programme; ii, Aims and Objectives of the Public Health Programme; iii, The Curriculum; iv, Students and Graduates; v, Human Resources and Staffing; vi, Supportive Services; Budgeting and Facilities; vii, Internal Quality Management (see Appendix B).

However, during the early stages it became evident that the criteria did not lend themselves easily to this "simplified" form of questioning. In most cases, individual criteria contained a multitude of questions which were not categorised. For example, Table 14 below highlights the overarching criterion V "Human Resources and Staffing." Under this criterion there are 3 further sub categories (Criteria 5.1, 5.2 and 5.3 respectively). Within criterion 5.1 we found 9 individual questions, whereas in 5.2 there was 1 question and subsequently, criterion 5.3 broke down into 4 individual questions. Therefore, when separated into individual questions, this particular criterion on human resources and staffing, formed 14 individual sub-criteria that could operate as questions (see Table 15).

\begin{tabular}{|c|c|}
\hline \multicolumn{2}{|c|}{$\begin{array}{l}\text { Criterion V: Human Resources and Staffing } \\
\text { Sub-Criteria }\end{array}$} \\
\hline 5.1 & $\begin{array}{l}\text { There is a central core of academically qualified teaching staff dedicated to the } \\
\text { programme. } \\
\text { The bulk of the programme is taught by persons belonging to the institution (or } \\
\text { multiple institutions in the case of a joint programme). } \\
\text { This regular faculty consists of a sufficient number of faculty significantly involved } \\
\text { within the programme to support their teaching responsibilities. } \\
\text { The teaching staff demonstrates knowledge in theory, practice, and methods in } \\
\text { public health as well as educational and pedagogical skills. } \\
\text { A sufficient number of the staff are actively involved in public health research } \\
\text { activities. } \\
\text { The teaching staff shows a balance between national, European and international }\end{array}$ \\
\hline
\end{tabular}




\begin{tabular}{|l|l|}
\hline & $\begin{array}{l}\text { experience, appropriate to the programme. } \\
\text { The composition of the departments/teaching staff represents the multidisciplinary } \\
\text { character of public health. } \\
\text { Procedures for evaluating faculty competence and performance, particularly in the } \\
\text { area of teaching, are in place and applied consistently. } \\
\text { The workload of teaching staff is adequately balanced between teaching (including } \\
\text { curriculum and material development and student guidance), administration, } \\
\text { research and service. }\end{array}$ \\
\hline 5.2 & $\begin{array}{l}\text { An appropriate administrative/support staff is available for the programme. } \\
\text { The institution has policies to support professional development for all staff. } \\
\text { There are explicit standards for the recruitment and appointment of teaching staff. } \\
\text { The recruitment policy of the programme is consistent with institutional } \\
\text { recruitment regulations and procedures and with the aim and qualifications of the } \\
\text { public health programme. }\end{array}$ \\
\hline
\end{tabular}

Table 14: Example criterion from APHEA accreditation scheme (2011 version)

Criterion 5.1.(1)There is a central core of academically qualified teaching staff dedicated to the programme.

Criterion 5.1.(2)The bulk of the programme is taught by persons belonging to the institution (or multiple institutions in the case of a joint programme).

Criterion 5.1.(3)This regular faculty consists of a sufficient number of faculty significantly involved within the programme to support their teaching responsibilities.

Criterion 5.1.(4)The teaching staff demonstrates knowledge in theory, practice, and methods in public health as well as educational and pedagogical skills.

Criterion 5.1.(5)A sufficient number of the staff are actively involved in public health research activities.

Criterion 5.1.(6)The teaching staff shows a balance between national, European and international experience, appropriate to the programme.

Criterion 5.1.(7)The composition of the departments/teaching staff represents the multidisciplinary character of public health.

Criterion 5.1.(8)Procedures for evaluating faculty competence and performance, particularly in the area of teaching, are in place and applied consistently.

Criterion 5.1.(9)The workload of teaching staff is adequately balanced between teaching (including curriculum and material development and student guidance), administration, research and service.

Criterion 5.2. An appropriate administrative/support staff is available for the programme.

Criterion 5.3.(1)The institution has policies to support professional development for all staff.

Criterion 5.3.(2)There are explicit standards for the recruitment and appointment of teaching staff.

Criterion 5.3.(3)The institution has policies in place for tenure and promotion.

Criterion 5.3.(4)The recruitment policy of the programme is consistent with institutional recruitment regulations and procedures and with the aim and qualifications of the public health programme.

Table 15: Criterion 5 broken down into individual questions

We also found that there were several sub-criteria that were "multi-faceted" which included two or more potential questions which would require deconstruction for singular responses. For example Criterion 5.3.(4) in Table 15 contains a possible 2 individual questions. During the analysis we also found that this issue had not been fully resolved 
whereby criterion 3.9. (subsequently coded as 3.6 for survey) asked for compliance on "international exchange of staff and students is facilitated" which produced an uncertain response as it remained unclear whether the respondents referred to the exchange of students or of faculty.

The result of this "deconstruction" exercise saw the original 38 individual sub criteria separated into individual questions which resulted in 62 individual questions. This number we deemed impracticable for a web-based survey as the length of time required to complete the survey would be a disincentive to potential respondents.

The second stage review therefore had the objective to reduce these 62 sub-criteria through comparing them to criteria from other accreditation agencies and organisations. The decision was taken to focus our comparison with other trans-national systems rather than national accreditation agency criteria. The APHEA accreditation criteria clearly state that programmes have to fulfil national accreditation requirements. Therefore the decision was made to focus on criteria which were used or applicable internationally which reflected the trans-national nature of the public health education agency. Programme accreditation criteria from six different agencies were used in our comparison including, The European Association for Public Administration Accreditation (EAPAA)(263), Council on Education for Public Health (CEPH)(132), World Federation of Medical Education (WFME)(264), The Swiss Center of Accreditation and Quality Assurance in Higher Education (OAQ)(265), The European Programme Accreditation System (EPAS)(266), and the European Association for Quality Assurance in Higher Education (ENQA)(267). The latter ENQA criteria were primarily institutionally focused but the individual criteria were found to correspond well to a programme focus. Criteria and standards from Western Association of Schools and Colleges (WASC) and EQUIS (268) were reviewed during this stage but were not used as they were found to be institutionally based. The UK Quality Assurance Agency for Higher Education or QAA (269) was also reviewed but was deemed rely on the production of evidence rather than interrogatory site visit based standards.

We compared the resultant criteria against the APHEA criteria based on three rounds of comparison upon when it was decided that any criteria with over 3 comparable mentions with another agency criteria would be considered for the survey (see Table 16).

During the verification of the data, we detected that there had been a repetition of one of the sub-criteria. Criterion 1.1 had been duplicated and reproduced as criterion 5.1(1) in error (please see relevant section in Appendix B) and as a result we decided that the subcriterion should be subtracted from the research leaving a total of 23 sub-criteria extracted from 61 sub-criteria. 


\section{APHEA CRITERIA}

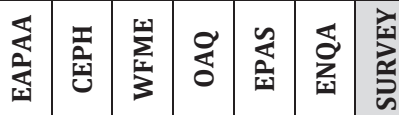

Overarching Criterion 1. Governance and Organisation of the Programme

Criterion 1.1. The parent institution is legally recognised / accredited by national educational authorities and allowed to deliver the Master programme and issue degrees.

Criterion 1.2. The programme administration and faculty shall have clearly defined rights and responsibilities concerning programme governance and academic policies appropriate to fulfilling the aim of the programme.

Criterion 1.3.

Criterion 1.4.There is a competent academically qualified person (or group) responsible for the coordination of the programme. This person must have influence in decisions concerning: General programme policy and planning, Degree requirements, New courses and curriculum modifications, Admissions, Certification of degree candidates, Teaching assignments, Use of financial and other resources for programmes.

Criterion 1.5.

Criterion 1.6. The programme has effective communication tools (website, brochures etc.) to present itself externally in an open, adequate, up-to-date and honest manner.

Criterion 1.7. Faculty and student representatives are involved in the management of the programme.

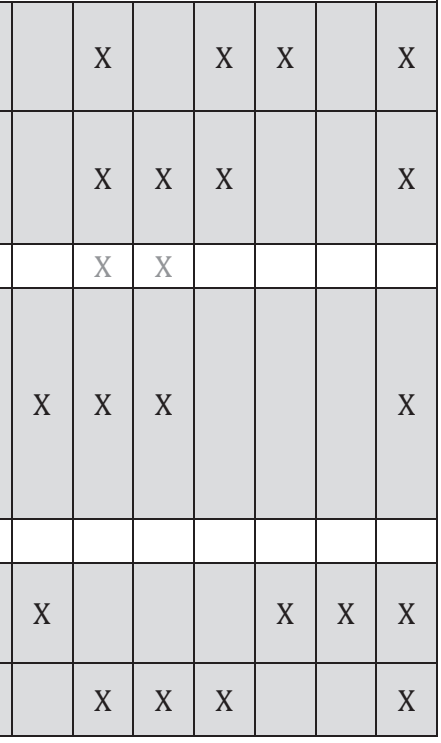

\section{Overarching Criterion 2. Aims and Objectives of the Public Health Programme}

Criterion 2.1.(1) The programme has explicit programme aims in line with the mission of the institution.

Criterion 2.1.(2) The programme aims are shared amongst the staff and host and/or founding institution(s) and known to students and stakeholders.

\begin{tabular}{|c|c|c|c|c|c|c|c|}
\hline $\begin{array}{l}\text { Criterion 2.1.(1) The programme has explicit programme aims in line } \\
\text { with the mission of the institution. }\end{array}$ & $\mathrm{X}$ & $\mathrm{X}$ & $\mathrm{X}$ & $\mathrm{X}$ & $\mathrm{X}$ & & $\mathrm{X}$ \\
\hline $\begin{array}{l}\text { Criterion 2.1.(2) The programme aims are shared amongst the staff and } \\
\text { host and/or founding institution(s) and known to students and } \\
\text { stakeholders. }\end{array}$ & & & $\mathrm{X}$ & $\mathrm{X}$ & & $\mathrm{X}$ & $\mathrm{X}$ \\
\hline Criterion 2.1.(3) & & & & & $\mathrm{X}$ & & \\
\hline Criterion 2.2. & & & $\mathrm{X}$ & & & & \\
\hline Criterion 2.3. & & $\mathrm{X}$ & & & & & \\
\hline $\begin{array}{l}\text { Criterion 2.3.(1)The final qualifications and learning objectives } \\
\text { correspond to general, internationally accepted descriptions of the } \\
\text { qualifications of an academic Master programme. }\end{array}$ & $\mathrm{X}$ & $\mathrm{X}$ & & & $\mathrm{X}$ & & $\mathrm{X}$ \\
\hline Criterion 2.3(2) & & & $\mathrm{X}$ & & $\mathrm{X}$ & & \\
\hline $\begin{array}{l}\text { Criterion 2.4.The programme demonstrates appropriate } \\
\text { responsiveness to change in the environment, scientific evidence and } \\
\text { health needs and demands of populations. }\end{array}$ & & $\mathrm{X}$ & $\mathrm{X}$ & & & $\mathrm{X}$ & $\mathrm{X}$ \\
\hline
\end{tabular}

\section{Overarching Criterion 3. The Curriculum}

Criterion 3.1.The programme content falls within the following core areas:- Methods in Public Health - Population health and its determinants - Health policy, economics and management - Health education and promotion - Other/cross-disciplinary themes

Criterion 3.2 (1)

Criterion 3.2.(2)

Criterion 3.3. The core components of the curriculum provide a thorough teaching of the basic concepts, theories and methods of public health.

\begin{tabular}{|c|c|c|c|c|c|c|}
$\mathrm{X}$ & $\mathrm{X}$ & $\mathrm{X}$ & & & $\mathrm{X}$ & $\mathrm{X}$ \\
$\mathrm{X}$ & & $\mathrm{X}$ & & & & \\
\hline $\mathrm{X}$ & & & & $\mathrm{X}$ & & \\
$\mathrm{X}$ & $\mathrm{X}$ & $\mathrm{X}$ & & & & $\mathrm{X}$ \\
\hline
\end{tabular}


Criterion 3.4. The didactic concept as applied throughout the programme is in line with the programme aims and final qualifications of the programme. The teaching methods correspond to the didactic philosophy of the programme.

Criterion 3.5. Students are assessed in an adequate, meaningful and insightful manner by means of evaluations, tests and examinations, to determine whether the learning objectives or parts thereof have been achieved.

\section{Criterion 3.6.}

Criterion 3.7. There is evidence of inclusion of elements stemming from the Bologna Declaration and process within the programme.

Criterion 3.8.

Criterion 3.9. There are opportunities for international exchange of staff and students.

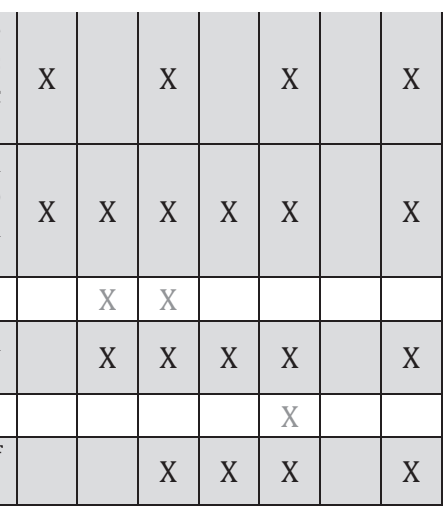

\begin{tabular}{|c|c|c|c|c|c|c|c|}
\hline \multicolumn{8}{|l|}{ Overarching Criterion 4. Students and Graduates } \\
\hline $\begin{array}{l}\text { Criterion 4.1.(1)The programme has clearly defined admission criteria } \\
\text { and recruiting policies coherent with the aim and objectives of the } \\
\text { programme: formal criteria for admission requirements include that of } \\
\text { an undergraduate degree from a recognised university, further } \\
\text { requirements (e.g. language skills, additional academic degree, } \\
\text { international experience) and the profile of individuals showing } \\
\text { motivation to undertake a career in public health. }\end{array}$ & $\mathrm{X}$ & $\mathrm{X}$ & & $\mathrm{X}$ & $\mathrm{X}$ & $\mathrm{X}$ & $\mathrm{X}$ \\
\hline Criterion $4.1 .(2)$ & $\mathrm{X}$ & & $\mathrm{X}$ & & & & \\
\hline \multicolumn{8}{|l|}{ Criterion 4.1.(3) } \\
\hline Criterion 4.2. & & & $\mathrm{X}$ & & & $\mathrm{X}$ & \\
\hline $\begin{array}{l}\text { Criterion 4.3. The institution provides accessible counselling services } \\
\text { for personal, academic and professional development of students. }\end{array}$ & $\mathrm{X}$ & $\mathrm{X}$ & $\mathrm{X}$ & $\mathrm{X}$ & $\mathrm{X}$ & $\mathrm{X}$ & $\mathrm{X}$ \\
\hline \multicolumn{8}{|l|}{ Criterion 4.4.(1) } \\
\hline Criterion 4.4.(2) & & & & & $\mathrm{X}$ & & \\
\hline Criterion 4.5. & & & & & $\mathrm{X}$ & & \\
\hline
\end{tabular}

\begin{tabular}{|c|c|c|c|c|c|c|c|}
\hline \multicolumn{8}{|c|}{ Overarching Criterion 5. Human Resources and Staffing } \\
\hline $\begin{array}{l}\text { Criterion 5.1.(1)There is a central core of academically qualified } \\
\text { teaching staff dedicated to the programme. }\end{array}$ & $\mathrm{X}$ & $\mathrm{X}$ & $\mathrm{X}$ & $\mathrm{X}$ & $\mathrm{X}$ & $\mathrm{X}$ & $X$ \\
\hline \multicolumn{8}{|l|}{ Criterion 5.1.(2) } \\
\hline \multicolumn{8}{|l|}{ Criterion 5.1.(3) } \\
\hline Criterion 5.1.(4) & $\mathrm{X}$ & & & & $\mathrm{X}$ & & \\
\hline Criterion 5.1.(5) & $\mathrm{X}$ & $\mathrm{X}$ & & & & & \\
\hline Criterion 5.1.(6) & & & & & $\mathrm{X}$ & & \\
\hline Criterion 5.1.(7) & & $\mathrm{X}$ & $\mathrm{X}$ & & & & \\
\hline Criterion 5.1.(8) & & $\mathrm{X}$ & & & & & \\
\hline $\begin{array}{l}\text { Criterion 5.1.(9) The workload of teaching staff is adequately balanced } \\
\text { between teaching (including curriculum and material development and } \\
\text { student guidance), administration, research and service. }\end{array}$ & $\mathrm{X}$ & & $\mathrm{X}$ & $\mathrm{X}$ & & & $\mathrm{X}$ \\
\hline Criterion 5.2 & & $\mathrm{X}$ & $\mathrm{X}$ & & & & \\
\hline Criterion 5.3.(1) & & & $\mathrm{X}$ & & $\mathrm{X}$ & & \\
\hline Criterion 5.3.(2) & & & $\mathrm{X}$ & & & & \\
\hline Criterion 5.3.(3) & & & $\mathrm{X}$ & & $\mathrm{X}$ & & \\
\hline Criterion 5.3.(4) & & & & & & & \\
\hline
\end{tabular}




\section{Overarching Criterion 6. Supportive Services, Budgeting and Facilities}

\begin{tabular}{|l|l|l|l|l|l|l|l|}
\hline $\begin{array}{l}\text { Criterion 6.1. The programme has financial resources sufficient to } \\
\text { support its stated aims, final qualifications and learning objectives. }\end{array}$ & $\mathrm{X}$ & $\mathrm{X}$ & & $\mathrm{X}$ & & $\mathrm{X}$ \\
\hline $\begin{array}{l}\text { Criterion 6.2.(1) Library learning resources are provided for students } \\
\text { and staff with sufficient access to these resources. }\end{array}$ & $\mathrm{X}$ & $\mathrm{X}$ & $\mathrm{X}$ & $\mathrm{X}$ & $\mathrm{X}$ & $\mathrm{X}$ & $\mathrm{X}$ \\
\hline $\begin{array}{l}\text { Criterion 6.2.(2) The school holds online journal subscriptions to } \\
\text { support up-to-date relevant health literature searches, databases and } \\
\text { online educational material. }\end{array}$ & $\mathrm{X}$ & $\mathrm{X}$ & $\mathrm{X}$ & $\mathrm{X}$ & $\mathrm{X}$ & $\mathrm{X}$ & $\mathrm{X}$ \\
\hline Criterion 6.2.(3) & & & & & & \\
\hline Criterion 6.2.(4) & & & & & & & \\
\hline Criterion 6.3. & & & & & & \\
\hline Criterion 6.4. & & & & & & \\
\hline Criterion 6.5.(1) & & & & & & \\
\hline Criterion 6.5.(2) & & $\mathrm{X}$ & & & & \\
\hline Criterion 6.5.(3) & & & \\
\hline
\end{tabular}

\section{Overarching Criterion 7. Internal Quality Management}

\begin{tabular}{|c|c|c|c|c|c|c|}
\hline $\begin{array}{l}\text { Criterion 7.1. An operational internal quality management system is in } \\
\text { place, broadly inclusive of staff, students and stakeholders. }\end{array}$ & $\mathrm{X}$ & $\mathrm{X}$ & $\mathrm{X}$ & $\mathrm{X}$ & $\mathrm{X}$ & $\mathrm{X}$ \\
\hline $\begin{array}{l}\text { Criterion 7.2. There is continuous data collection and analysis that } \\
\text { assures necessary modifications in the learning objectives, the content } \\
\text { of modules, staffing, and pedagogical approaches. Results of analysis } \\
\text { are relayed accordingly to senior management, staff and students. }\end{array}$ & $\mathrm{X}$ & $\mathrm{X}$ & $\mathrm{X}$ & $\mathrm{X}$ & $\mathrm{X}$ & $\mathrm{X}$ \\
\hline Criterion 7.3. & & & & & $\mathrm{X}$ & \\
\hline Criterion 7.4. & & & & & & \\
\hline Criterion 7.5 . & $X$ & & & & & \\
\hline
\end{tabular}

Table 16: Comparison of APHEA sub-categories with 6 other agency accreditation standards. (190)

\subsubsection{Scaling system used}

The next task was to assign a scaling system. Our initial objective was to understand both the level of compliance and whether schools were in a process of changing their systems. A four point Likert scale was initially proposed to investigate both compliance and change: Yes, we comply / No, we don't comply but we are in the process of trying to reach this level / No, we don't comply and it is very difficult for us to reach this level / No, we don't comply and so far we are not moving towards this goal. After discussion we deemed that the responses would be too wide to be analysed. To this end, we reduced the scale whereby the questionnaire asked for the compliance of each sub-criteria with three possible answer categories: i, We comply, ii, We don't yet comply but we are in the process of trying to reach this level and, iii. We don't comply.

\subsubsection{Pilot testing and revision of survey questions}

We then undertook a pilot study of the questionnaire which was tested on five Deans where feedback was requested. Alterations to the wording of 11 sub-criteria were highlighted and the changes based upon this feedback were translated into a web survey (see Table 17). 
As part of the revision process, the language used in the criteria was furthermore considered for clarity. For example, the term "appropriate" was highlighted during the pilot phase in criterion 2.4. "the programme demonstrates appropriate responsiveness to change in the environment, scientific evidence and health needs and demands of populations." We considered that this particular word "appropriate" was vague and would rely heavily on a subjective appreciation. In this particular instance the criteria wording was changed to the following: (Criterion 2.4.) "The programme is designed to respond to changes in the environment, scientific evidence and health needs and demands of populations."

\begin{tabular}{|c|c|c|}
\hline Criteria & Issue & $\begin{array}{c}\text { Solution } \\
\end{array}$ \\
\hline 4 & Programme should be defined & \multirow{2}{*}{$\begin{array}{l}\text { Use of "At least after 1st Cycle" to } \\
\text { look at APHEA. }\end{array}$} \\
\hline 6 & MPH should be defined & \\
\hline 1.4 & Large areas - what happens if only partially met? & Reduce areas \\
\hline 1.7 & "involvement" not very specific & Use "formally involved" \\
\hline $2.1(2)$ & $\begin{array}{l}\text { Shared aims too broad perhaps breakdown } \\
\text { staff/students/stakeholders }\end{array}$ & Use just Staff \\
\hline 2.3 & Review second cycle & Add "academic master programme" \\
\hline 2.4 & "Appropriate responsiveness" What does this mean? & $\begin{array}{l}\text { Use "the programme is designed to } \\
\text { respond" }\end{array}$ \\
\hline 3.9 & $\begin{array}{l}\text { What does "opportunities" entail i.e. financial support } \\
\text { etc }\end{array}$ & $\begin{array}{l}\text { "International exchange of staff and } \\
\text { students is facilitated" }\end{array}$ \\
\hline $4.1(1)$ & "motivation to study" not needed in national system & End text at "programmes" \\
\hline $5.1(1)$ & Academically qualified should be clearer & Leave text as is. \\
\hline $6.2(1)$ & Library open outside of usual school hours? & $\begin{array}{l}\text { "sufficient access to learning } \\
\text { resources" }\end{array}$ \\
\hline
\end{tabular}

Table 17: Pilot testing feedback and changes made (190)

\subsubsection{Generating, distributing and collecting the web survey}

Initially we had discussed the possibility of using an online survey service such as surveygizmo or surveymonkey but as none of the team possessed any thorough knowledge or expertise of these services we opted for a simple "form" based process through contracting our web-administrators. The web based survey used php scripting which stored all the responses within a Comma Separated Values (CSV) file which could be exported into Microsoft excel and SPSS. Once completed by the respondent, an email was also sent to the survey coordinator where the data was presented in a html tabulated form.

Deans and Directors from schools in the ASPHER network across 37 countries were contacted by email $(n=71)$ and sent a link to a web based survey. This number was 12 schools less than the membership list of ASPHER at that point in time, as in some cases the schools were known not to have master level public health education and in several other cases the contact points in the schools were unavailable.

The whole process of distribution and collection took two months to complete with a total of four rounds of contact to the schools. The first response came on 15th February 2013 and the last response was received on the 12th April 2013.

One week before the closure of the survey, an email was sent to the respondent programmes which contained their complete given feedback in the html form. This was to double check the data provided and also to address and missing data. During the process it 
was evident that an amount of data from some programmes required double checking. Other issues encountered included some schools had entered terms too cryptic to decipher; entering their names in national languages or simply copy and pasting the school name in both the school and programme title sections. The follow-up process provided (surmountable) obstacles through the inability to clearly recognise individual schools within a country as city identifiers had not been used.

\subsubsection{Analysis}

We deemed the small sample size too small for multivariate analysis and therefore agreed to test for significance using Fischer's chi square exact test using SPSS version 17.0 (see Appendix A for full breakdown). In order to accomplish this analysis we began by aggregating the responses of the 23 individual sub-criteria by converting the three responses, (i) we comply, (ii) we don't yet comply but we are in the process of trying to reach this level and, (iii) we don't comply, into a binary yes / no response. The response (i) "we comply" formed a 1 integer whereas the last two responses formed a 0 integer. The second step then focused upon aggregating the 7 overarching criteria. Any overarching criteria containing at least one sub-criteria with a value of 0 , would subsequently assigned a 0 integer.

The individual 23 sub-criteria as well as the 7 over-arching criteria were then analysed against the information deriving from the Part A introductory questions. We applied Fischer's chi square exact test to test for differences in compliance to the sub-criteria ( 1 / 0) between the range of contextual variables included in part A introductory questions. As mentioned, the country information would allow the addition of two extra variables to be considered. Firstly, the countries could be associated with the GNI / capita from the World Bank which would be taken as giving an indication of the wealth of the country. The World Bank categorises countries based around a classification of high, upper middle, lower middle and low income but these produce a rather simplistic classification whereby all but one of the schools in the survey would exist in the top two categories. As a result, we had decided to use the World Bank wealth data but group the countries into categories of $\$ 20,000$ which produced four delimitations of wealth status with the band for $\$ 61,000$ to 80,000 omitted as there were no examples within the survey of countries falling in this category.

A secondary variable was created by associating the country within a United Nations regional definition (270) which would allow for a separation of countries along North/East/South/West criteria. However, we found this classification rather crude and precarious as, for example, the Northern region contained both Lithuania $(\$ 12,280$ GNI/capita) and Norway (\$88,890 GNI/capita) which politically, socially and economically are incomparable. Therefore we decided to refine the categorisation for analysis to ensure that countries typically viewed or perceived as "CEE" (principally post-socialist countries) were included in a new CEE region classification. The resultant categorisation was for Northern, Western, Southern and CEE European region. Table 18 highlights the regional classification used during our analysis along with the changes made to construct the CEE region. 


\begin{tabular}{|llll|}
\hline Central \& Eastern Europe & Northern Europe & Southern Europe & Western Europe \\
\hline Albania $(1-1)^{\mathrm{c}}$ & Britain $(5-4)$ & Greece $(1-0)$ & Austria $(3-2)$ \\
Armenia $(1-1)$ & Denmark $(2-2)$ & Israel $(1-1)$ & Belgium $(1-0)$ \\
Bulgaria $(3-2)^{\mathrm{a}}$ & Finland $(2-2)$ & Italy $(5-4)$ & France $(2$ - 2) \\
Estonia $(1-1)^{\mathrm{b}}$ & Iceland $(1-0)$ & Portugal $(1-0)$ & Germany $(8-5)$ \\
Hungary $(1-1)^{\mathrm{a}}$ & Ireland $(1-1)$ & Spain $(4-3)$ & Netherlands $(1-1)$ \\
Kazakhstan $(1-1)$ & Norway $(1-1)$ & & Switzerland $(1-0)$ \\
Latvia $(1-1)$ & Sweden $(5-2)$ & & \\
Lithuania $(3-3)^{\mathrm{b}}$ & & & \\
Macedonia $(1-1)^{\mathrm{c}}$ & & & \\
Moldova $(1-1)^{\mathrm{a}}$ & & & \\
Poland $(2-2)^{\mathrm{a}}$ & & & \\
Romania $(1-1)^{\mathrm{a}}$ & & & \\
Russian Federation $(1-1)^{\mathrm{a}}$ & & & \\
Serbia $(2-1)^{\mathrm{c}}$ & & & \\
Slovakia $(2-2)^{\mathrm{a}}$ & & & \\
Slovenia $(1-0)$ & & & \\
Turkey $(1-0)$ & & & \\
Ukraine $(1-1)^{\mathrm{a}}$ & & & \\
Uzbekistan $(1-0)$ & & & \\
\hline
\end{tabular}

Table 18: Regional distribution and collection of survey (190)

NOTES

(a)Originally in Eastern Europe classification. (b) Originally in Northern Europe classification. (c) Originally in Southern Europe classification

(Numbers in brackets) first number shows number of programmes sent questionnaire in each country $(n=71)$ whereas the second number indicates number that replied $(n=51)$.

Dates of school establishment were banded into three epochs (1899-1960, 1961-1990 and 1991-2013) which reflected periods of development (also graphically represented in Figure 7). Establishing categories for programme establishment was less straight forward as the majority of programmes started after the year 2000. Here, the banding consisted of four categories (up to 1980, the 1980s, the 1990's and after 2000). The existence of national accreditation systems formed the penultimate enquiry based around a simple binary yes or no as to whether they existed. We further examined whether the national accreditation agency was a member of ENQA and whether this affected compliance. Finally, as the sample size was very small we also opted for a graphical representation of the data through the use of Microsoft Excel. We then tested for any significance in the term "public health" in either the title of the programme or school. Responses were aggregated around a binary of whether the term public health appeared (1) or did not (0).

\subsection{Results}

A total of 61 out of 71 (86\%) programme representatives responded. From this number we excluded 6 programmes for not having a Master of Public Health (MPH) type award, 2 programmes did not want to participate and 2 programmes returned substantially 
incomplete questionnaires, they had only completed the Part A contextual questions. As a result we analysed data deriving from 51 programmes. The regional breakdown of the 51 programmes was as follows: Northern Europe (NE) = 12 schools, Western Europe (WE) = 10 schools, Southern Europe (SE) = 8 schools and Central and Eastern Europe (CEE) = 21 schools (see Table 18).

Within the questions regarding national accreditation bodies 84\% $(n=43)$ of programmes indicated that they were licensed and / or accredited by their national authorities. Only one out of the 51 programmes left one sub-criterion blank in the first criterion and we deemed this sufficiently small (6 of the 7 sub-criteria had been answered) to ignore when aggregating the data for the over-arching criterion. Table 19 shows the levels of compliance for the seven overarching accreditation criteria according to European region. The regional location of the programmes was significantly associated with compliance rates in five of the seven overarching accreditation criteria.

\begin{tabular}{|c|c|c|c|c|c|}
\hline \multirow[b]{2}{*}{ Overarching-Criteria } & \multicolumn{4}{|c|}{$\begin{array}{c}\text { Aggregated EHEA Regional } \\
\text { compliance }\end{array}$} & \multirow[b]{2}{*}{ Chi * } \\
\hline & NE & WE & SE & CEE & \\
\hline $\begin{array}{l}\text { Criterion 1: Governance and Organisation of the } \\
\text { Programme }\end{array}$ & $100 \%$ & $80 \%$ & $50 \%$ & $62 \%$ & 0.026 \\
\hline $\begin{array}{l}\text { Criterion 2: Aims and Objectives of the Public } \\
\text { Health Programme }\end{array}$ & $100 \%$ & $80 \%$ & $50 \%$ & $81 \%$ & 0.046 \\
\hline Criterion 3: The Curriculum & $75 \%$ & $60 \%$ & $25 \%$ & $52 \%$ & 0.182 \\
\hline Criterion 4: Students and Graduates & $100 \%$ & $90 \%$ & $63 \%$ & $76 \%$ & 0.112 \\
\hline Criterion 5: Human Resources and Staffing & $100 \%$ & $70 \%$ & $50 \%$ & $81 \%$ & 0.039 \\
\hline $\begin{array}{l}\text { Criterion 6: Supportive Services, Budgeting and } \\
\text { Facilities }\end{array}$ & $100 \%$ & $50 \%$ & $63 \%$ & $38 \%$ & 0.002 \\
\hline Criterion 7: Internal Quality Management & $100 \%$ & $40 \%$ & $25 \%$ & $57 \%$ & 0.001 \\
\hline
\end{tabular}

Table 19: Average compliance with the overarching criteria in the four European regions

Out of the 23 sub-criteria, 3 areas demonstrated the least amount of compliance (identified in Table 20). The first question was "International exchange of staff and students is facilitated?" where non-compliance pervaded all regions but where the Southern and Central Eastern regions displayed the least compliance. The average responses from all 51 programmes were "we comply" = 67\%, "we don't yet comply but we are in the process of trying to reach this level" = $23 \%$ and "we don't comply" $=10 \%$.

The second area covered the two sub-criteria under the 7th accreditation criterion "quality management systems (QMS)." The first sub-criteria enquired if the programme had, "an operational internal quality management system is in place, broadly inclusive of staff, students and stakeholders." The average results were, "we comply" = 67\%, "we don't yet comply but we are in the process of trying to reach this level" = $27 \%$ and "we don't comply" $=6 \%$. The second part of the question asked if, "there is continuous data collection and analysis that assures necessary modifications in the learning objectives, the content of modules, staffing, and pedagogical approaches. Results of analysis are relayed accordingly 
to senior management, staff and students." Once again the average responses were "we comply" $=67 \%$, "we don't yet comply but we are in the process of trying to reach this level" = 27\% and "we don't comply"=6\%.

\begin{tabular}{|l|c|c|c|c|c|}
\cline { 2 - 5 } \multicolumn{1}{c|}{} & \multicolumn{3}{c|}{ Aggregated EHEA } & \multicolumn{1}{c|}{ Regional compliance } & \\
\hline \multicolumn{1}{c|}{ Sub-Criteria } & NE & WE & SE & CEE & Chi* \\
\hline $\begin{array}{l}\text { Criterion 3.6: International exchange of staff and } \\
\text { students is facilitated }\end{array}$ & $75 \%$ & $70 \%$ & $63 \%$ & $62 \%$ & 0.886 \\
\hline $\begin{array}{l}\text { Criterion 7.1: Quality Management Systems in place } \\
\text { including faculty / students / stakeholders }\end{array}$ & $100 \%$ & $50 \%$ & $38 \%$ & $67 \%$ & 0.008 \\
\hline Criterion 7.2: Continuous data collection & $100 \%$ & $50 \%$ & $25 \%$ & $71 \%$ & 0.002 \\
\hline * Chi Square exact test p values. & & & & \\
\hline
\end{tabular}

Table 20: The three least complied sub-criteria in the four European regions

Table 20 shows the sub-criteria with the lowest compliance stratified by European region in which the programmes were located. Unlike exchange issues, the compliance to QMS significantly differed between the regions with Southern and Western European regions exhibiting the lowest compliance.

\subsection{Discussion}

The research clearly demonstrates that issues concerning student and faculty exchange and quality management in the programmes of Public Health surveyed throughout the EHEA are a cause for concern with around a third of schools falling within the "non-compliance" category. In many ways both exchange and quality management demonstrate two desired and complementary forces upon public health education: global knowledge and experiences adapted to local contexts determined by national stakeholders (3) which has been a constant in the development of schools and programmes for many years (113). The question then arises, if these are so important, why are we in this position and what solutions can be sought?

The research identifies that student and faculty exchange throughout the EHEA has a noncompliance range between $25 \%$ and $38 \%$ (see Table 20). Exchange is included in accreditation to monitor the programmes alignment / adherence with the Bologna processes (205) and as student and faculty exchange is a central tenet of the Bologna declaration (271) which all countries of the EHEA have by default signed, why does it remain one of the weakest areas of compliance? With $84 \%$ of programmes licensed or accredited by national agencies how are these agencies ensuring the integration of their governments' international treaty obligations?

Exchange of students and faculty is a core aspect of mobility and a hallmark of internationalisation (272). Exchange can be seen within a context benefiting individuals from increasing competences, knowledge and skills (273) through to organisational change models in setting academic standards and institution building (274). The use of the aforementioned PEER Review as a framework for developing schools and programmes 
across the Central and Eastern Region provides a good example. Faculty exchange was seen as a key element and focused upon both increasing and improving academic capacity but also on giving schools first-hand experience and insight into the operational intricacies of differing European models of education from module design, through to pedagogical approaches and assessment (113). The returning faculty were expected to adapt their knowledge to their local situations.

However, exchange generally requires funding. There are funds available through European instruments but these require that schools have an Erasmus University Charter which not all schools possess. Language barriers will continue to stifle both student and faculty mobility (182). In some countries mobility of students is deterred by compulsory testing on the return home (275). For both students and faculty, mobility requires an element of "uprooting" which does not always fit in personal life which is especially difficult if programmes focus on part time teaching of professional staff. A limitation of this line of enquiry is that the question does not specify the constituent parts of "exchange." European Union funding documents (276) state that mobility covers faculty for teaching, providing training, participation in structured courses or training events (excluding conferences) or job shadowing/observation and for students, a study period which may include a traineeship. All of these activities have to occur in a foreign country and therefore is open to differences in interpretation where schools may have included wider notions of exchange, such as, conferencing or joint research projects.

Adapting to local situations mentioned earlier is a central feature also for quality management systems. This activity is aimed at improvement through listening to and integrating the needs of the (most notably national) stakeholders (277). In theory this is commendable but the low compliance may be a result of its impracticability. The EHEA consists of 53 countries with large diversities, inequalities and understandings of public health (278). On the "Western" side there are the older European Union states who, over the last 30 to 40 years, have been embracing new public health which, "includes all possible activities known to be useful and effective in promoting health and in the prevention, treatment and rehabilitation of diseases for the individual, the community, and the population as a whole" (73). Ironically the term "new public health" was first coined over a century ago in 1913 in which public health was viewed as a composition of hygiene and sanitation for the control of infectious disease at an individual level (50) which is historically not too dissimilar to the understanding of public health developed and lingering in the "Eastern" side of the EHEA $(56,136)$. On this latter side, many countries and their stakeholders continue to perceive public health through an historical san-epid paradigm (49) which placed a narrower focus on medicalised surveillance of infectious diseases and sanitary issues (136) through a network of public health centres in nearly every district of the country for the surveillance and control of all potentially preventable diseases (279). Such understandings have created a situation of high premature mortality, up to four times higher in some former Soviet states than in Western Europe (136). In such circumstances it will be very difficult for programmes to approach potential stakeholders as they will not consider themselves to be "public Health" stakeholders 
(113). To integrate "out-moded" stakeholder opinions in such a climate may also be counter-productive by reflecting and reinforcing historical understandings.

Even in more westernised systems stakeholder input has limitations as many (sometimes the majority of) stakeholders do not have an education in public health $(13,280)$. This may raise issues in understanding where or whether stakeholders fit in a "public health" system and what the expectations of public health education are if systems and workforce survive and thrive on untrained individuals.

The low compliance rates in the Western and Southern regions may well be also indicative of a continued "ivory tower" approach to education (281) where programmes are disconnected and non-responsive to the environments they are meant to serve. Finally, the low compliance in the first sub-category may also be due to a longstanding confusion between what constitutes and differentiates quality management from quality assurance (282). "Quality management" is used here to refer to the philosophy of continuous improvement, customer focus and integrated management systems (283) whereas "quality assurance" is seen as a process for establishing that provision (input, processes and outcomes) fulfils expectations or measures up to minimum requirements (284) generally through the use of standards or criteria.

\subsection{Conclusion}

The results of this research focus on the least compliant themes of public health educational programmes to the new European Accreditation: exchange and quality management. Both of these sub-criteria stress the importance of programmes and schools of public health to learn from within and outside of their national systems with the aim of improving the quality, vision and employability of their respective public health workforces but also their accountability to societies they serve (13).

However, problems persist. Exchange of students and faculty (mobility), although enshrined in legislation is, in many countries poorly implemented and enforced. Quality management systems which inherently rely upon feedback from stakeholders are limited by a lack of understanding and dialogue from both schools and stakeholders.

National and European governments will need to support (and enforce) faculty and student exchange. Schools should also understand this activity as a long-term investment for internal quality improvement. For quality management systems there is a need for schools to be trained in some basic concepts and instruments to remain in tune with the needs of the field and outside of their ivory towers. This activity should be seen as improving internal quality rather than ticking bureaucratic boxes.

As to identifying the stakeholders within the public health workforce it will be interesting to see how the WHO's new essential public health operations (EPHOs) and most particularly EPHO 7 on workforce, will assist in this manner by identifying and categorising responsibilities within the public health workforce. The EPHOs, for example, could be used 
by schools for both identifying stakeholders and also informing these stakeholders of how they are seen within an international perspective. This would give good ground toward understanding the competences needed in each arm of the workforce and this work has already begun (260). This will be an interesting avenue as previously the WHO's Health For All targets helped initiate the latest version of "new public health" and the new EPHOs, hold the possibility to define public health in terms of function related competences which can help schools determine both the content and delivery of their programmes (285). This is an area that perhaps networks or research consortia should concentrate upon. In all cases public health programmes should be keeping in contact and listening to their alumni which does not seem to be a common exercise at present.

Many of these issues may be become calcified because national accreditation systems act as gate-keepers to the existence of schools and programmes and these are intrinsically tied up with the financing and politics of their education systems (157). Disregarding the potential for conflicts of interest these systems tend to be non-sector specific to public health but rather limited to generalised academic measurements. As a result, programmes and schools of public health are legally, financially and politically guided in their development through generic education standards set at a national level which are not necessarily focused upon the delivery of a competent public health workforce at either a national, European or global level. The role of European accreditation should therefore be to add value to these national systems through sector specific and internationally accepted standards and benchmarks. These should be focused on the relevance of education for real-world public health and not only on the formal academic measurements of the national agencies which are, at present, applied equally to a programme or school of public health, engineering, law or aesthetics. 



\section{Chapter 5. Harmonisation in European Public Health Education: A Question of Looking in the Right Places?}

Based upon:

Goodman JD, Muckelbauer R, Muller-Nordhorn J, Cavallo F, Kalediene R, Kuiper T. Harmonisation in European Public Health Education: A Question of Looking in the Right Places? 


\subsection{Introduction}

Public health education in the European region seemingly demonstrates very little commonality or "harmony" in structure, definition, or scope with responses to health often being driven by individual national perspectives (278). In 1995 De Leeuw used the membership directory of the Association of Schools of Public Health in the European Region (ASPHER) to argue that in the European region, the organisational structures, teaching programmes, disciplinary emphases and quality of teaching and research varied hugely (15). The author postulated that to meet future needs, schools of public health (SPHs) may develop and harmonise, with the aid of accreditation, into the American stand alone model. Navarro subsequently argued that this missed the point as the structures affected curricula. The classic model of SPHs, as departments of medical schools, reproduced medicalised public health that constrained development (286). Unlike the American model, European public health education developed alongside the emergence of the individual nation state and was traditionally part of the medical curriculum $(14,191)$. This historical development ensures that there is little commonality in the names of schools, programmes (see Table 21 and Table 22) or indeed "public health" as a lexical term (287). Such variance can be difficult to assimilate. In 2010, the global independent commission of Frenk et al., again using the membership of ASPHER, found their global count of SPHs hampered and ultimately incomplete due to a "definitional ambiguity" (3). Other commentators have taken a different route and opted to describe public health education in terms of scope, such as, professional or graduate education to prepare for careers in public health (51). This scope can be seen within the remit of both a school but also a programme of public health $(119,288)$. Although not common currency as seen in the American accreditation context (80), The Master of Public Health and public health master degrees in general are considered by some as defining an SPH (6) but, it has also been noted that the presence of a course with the same name does not imply a uniformity of content (289). Only an in-depth study of content would be able to discern the uniformity or harmonisation. The aim of this chapter is to discern whether there is any commonality, uniformity or harmonisation in European Master level public health education. To do this we looked at the highest selfattested compliance rates to the accreditation criteria. This complements chapter four above which focused upon the lowest compliance to the accreditation criteria (290).

\subsection{Methods}

The 71 programmes of public health within the ASPHER membership were invited by email to participate in a web-based survey. Details of this process have been described elsewhere (290). The survey consisted of school and programme identifying questions, such as, school and programme name, year of establishment and location followed by the accreditation criteria. The accreditation criteria consist of 7 overarching criteria or headings and a series of sub-criteria which fit under those headings. There were originally 61 individual accreditation sub-criteria which we reduced to 23 following a comparison of other accreditation agency criteria. The survey asked for the name of the school under which the programmes run and the dates the school and programme were established. The age of the school and of the programme was calculated with the reference year 2013. After these questions, the survey contained 7 separate pages relating to the overarching accreditation 
headings. These in turn, enclosed the related sub-criteria and a choice of response: i, We comply; ii, We don't yet comply but we are in the process of trying to reach this level and; iii. We don't comply. Sub-criteria 3.1 required the respondent to click an extra link which opened up a "pop-up" window in which appeared a table outlining seven core subject areas and their associated curriculum content (205). This table was devised based on a previous ASPHER publication focusing on European core competences for Master of Public Health (MPH) programmes (291).

Several respondents had indicated the University name rather than their school or institution name which was requested and this necessitated sending follow-up emails and visiting the websites to correctly identify the precise department/faculty/school name. Where the establishment dates of the schools and programmes could not be determined the dates were omitted. The United Nations regional definitions (270) were refined to accommodate other international agency's definition of Central and Eastern Europe and resulted in four principal sub-regions of the European Region: Northern Europe (NE), Western Europe (WE), Southern Europe (SE) and Central Eastern Europe (CEE).

\subsection{Results}

61 out of 71 contacted programmes, responded to the initial survey email with 6 schools indicating that they didn't have Master level public health education, 2 schools highlighting their unwillingness to participate and 2 schools only completing the identifying data. Subsequently, data from 51 programmes throughout 29 different countries was used for analysis.

All schools except one provided information regarding their school name $(n=50)$ and all schools provided the name of their programmes $(n=51)$. We found 20 different names for Schools of public health with just over one quarter (13 out of 51 ) being designated as a "School of Public Health" see (Table 21). The term "Faculty of Public Health" existed solely in Central and Eastern Europe where 8 of the 21 schools in this region used this name. In Southern Europe, all schools from one country (4 in total) were named, "Departments of Hygiene and Preventive Medicine." Out of the 20 different school name types only 35\% (7 out of 20) incorporated the term "public health." The names for programmes of public health exhibited an equal variance with 12 different names in use from the sample. The most common was the "Master of Public Health" with just over half (26 out of 50 or 52\%) of programmes using this name. Out of the 12 different name types 5 name types incorporated the term "public health" (see Table 22). 


\begin{tabular}{|c|c|c|c|c|c|}
\hline \multirow[b]{2}{*}{$\begin{array}{r}\text { School name types } \\
\end{array}$} & \multicolumn{4}{|c|}{ Regional location } & \multirow[b]{2}{*}{$N=$} \\
\hline & NE & WE & SE & CEE & \\
\hline \multirow{20}{*}{$\begin{array}{l}\text { School of Public Health } \\
\text { Faculty of Public Health } \\
\text { Department of Public Health } \\
\text { Dept Hygiene and Preventive Medicine } \\
\text { Institute of Public Health } \\
\text { Faculty of Medicine } \\
\text { School of Health Sciences } \\
\text { Centre of Public Health } \\
\text { College of Health Sciences } \\
\text { Department of Community Medicine } \\
\text { Department of Health and Applied Social Sciences } \\
\text { Department of PH \& Health Technology Assessment } \\
\text { Department of Social and Health Sciences } \\
\text { Faculty of Health Care and Social Work } \\
\text { Faculty of Health, Medicine \& Life Sciences } \\
\text { Faculty of Life Sciences } \\
\text { School of Health Studies } \\
\text { School of Hygiene \& Tropical Medicine } \\
\text { School of Management in Public Health } \\
\text { School of Medicine }\end{array}$} & 2 & 4 & 3 & 4 & 13 \\
\hline & - & - & - & 8 & 8 \\
\hline & 3 & - & - & 1 & 4 \\
\hline & - & - & 4 & - & 4 \\
\hline & 1 & 1 & - & 2 & 4 \\
\hline & - & 1 & - & 2 & 3 \\
\hline & 2 & - & - & - & 2 \\
\hline & - & - & - & 1 & 1 \\
\hline & - & - & - & 1 & 1 \\
\hline & 1 & - & - & - & 1 \\
\hline & 1 & - & - & - & 1 \\
\hline & - & 1 & - & - & 1 \\
\hline & - & 1 & - & - & 1 \\
\hline & - & - & - & 1 & 1 \\
\hline & - & 1 & - & - & 1 \\
\hline & & 1 & - & - & 1 \\
\hline & - & - & 1 & & 1 \\
\hline & 1 & - & - & - & 1 \\
\hline & - & - & - & 1 & 1 \\
\hline & 1 & - & - & - & 1 \\
\hline Total & 12 & 10 & 8 & 21 & 51 \\
\hline
\end{tabular}

Table 21: School name types from the survey

\begin{tabular}{|c|c|c|c|c|c|}
\hline \multirow[b]{2}{*}{ Programme name types } & \multicolumn{4}{|c|}{ Regional location } & \multirow[b]{2}{*}{$N=$} \\
\hline & NE & WE & SE & CEE & \\
\hline Master of Public Health & 7 & 6 & 3 & 10 & 26 \\
\hline Master of Science in Public Health & 3 & 3 & - & 3 & 9 \\
\hline Post graduate specialisation in Public Health & - & - & 3 & - & 3 \\
\hline Master in Public Health and Health Management & - & - & 1 & 1 & 2 \\
\hline Master in Public Health Care & - & - & - & 2 & 2 \\
\hline Master in Health Sciences & 2 & - & - & - & 2 \\
\hline Public Health Epidemiology (postgraduate) & - & - & - & 1 & 1 \\
\hline Master of Medical Sciences & - & - & - & 1 & 1 \\
\hline Management of Social and Health Services & - & - & - & 1 & 1 \\
\hline Management in Public Health & - & - & - & 1 & 1 \\
\hline Health Promoting Organisational Development & - & 1 & - & - & 1 \\
\hline Health Care Management & - & - & - & 1 & 1 \\
\hline Total & 12 & 10 & 7 & 21 & 50 \\
\hline
\end{tabular}

Table 22: Programme name types from the survey

The data concerning the date of establishment of the schools and programmes was less comprehensive with 2 respondents $(n=49)$ not providing a date for the school and 5 respondents $(n=46)$ not providing the programme date. We found that only 1 school was established before the turn of the 20th century whereas in the period 1991-2010 over half of the schools appeared (53\%). This was due primarily to the CEE input (89\% were 
established in these two decades) while in Southern Europe no new schools appeared in this period (see Table 23).

Programmes in the sample were established later (see Table 23) and it was again the two decades 1991-2010 which saw the most establishment across all the regions. The average age of the schools (in 2013) was 32 years and of the programmes was 13 years.

The survey results concerning the criteria based questions found that overall 11 out of the 23 (48\%) sub-criteria based questions had "we comply" responses of $90 \%$ and over which we therefore used as a cut-off percentage (see Figure 9).

\begin{tabular}{|c|c|c|c|c|c|c|c|c|}
\hline \multirow[b]{2}{*}{ Time period } & \multicolumn{4}{|c|}{$\begin{array}{l}\text { Regional location of } \\
\text { school }\end{array}$} & \multicolumn{4}{|c|}{$\begin{array}{c}\text { Regional location of } \\
\text { programme }\end{array}$} \\
\hline & NE & WE & SE & CEE & NE & WE & SE & CEE \\
\hline 2011- end of survey & - & 1 & - & 1 & 1 & - & - & - \\
\hline $2001-2010$ & 1 & 2 & - & 9 & 6 & 7 & 1 & 15 \\
\hline $1991-2000$ & 3 & 3 & - & 8 & 2 & 1 & 2 & 5 \\
\hline 1981-1990 & 1 & 1 & 5 & - & 2 & - & 2 & - \\
\hline 1971-1980 & 3 & 1 & - & - & - & - & 1 & - \\
\hline 1961-1970 & - & 1 & - & - & - & - & - & - \\
\hline $1951-1960$ & - & - & 2 & - & - & - & 1 & - \\
\hline 1901-1950 & 3 & 1 & 1 & 1 & - & - & - & - \\
\hline pre 1900 & 1 & - & - & - & - & - & - & - \\
\hline Total & 12 & 10 & 8 & 19 & 11 & 8 & 7 & 20 \\
\hline
\end{tabular}

Table 23: Temporal and spatial establishment of schools and programmes

\subsection{Discussion}

The high compliance rates associated with the 11 sub-criteria reside in a region characterised by divergent spatial and temporal understandings and practice of public health. Much of the pervading ideologies from the early part of the 20th century laid the foundations for country level public health approaches and their ability to address the changing causation of disease throughout the last century. The Eastern part of the region was influenced by the San-epid approach to public health built upon a focus on health protection and administrative centralisation (56). This system was slow to change and remained intact throughout the majority 


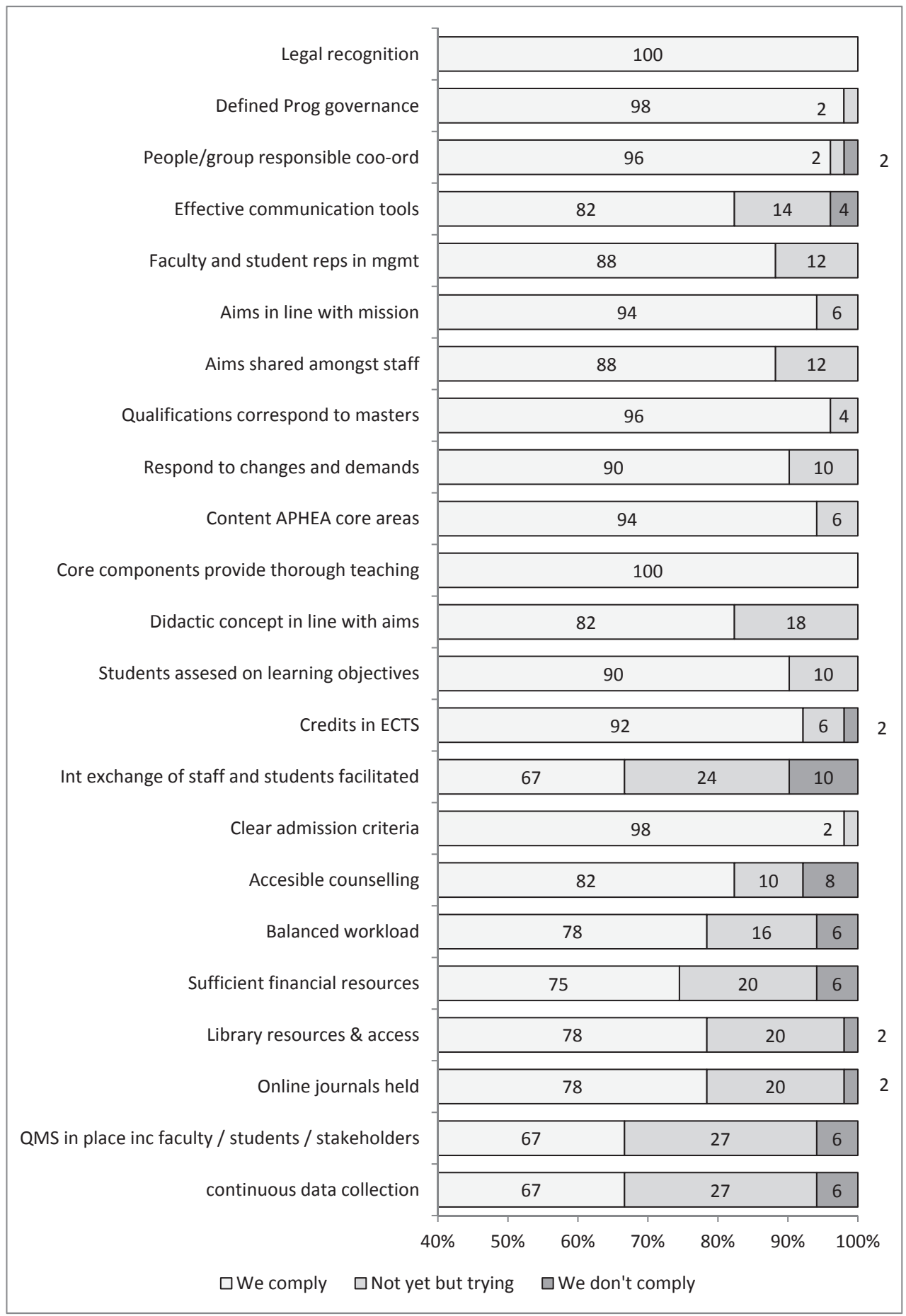

Figure 9: Percentage compliance to 23 selected accreditation criteria (see Table 16 and Appendix E for full descriptors)(190). 
of the century leading to an inability to address non-communicable mortality (292). Alternatively, the western side witnessed changing concepts and names for public health until the broader concepts of the WHO's Health for all strategies led to the creation of an embracing term in "New Public Health." $(72,256)$

In 1995 De Leeuw analysed the same ASPHER membership sample group and found that organisational structures, teaching programmes, disciplinary emphasis and quality of teaching varied "hugely."(15). Although this survey found potential evidence of an equally varied array of structural locations (through the use of school titles) it could not substantiate the findings concerning the teaching programmes, disciplines and teaching quality. This survey found quite the reverse with a consistency in multidisciplinary approaches, the teaching of concepts, theories and methods as well as assessments based around learning objectives. Most importantly perhaps is that $90 \%$ of programmes stated that they responded to changes in the environment, scientific evidence and health needs and demands of populations. This finding appears to oppose much of the discussion concerning the stagnant and ivory tower nature of curricula in many countries $(3,293)$. The findings also demonstrate a similitude with a recent survey of European Union countries which indicated that up to $86 \%(n=24)$ of the 28 EU countries allowed Universities the liberty to set their own curricula content with only $14 \%(n=4)$ having to abide by government dictates (114). These latter countries were Italy, Latvia, Lithuania and Poland. The comparisons with the lowest scores found (all in the range of "we don't yet comply but we are in the process of trying to reach this level") for multidisciplinary learning (subcriterion 3.1) are stark with the programmes coming from Italy, Lithuania and Poland.

The research could not corroborate Navarro's assertion that schools of public health, as a department of medical schools, reproduce a medicalised version of public health (286). The present survey found that $94 \%$ of the respondents complied to a multidisciplinary teaching of public health. However both his and De Leeuw's assertions were made in the beginning of the 1990s at the same time that public health education was witnessing a renaissance. Table 23 demonstrates that, within the ASPHER membership, between 1991 and 2010, $73 \%$ of the schools of public health and $85 \%$ of the programmes of public health were established. It is unclear if these were generated from existing structures or completely new entities. This period witnessed the breakup of the soviet bloc and it has been argued that the emergence of democracy in these countries led to a fundamental reappraisal of their public health services and training requirements (294) as well as the introduction of the fist accreditation schemes (158). Such a transition was not unique to the former soviet bloc as Table 23 establishes. Although "schools" were seen predominantly appearing in the CEE during this 20 year period, the vast majority of programmes of public health in the sample were established across all the European sub-regions.

A potential hindrance facing the further development of public health education as a unified academic body is the lack of definition, not only in terms of "public Health" which is well documented but also how that term relates to "schools" and education. Both De Leeuw and Frenk et al had highlighted the difficulties in the definitions of schools of public health. This 
is not unique situation to Europe and continues to create a major problem in global mapping $(3,15)$.

The lack of common terminology at a programme level in the European Region is equally concerning and sits in stark contrast to the MPH degree which is common currency in America. The Council on Education for Public Health (CEPH) in America has accredited 108 programmes of public health of which only one does not carry the term "public Health" in its title and this comes from a French speaking university in Quebec, Canada (80). Our survey did not find a common use of the term "public health" in programme names. It is unclear if this is a result of governance, such as the University or Ministries restricting the use of specific terms. For example, it was only in 2009 that the Russian state formally recognised the MPH award (190). Alternatively it may be due to a lingual interpretation whereby "public Health" as a term does not exist in some countries. In German, for example, in addition to the English term public health, the term Gesundheitswissenschaften is used for public health, which translated means "health sciences" (295). This is not uncommon within school and programme names in the region (see Table 21 and Table 22). Finally, it may also be due to internal marketing strategies whereby programmes wish to distinguish themselves from "competitor" programmes.

When comparing the highest and lowest areas of compliance from chapters 4 and 5 we must remember that the survey focuses at a programme level. Programmes often exist within a department or faculty of a larger academic body, such as a University. We found that around half of the programmes surveyed could be identified as sub-units through their names being either Faculty or Department. Less clear is the use of the term "school." As De Leeuw highlighted in 1995 in 5 out of 8 structures identified as "schools" were a constituent part of a University. This therefore raises questions over autonomous decision making and how much of the criteria surveyed are, or could be, determined at a programme level.

Many of the low compliance areas can be seen as functions of the larger organisational unit rather than at a programme level. For example, as seen in the findings of chapter 6 resources are often controlled centrally through the university. Available financial resources, for example, would impinge on the programme's ability to facilitate staff and student mobility. Equally, quality management systems can often be found at a central level rather than at a programme level. These are examples of areas potentially controlled by the University. Governments may provide an additional hierarchical level which constricts movement. We are unsure, for example, of the relationship between the title of the programme and government dictates. How many of the programmes surveyed have the freedom to determine their own name?

When we review the highest compliance we must question whether these are a result of autonomous decision making. It would be perceived that the content of a programme, for example, would be directly under the control of the programme governance but this too has to be questioned. The evidence provided in this survey identifies only programmes from Italy, Lithuania and Poland indicated that they did not fully comply with the curriculum 
core areas of the survey. These three countries comprise 3 of the 4 countries within the EU where the governments directly dictate curriculum content. Equally, as found in chapter 6, the Serbian programme provides evidence from outside the EU that programme change can be limited by governments through accreditation agencies.

\subsection{Conclusions}

The survey of programmes reaffirms a lack of harmonisation across the European Region in terms of structures, definitions and the names of schools and programmes which is in contrast to the situation with American accredited schools and programmes. It remains unclear whether this is determined, top down, by state or university governance which may play a larger role in determining the actions and remit of schools and programmes. The evidence from this survey combined with other surveys in the European Union would seem to suggest this is the case. Harmonisation however does occur in the in-depth study of the programmatic elements such as curricula content and assessments. These latter elements, unlike structures and names, may fall under the direct control of the programmes which, in turn, seem to be influenced by a bottom-up response to changes in the environment, scientific evidence and health needs and demands of populations. More research needs to be conducted on the autonomous decision making of programmes within their hierarchical governance systems and the affect these have on achieving compliance to accreditation systems outside of those instigated by the same hierarchical structures. 



\section{Chapter 6. The Use of Quality Assurance Indicators as a Framework for Developing New Schools and Programmes}

\section{Based upon:}

Goodman J, Müller-Nordhorn J, Cavallo F, Kalediene F, Kuiper F, Muckelbauer R. (2015). Public Health Workforce Capacity Building: The use of quality assurance indicators for the improvement in public health programmes. Moldovan Journal of Health Sciences. vol. 4, 2: 17-25 


\subsection{Introduction}

Supplementing the quantitative survey found in chapters 4 and 5 we also conducted a series of micro level qualitative site visits to three programmes in the European Region. The objective of this research was to provide qualitative and in-depth data on the schools, programmes and operations. We also considered this part of the research to act as verification of the quantitative data whereby the programmes could be assessed based upon their answers to the quantitative survey. The preliminary aim was to identify programmes and schools based upon the outcomes of the quantitative results. However, we were unable to achieve this due to the funder requirements which included a presubmission, as part of the research application stage, of the names and dates of the site visits to be conducted.

The countries chosen were representative of three different types of countries within the EHEA region. The first was Spain as it represented an older EU member in the southern sub-region. The second country was Serbia which, in January 2014, was beginning EU accession talks and is a representative of South East Europe which was aggregated during the quantitative methodology into the Central Eastern Region. Finally, Russia was chosen as the country has historical influence over many other countries which continues to permeate today. Although a member of the Bologna process, Russia will remain outside of the EU.

As highlighted in chapter 2 the previous PEER Review gave valuable insights for accreditation (205) and demonstrated how PEER could be used as a framework for development. The question addressed in this chapter is, could accreditation offer a suitable framework for quality improvement in the same way PEER had done?

\subsection{Methods}

The first part of the methodology concerned the use of the original 24 criteria outlined in the methodology section of chapter 4 (at this point the erroneous criteria 5.1. had not been identified).

Within the existent accreditation criteria there is a heavy focus on the information given as part of the self-evaluation documentation and processes. The accreditation site visits then have a role to verify the information during the on-site visitations (see Table 2 on standard processes). After initial consultation with the programmes we felt that a reliance on an extensive self-evaluation was not possible due to the "strain" on the participating schools. Instead we adopted a "light touch" approach, which consisted of a representative selfevaluation, covering the main areas of the school and programme, along with a more interrogative series of meetings within the site visits (see Appendix E). We designed the site visits to not only provide the schools a yes / no feedback on the evidence found but also to produce a series of quality improvement recommendations. This secondary aspect was seen to reintegrate the essence of the earlier PEER Review.

During the first qualitative research meeting we decided that a series of standardised openended questions should be devised to provide the framework for interviews. These we 
called "protocols" and can be found in Appendix E. These would provide both programmes and site visitors with a common set of questions which could be applied equally and appended by more open or free flowing discussion afterwards. To achieve this, our task consisted of converting the 24 criteria statements into a series of questions and scheduling. The APHEA checkpoints were first assigned to the chosen 24 criteria (as detailed in Chapter 4) to ensure that any verification or checking required could be accomplished through the site visits. The criteria were then aligned to the standards used within the previous PEER Review. This (PEER) review offered a series of questions, rather than checkpoints, which were designed for quality improvement purposes. Where we could not find associated questions we looked within the standards and criteria used by other accreditation agencies. We then conducted a secondary round of review to locate any alternative ways of asking these criteria based questions.

The questions were then finalised with several ambitions in mind. Firstly that they provide a set of basic questions which could be standardised and applied equally to all programmes. Secondly, the responses could then be transcribed and subsequently analysed. Finally, as mentioned, the questions were designed as a first line of questioning which could be opened up afterwards for further lines of investigation.

Site visits consist of a series of meetings with actors and key members of each school. Having associated the questions to the 24 criteria it became clear who were to be involved and Table 24 outlines the 10 individual actors that the questions were to be directed at. Interestingly, during the write-up it became apparent that alumni had not been involved at this stage. As mentioned the questions were drawn from the original 24 criteria and as these had not contained alumni focused questions they had not been involved. In hindsight this can be seen as a mistake. Alumni are a major stakeholder as they perform a bridge between the programme and the workforce and could have been involved, at a minimum in the student interviews. Having stated this, alumni were involved as student representatives in Russia and Serbia.

1. Dean / Director

2. Programme coordinator or group

3. Faculty Representative in formal school body

4. Teaching faculty

5. Librarian
6. Computer staff

7. Students

8. Student Representative in formal school body

9. Stakeholders - especially employers

10. Quality management section - if applicable

Table 24: On site review interviewee list

The site visit schedules were to cover two days of interviews followed by the third day for site team reflection and feedback to the programme. During this feedback, comments and recommendations were to be given to the programmes and include all the actors who took part in the interviews to inform them of the findings and seek their initial feedback to the findings. There were two separate visiting teams covering the three reviews with the first team attending both the first and final visit. From experience, an estimation of time allocations for asking and replying to each question was made. Table 25 highlights the 
initial estimations for time required by the questions with both faculty and students also being involved as representatives.

\begin{tabular}{|l|c|c|c|c|c|c|c|c|}
\cline { 2 - 9 } \multicolumn{1}{c|}{} & Criteria 1 & Criteria 2 & Criteria 3 & Criteria 4 & Criteria 5 & Criteria 6 & Criteria 7 & minutes \\
\hline Director & 10 & 10 & 20 & & 15 & & 10 & $\mathbf{6 5}$ \\
\hline $\begin{array}{l}\text { Coordinator / } \\
\text { QMS }\end{array}$ & 10 & 25 & 45 & 10 & 10 & & 10 & $\mathbf{1 1 0}$ \\
\hline Faculty & 10 & 15 & 10 & & 30 & & 10 & $\mathbf{7 5}$ \\
\hline $\begin{array}{l}\text { Librarian / } \\
\text { computer }\end{array}$ & 10 & 10 & 30 & 15 & & 10 & 15 & $\mathbf{9 0}$ \\
\hline Students & 10 & 25 & & & & & 15 & $\mathbf{5 0}$ \\
\hline Stake-holders & $\mathbf{5 0}$ & $\mathbf{8 5}$ & $\mathbf{1 0 5}$ & $\mathbf{2 5}$ & $\mathbf{5 5}$ & $\mathbf{3 0}$ & $\mathbf{6 0}$ & $\mathbf{4 1 0}$ \\
\hline
\end{tabular}

Table 25: Estimation of the time needed (in minutes) for the questions proposed.

The total number of minutes estimated came to just under one working day of interviews. By doubling this amount, the schedule could be drawn up to cover two days of meetings and allocate the amount of time for the individual interviews. As there was no way to pilot test this beforehand, the first site visit was used to review and reform scheduling whilst keeping the questions in-tact for analysis.

Initially and in line with the current accreditation practice, the questions were to be delivered without the interviewee's prior knowledge. However, it was decided that the protocols should be sent beforehand to give the interviewees more time to reflect. This was deemed important as many interviewees would not be native English speakers and they could arrive prepared which also had the potential to economise of the timing of the process. One negative side point of this was that the protocols appeared to some as very formal and tantamount to accreditation proper.

The process of question generation also highlighted the requirements of the self-evaluation documentation and what information was desired prior to the arrival of the on-site reviewers (see Appendix E). The self-evaluation documentation, within the accreditation procedure, is a fundamental part of the process and requires that the schools invest a heavy amount of time and manpower. Within these site visits the process was expected to be lean or "light," with a minimum amount of effort being required from the schools. To this end, schools were presented with self-evaluation requirements and asked for any information to be sent to the research team so that the they could collate the relevant information. Often this meant receiving documentation in a national language which had to be translated through Google translation, as well as having to verify information contained within websites. Once the documentation had been compiled it was re-circulated to the school for verification before distribution to the on-site reviewers. This ensured that an introductory overview and a minimum amount of information regarding the school and programme was given to the on-site reviewers before their arrival so that there was some amount of precognisance of the situation. 


\subsubsection{Analysis}

All interviews were recorded for analysis. The original intention was to transcribe the interviews for comparative analysis. However, during the transcriptions it became clear that the recordings were unable to provide the quality required. Generally, meetings were conducted with three interviewers and a range of respondents ranging from 3 to 8 . The questions provoked lively debate with the consequence that many of the respondents talked over each other which made it impossible to transcribe individual responses. This was also the case, where translators were involved (principally in Russia). As such the research produced site visit reports which summed up the key statements made during the interviews, but could not analyse the individual responses or statements made by the programmes.

The site visit reports were generated by the visiting members and distributed to the programmes afterwards to ensure correctness of fact and statement. Agreement was given by all of the programmes for these site visit reports to be available in the public domain as case studies (190). The schools and their programmes represented a range of different entities and working structures and hence there was no possibility to apply a "commonality" to all. However, one of the ambitions of the research was to highlight the differences and similarities between these programmes to enable a greater understanding and reflection of the needs and processes involved at a local level. Much of the investigations raised and uncovered areas which are known to affect many schools and as such can potentially provide reflective material for programmes and schools throughout the region.

\subsection{Results}

The first school to be visited was the Escuala Andulza de Salud Publica in Granada, Spain (17-19 April 2013). The school began in 1985 and was established by the regional government in Andalusia to build a strong workforce. The school offers a medical specialisation in public health called a Masters in Public Health and Health Management which is simultaneously offered as part of a two-year international master collaboration entitled Europubhealth. The second school to be visited was the Centre - School of Public Health and Health Management, Belgrade, Serbia (9-11 May 2013) which was founded in 2004 as an organisational unit within the Faculty of Medicine, University of Belgrade. This school began with support from the European Agency for Reconstruction and was funded initially by the European Union. The Master of Public Health programme available at the school is two-year part-time award and is taught alongside the provision of two other Masters and two doctoral programmes. The final school to be visited was the International School of Public Health in Arkhangelsk, Russia (28 June to 1 July 2013) which was founded at the Northern State Medical University in 2006 as part of an international collaborative project involving seven Nordic universities. The Master of Public Health is a two-year fulltime course and is the main output of the school. The headings below highlight the results from the on-site visits. 


\subsubsection{Criterion 1: governance and organisation of the programme}

\section{Criterion 1.2. School institutional position}

Two of the programmes visited were housed within medical university structures. In both cases, this was recommended to remain unchanged as it was seen as positive. This provides evidence that, unlike the American prescriptions for schools, many in Europe exist within Medical universities or faculties.

- "Often there is a question as to whether schools of public health should be autonomous or should be part of a medical faculty. To the team, given the support from the medical faculty it would not be worth pursuing autonomy and therefore the team suggested to retain the current situation." "The team felt that being part of the faculty of medicine some basic elements of the school are safeguarded, housing, facilities et cetera." Centre - School of Public Health and Health Management, Belgrade (190).

- $\quad$ "It would seem that the school has a very functional identity within the university system, in the sense that they are called to develop and put forward part of the University mission within the public health field" International School of Public Health, Arkhangelsk (190).

\section{Criterion 1.6. Communication and marketing}

Communications and marketing was raised in all three programmes. The feedback from the visiting teams firstly demonstrates the benefits of site-visits are not solely for the visited programmes and schools but that the visitors also gain exposure to new knowledge and practices. Secondly they provide evidence that schools and programmes have to actively attract students and one reason for this, provided in Russia, is that public health as a professional sector is not widely understood.

- "The marketing presentation of the school was outstanding. The team would like to applaud this area and it was a good learning experience for the team as well." Escuala Andulza de Salud Publica, Granada (190).

- "The team understood and witnessed the difficulties in securing a minimum number of students and were aware of the difficulties associated. The team suggested to the school that they may want to consider focusing on marketing and communication to give them greater security by increasing the perspective admissions." "The team did not want to explicitly recommend an alumni association, although it was suggested that the school should use the alumni in marketing, recruiting and teaching." Centre - School of Public Health and Health Management, Belgrade (190).

- "The team realised that there are issues in the region with regard to the understanding of public health and with local regulations." "The school have just started issuing new Russian degree masters, which are not well known or recognised." "The team think that the school should concentrate on marketing, not only within the local area or university, but also around the country and other foreign Russian speaking countries." International School of Public Health, Arkhangelsk (190).

\subsubsection{Criterion 2: Aims and Objectives}

\section{Criterion 2.1.(1). Strategic Planning}

Strategic planning was raised in all visits. In Serbia there were reservations made outside of the formal meetings over the implementation of their own strategic plan whereas strategic 
development of didactic approaches as well as the development of a precise and reflective mission was highlighted in one visit. This provides evidence that mission statements are not always truly reflective of activity and will need periodic reappraisal.

- "The team however didn't get the sense, or see the evidence, of an overriding strategy or formalised policies for the didactic processes used within the school." Escuala Andulza de Salud Publica, Granada (190).

- $\quad$ "One of the main points to be developed now is to set up a strategy for the future and setting out a strategic plan, which means first of all defining a clear mission for the school. The team had discussed with some of the interviewees during the site visit what this mission could be. The impression was that there was a very loose definition of the mission. The team believes that the school should have a much more strict and precise definition." International School of Public Health, Arkhangelsk (190).

Internationalisation (no associated research sub-criteria)

There were similarities between all three schools in their international intentions. Although this area exists outside of the accreditation framework it was discussed during all visits with each school being at varying levels of internationalisation.

- $\quad$ The school is very particular in a sense, in the way that it integrates both Europubhealth and also the first year of the School of Specialty in Public health for medical doctors." Escuala Andulza de Salud Publica, Granada (190).

- "The team would encourage the school to continue on the road towards its English taught programme. To achieve the regional role, the school would require extra manpower, particularly dealing with IT. To advance the school based only on the existing staffing would be very difficult." Centre - School of Public Health and Health Management, Belgrade (190).

- $\quad$ "The school could publicise the programme not only in Russia but also in other countries which speak Russian, for example former Soviet Union countries which are lower developed in terms of public health training. The team would also suggest that the school approach foreign graduates who have graduated or are graduating from the existing Russian system in medicine. This would be a large market for the school and later would be of great value to their countries as health managers, public health workers, coordinators of different projects or programmes." International School of Public Health, Arkhangelsk (190)

\subsubsection{Criterion 3: The Curriculum}

Offering curriculum in parts (no associated research sub-criteria)

In two of the schools reviewed the site visit teams recommended that the schools should investigate the possibility of offering the curriculum in parts, such as CPD modules, or as a part-time programme. The text provides evidence that there are often legal restrictions on the format for Masters degrees which can inhibit this latter element but full-time degrees are often not attractive to the working population and hence can create a reduction in potential admissions.

- "The team would also support the expansion of the programme to a part-time basis." Escuala Andulza de Salud Publica, Granada (190).

- "As most of the students were working it should be a part-time basis" however, The team noted that there was only "10\% degrees of freedom to change which was allowed the course 
by the national accreditation system." Centre - School of Public Health and Health Management, Belgrade (190).

- $\quad$ The team had seen and were informed about the rigidity which underlines the programme which doesn't allow it to be so attractive from the point of view of students. So the school should look at the possibility of offering the curriculum in parts." However, "there are often legal restrictions on the format for Masters degrees which can inhibit this latter element but full-time degrees are often not attractive to the working population and hence can create a reduction in potential admissions" International School of Public Health, Arkhangelsk (190).

\subsubsection{Criterion 4. Students and graduates}

Alumni data on career paths (no associated research sub-criteria)

In all of the site visits that took place the site-reviewers had stressed the career potential of the courses for the students. The use of electives previously mentioned was seen to offer concrete career advantages to many participants as it would allow them to specialise in key areas without having to undergo a full Master degree. In the other two schools the advice was to collect alumni career data. It was found that there was no systematic collection of this data which could be recycled within the schools for marketing, career services and pedagogy. During these discussions it also became apparent how some of the on-site reviewers' schools were either not doing this or had sought unsuccessfully to undertake this activity.

- "The team felt that perhaps the school could look at getting more information on careers and alumni careers with regard to potential career paths." Escuala Andulza de Salud Publica, Granada (190).

- $\quad$ "The team had not witnessed the systematic collection of alumni data concerning the career paths or pertinence of training within performance." Centre - School of Public Health and Health Management, Belgrade (190).

\subsubsection{Criterion 5. Human resources and staffing}

Faculty development and exchange (exchange contained within sub-criterion 3.9)

Contained within two reviews were recommendations for more formal policies in the development of faculty. This provides evidence that many activities (at least at the time of their conception) within schools and programmes exist in an informal manner with the advice of the sector being drawn toward formalising these structures and activities.

- $\quad$ The team did note the lack of formalised policies for faculty development. The reviewers heard about the possibilities for the faculty to go abroad for training and collaborative work. However, the team didn't get the sense of a formalised faculty development policy or process, which should be considered by the school." Escuala Andulza de Salud Publica, Granada (190).

- "The school which has a lot of enthusiastic staff who use a range of teaching methods. However, these seemed to depend very much on personal enthusiasm, for example, some might use case studies where as others might use different techniques. So the school might consider integrating an educational policy including learning methods in different sections to act more as a framework." Centre - School of Public Health and Health Management, Belgrade (190). 
- The team thought that it is not enough that senior teachers train junior teachers and they just follow." "The strength of the school was that all members of the faculty were trained in the international project. People with whom the team interviewed understood the concept of contemporary public health and the methods of modern training as they had gone through the training of trainers programme." International School of Public Health, Arkhangelsk (190)

\subsubsection{Criterion 6. Supportive services}

Online resources (sub-criterion 6.2.(2).)

All of the schools involved had access to journals provided through centralised systems either through a national library consortium, a regional health authority or through the university bodies. However, a note of caution was issued that schools should be given the opportunity to guide the purchase of supportive international learning resources.

- "The review team were aware that there are issues concerning the student's ability to procure international online journals but were aware that a remedy for this was in process, as well as workarounds available for students to use." Escuala Andulza de Salud Publica, Granada (190).

- $\quad$ "On the positive side it was evident that the school can use all of the supportive services of the main university body and this is a real facility. One key point, if the school wants to become a real modern up-to-date European training and research centre, is to have access to international literature. If the school does not have access to international literature it will be impossible to keep updated and to keep the students updated and show that the school and programme are updated with the European or world situation. This is something that the school should work upon as it is a key point and beyond the point of having access just to Russian literature. This will make the future very difficult for the school, especially in terms of attractiveness, if this is not resolved." International School of Public Health, Arkhangelsk (190).

\subsubsection{Criterion 7. Quality Management Systems}

Stakeholders (sub-criterion 7.1)

All three schools were advised to refine procedures with regard to the stakeholders of the school as quality management systems found were heavily focused on the evaluation of student perceptions and satisfaction. These were often taken during the courses but no formal structures existed for the assessment or needs of the external stakeholders which also contain alumni. The views of the site-visitors in all three reviews cast doubts on the veracity of the information contained in the quantitative survey (chapter 4) in which all of these three programmes stated that they fully complied to this sub-criterion.

- "The team noticed that a lot of issues in quality management were going through the programme coordinator in a very informal nature, which was deemed as nice and also reflective of the earlier comments made with regard to the student appreciation for the friendliness of staff. However, the team felt that the school may wish to introduce a quality management committee consisting of faculty, students and stakeholders which, in turn, would be perhaps more transparent." Escuala Andulza de Salud Publica, Granada (190). 
- $\quad$ "The team did note that the evaluation was heavily student focused with students ranking faculty and providing information. The school could consider further inputs from stakeholders and especially faculty." Centre - School of Public Health and Health Management, Belgrade (190).

- "When the school does develop and get more students, the school will need to then concentrate on formalising the quality processes and mechanisms through both qualitative and quantitative aspects. This is about gearing the school and programme to learn and develop from the people that they are there to serve so the school is dynamic and adapts and focuses more on outputs and the needs of the students, stakeholders and the wider community" International School of Public Health, Arkhangelsk (190).

\subsection{Discussions}

A direct comparison for quality improvement between the previous use of the PEER Review in Central Eastern Europe and accreditation as identified in chapter 2 is impossible for several reasons. Firstly the PEER was used as part of a five year funded project by the Open Society Institute. This meant that many of the recommendations were for funded activity, such as international travel and partnerships. Secondly, the PEER Reviews conducted in the OSI ASPHER project for the more developed schools, relied on the existence of a selfevaluation which provided programmes with a large introspection on their processes which is seen as a central part of quality Improvement. Finally, the site-visits conducted as part of this research project did not use all of the accreditation criteria (23 out of 61) and therefore only provide a reference point to around 38\% of the total accreditation criteria. In many cases the observations and recommendations of the visiting teams were not contained in these 23 criteria.

However, what was found in terms of recommendations and observations proved that there are areas of quality improvement in which accreditation criteria can be used. The question then, is how to integrate quality improvement into a quality assurance framework? One method already used is by the World Federation of Medical Education (264) who use accreditation criteria for quality assurance by expressing them as "should" statements for quality improvement. A potential global accreditation scheme may wish to follow suit but will also need to be mindful of those programmes in the earlier stages of establishment. It might be wise to ensure that for establishment and development reviews are not solely focused on passing through the target of accreditation. Many early necessities of activity, such as planning, situational and stakeholder analysis or capacity identification will not be specifically addressed by accreditation as it focuses upon programmes (and more recently schools and continuous professional development courses) that have already achieved a high level of development. Finally, any pursuit of using quality assurance for quality improvement would need to allow for a self-evaluation process which provides programmes and schools with tools for introspection either as part of an external review process or simply as an internal exercise.

\subsection{Limitations of research within chapters 4,5 and 6}

\subsubsection{Internal validity.}

From the beginning of the research contained within chapters 4,5 and 6 , we were aware that a selection bias was a factor due to those being questioned all being members of an 
association which provided the mailing list. We had attempted to implement a process to overcome this by asking the respondents about other existing programmes in their country as part of the introductory questions: "Number of MPH or MPH type programmes in your country?" The question was designed with the objective to identify programmes and schools outside of the association network which could be contacted to avoid solely questioning those programmes within their membership. However, alongside time constraints of the funded research, a lack of clarity into existing programmes hindered potential approaches to programmes outside of this selection group. Data gathered demonstrated that all but one of the countries having two or more respondents $(n=13)$ could not provide a consensus on the amount of MPHs in their country, i.e. their responses were all different. This could have demonstrated a "guess" from the respondent in order to have something written in the answer box. For example (from later research) the UK is known to have 59 public health masters although one UK respondent had entered between 11 and 20. As a result, there was never clarity whether additional programmes existed, who they were, or indeed their contact details. This created a lack of certainty and confidence in the responses for this question across the entire selection group.

The language considerations working across 37 countries also came into focus in this part of the research. Internet based searches would only prove useful in identifying other programmes if they had websites and if those websites were in a language spoken by one of the team. This was further exacerbated by the lack of clarity in search terms to be used, for example many of the programmes and schools in the survey did not use generic terms such as "public health" in their titles (see Table 21 and Table 22). As a result no other schools or programmes outside of the membership of the association were contacted.

The selection bias threatens the external validity of the findings and research as we are unsure as to why they joined the association, as opposed to others in the region that didn't and whether this had a bearing on the responses given. Furthermore, as the questionnaire was distributed via the association there may have been a sense of appearing "under review" by the association which may have influenced the responses, both positively or negatively.

\subsubsection{Confounding bias}

With regard to the two lowest criteria we must also question the questions. The exchange of faculty and students, although embraced within a larger rubric of mobility, consists of two variables and hence there cannot be clarity as to whether respondents were referring to faculty, students or both. Secondly, the issue of "quality" causes concern. Criteria 7.1 makes reference to "quality management systems" and in other areas of research it was detected that some schools could not distinguish quality assurance from quality management (190). This reinforces concerns raised as part of the wider research within the Central and Eastern European region, identified in chapter 2: "reviewers sensed that the schools in the region require a logical or philosophical understanding of the purpose of quality processes which can provide an intellectual framework on which to establish practical mechanisms" (113). 
Quality mechanisms also raise concern over structural variables confounding the results. We are unaware of how quality systems are implemented and whether they are a responsibility of the programme or centralised within larger university structures in which they sit. As a result the amount of control on quality mechanisms by the programme is variable and this may cause discrepancies in responses as the questionnaire was completed by the programmes and not the wider university structures. The structural location of programmes of public health (Ministry, university, faculty, department etc) was a focus of the work undertaken by De Leeuw in 1995 (15). We did not test for this and hence there is no way of ascertaining these structural variables affect responses. Although programmes had responded, many of their functions may be determined or organised by the institution which houses them. Therefore the responses may not be entirely accurate if the respondent focused solely on the programme.

The programme base also raises a further threat as responses came from MPH type awards following on from 1st cycle. In this case both independent MPH degree types as well as medical specialisations would have been included. These might not be the same construct or even content and therefore hold the potential to affect the responses. This is compounded if we focus on Southern Europe where $50 \%$ of the responses came from one country. In this country all of the programmes were located in departments of hygiene and preventive medicine as medical specialisations. Because of the influence of this one country in the sub-regional results there was an issue with the data being skewed. Of special interest is why all the departments were equally named after a paradigm of public health from the 1940 s to 1960 s (See Table 3).

In chapter 5 we see that the content of the curricula was one of the highest compliant areas. However, we must place focus on how this question was raised. The web based survey included a "pop-up" window detailing the curricula sections (See appendix C) . We have no way of knowing whether participants had opened this window or simply entered the responses based on a subjective understanding of the question.

Subjectivity is a key aspect in this survey. All the questions and their responses are liable to a subjective interpretation. An onsite-visit, on the other hand, might be the only possible way in determining true objective responses. For example, all three of the programmes which underwent a site visit as part of this research (chapter 6), had indicated full compliance to the questions on quality management. However, the quality systems in all three programmes were commented upon by independent site visitors for improvement, most notably through the inclusion of wider stakeholder groups (190). The results from chapter 6 therefore creates uncertainty over the whole sample group.

\subsubsection{External Validity}

A difficulty therefore arises as to whether the results represent a true reflection of the situation in each country and / or region. For example, to what extent can the data deriving from programmes in any one sub region (Northern, Southern Europe etc) be a true reflection or even generalised over the whole of that region? In the European region we are 
aware of a landscape with large economic, social, political and cultural variations. We are also conscious that this region in particular is characterised by differences in understanding and practice of public health $(49,136)$. How far the respondent programmes from this region reflect the overall of the region is unknown.

If we then consider differences between countries within a smaller defined region, such as the EU, we can also see large variations. For example, as mentioned in a following piece of research we located 59 public health masters in the UK whereas in Germany we found only 9 programmes. What are the factors which cause such a discrepancy between these countries and how do these factors affect the generalisability from one national system to another?

If we then consider the delivery of Masters programmes within a single country we can find differences in their academic or practice / professional focus as well as their structural location from public universities through to private providers. These would all fit within the definition of the MPH type award but it remains unclear whether we could generalise between them. For example, within the 59 UK based Master courses found we can locate 4 different names for the programmes, MPH, MSc, MA and M.Phil. Although all second cycle in nature, further research would be required to understand the differences between these named programmes. Furthermore we may need to consider that each programme or institution has its own internal issues, such as resource allocation, capacity and the role of leadership which cannot be determined from the study.

Based on both the internal and external threats to validity it may be wise not to seek for generalisations but rather to consider the compliance levels as indicative that schools and programmes may not comply fully to all of the criteria presented. Even if we had complete confidence in the results from the 23 questions (which only form $38 \%$ of the total questions included in an accreditation) they would only lead us to conclude the same: schools and programmes are different to each other based around a multitude of variables. This viewpoint is perhaps the most prudent as it reinforces the need to consider the individual or heterogeneous nature of each programme and school. One way in which this could be achieved through an accreditation scheme is through a "fitness-for-purpose" approach which assesses a school or programme on its own mission and aims. This approach may prove the most pertinent as, unlike the original aims of the American accreditation (238), it would not seek for standardisation over such varied political, economic, social and cultural geographic landscape.

\subsection{Conclusions}

The research contained in this chapter provides evidence of many potential issues facing programmes, such as, the need to attract students, the focus on developing strategies and need to include wider stakeholder groups in programme processes and development. The results would seem to indicate that accreditation can operate as a framework for quality improvement but would potentially rely on closer collaboration with other actors and stakeholders, such as associations of schools of public health to ensure that a full spectrum 
of development is approached rather than focusing solely on achieving the accreditation criteria. As demonstrated in this chapter, many of the observations and recommendations of the review teams were not included under the specific sub-criterion of the research (see methodology section chapter 4 and Appendix E). The accreditation criteria would then need to be expressed in quality development terms, such as "should" statements as they could not, during this process, be considered as an "accreditation" process . Finally, as a product, quality improvement will need to consider the use of self-evaluation as a necessary part to provide both schools and programmes with valuable introspection which is one of the fundamental cornerstones to quality improvement. 
Chapter 7. General Discussion 


\subsection{Introduction}

The focus of this dissertation is to examine the potential practicability of an accreditation system in public health education operating for the development and improvement of both new and old schools, programmes and courses. Accreditation has been credited with maintaining and enhancing quality $(17,21,22,24,26,193,194)$ but the reality is often very different. For example, accreditation has also been criticised for neglecting improvement, failing to account for the varying educational contexts, and not ensuring societal accountability (18). Within the European region and, to a larger extent, the world, accreditation is used as a form of national level control under the banner of accountability. In this sense, the present systems tend to be summative in nature by operating either directly or indirectly as gate-keepers to nationally located funds, licensing or exclusive clubs. Global sector specific accreditation of public health education is fundamentally at odds with national accreditation systems: it is transnational and unaligned to national government funding. Furthermore, it is focused on a sector which, although highly developed in many countries, remains in an infant state in many parts of the world. This has drawn calls from various quarters for accreditation to help steward and steer these developing systems $(2,14-16)$.

Our research points to the development of public health education, as with the disease burden, being linked to the economic development of a country. Consequently, wealthier countries have more schools of public health than their poorer counterparts $(6,7)$. Equally, the burden of disease was historically different across the globe and saw a predominance of non-communicable diseases in wealthier countries and communicable disease in poorer countries. This situation is changing and poorer systems are now having to face the strains of a double burden of existing communicable disease and a sharp rise in non-communicable disease (296). At the same time, wealthier countries remain under threat from re-emerging and new diseases within a global context of rising antimicrobial resistance $(278,297)$. This entails that, in both developing and developed countries, workforces must adapt to changing circumstances and challenges now and in the future. Public health education has the responsibility to match the supply and skills of the workforce to ever changing population health needs.

This research begins with a literature review based on the key terms of public health, public health education and public health education accreditation. The objective was to identify and understand some of the key issues facing the development of accreditation in public health education globally and throughout time. Specific examples are then used in chapter 2 to show how the precursor to the European accreditation system designed by an association of schools of public health (the ASPHER PEER review) was used as a framework for the development and further improvement of schools and programmes across the Central and Eastern European region. As the European accreditation system became formalised in 2011, chapter 3 investigates the differences and similarities between the development of the American and European public health education accreditation schemes. Chapters 4 and 5 then study the practicability and applicability of the European accreditation system by means of a survey of 51 programmes of public health in 29 different countries of the EHEA. Each of the countries demonstrate distinct cultural, 
political, social, and economic backgrounds reflective of a broader global picture. The research focuses on the lack of compliance of programmes to the new system of accreditation and the consequences of this in chapter 4 . It then turns the tables and addresses the areas of highest compliance in chapter 5 . In chapter 6 the research uses data from on-site visits to understand the potential of using accreditation criteria as its antecedent PEER Review had similarly done in chapter 2 by focusing on the adaption of the self-evaluation and peer site visit processes.

In this final chapter we aim to integrate and synthesise the knowledge and findings from the previous 6 chapters toward future research and policy recommendations for the continued development of an accreditation scheme which addresses the diverse needs and functions of public health education across the globe. The structure of the section consists of three main statements in bold italics which summarise the main overall findings of the dissertation. Each of these statements is followed by a series of justifications and a defence of those statements. Within each justification, areas for further research are identified and policy recommendations are made.

The first statement concerns the need for any future global accreditation scheme to be flexible in order to accommodate the wide ranging levels of programme and institutional development in the field and the need for public health education to address differing burdens of disease. We explore four potential areas for increasing flexibility within accreditation. Although we focused on public health education, this section is considered to have a wider multidisciplinary application across various educational sectors. The second statement focuses on the connection and interaction of academia and the health of the population through the workforce and the need for a clearer identification of this workforce and their learning needs. Finally, the third statement re-examines the accountability triangles of Clarke and Burke (see chapter 1) and posits an alternative triangle, including three axes which are designed specifically for the domain of public health education accreditation. Once again, however, this section demonstrates a potential for more universal application across differing education sectors.

\subsection{Discussion of main findings}

The first main statement to summarise the overall findings is:

For accreditation to work for development and improvement, schools, programmes, and courses must participate in the accreditation processes. For accreditation to accommodate the varying levels of development across the globe, it must be flexible.

Public health education accreditation began in America in the 1940s. The person responsible for writing the first criteria was Charles-Edward Amory Winslow. Winslow is the earliest known proponent of multidisciplinary public health and the use of the term "new public health," and of health promotion, whilst his definition of public health is still used widely today $(74,75,254)$. The emphasis placed on accreditation by Winslow was that, to encourage participation, it should be flexible and light (241). In the following section we explore four differing potentials for increasing flexibility within accreditation. 


\section{Flexibility 1: An all-embracing decision-making structure}

Winslow's emphasis provides us with grounds for a fundamental assertion: for accreditation to work as accreditation, education (schools, programmes, and courses) must participate in the processes $(17,21,22,24,26,193,194)$. It has been estimated that fewer than $50 \%$ of countries worldwide have coherent higher education accreditation systems (135), which automatically places constraints on universal participation. There are, however, examples of the promotion of standards, such as the World Federation of Medical Education (WFME), or the PEER Review by ASPHER (chapter 2) which share many improvement-based objectives, but these are not included within an accreditation framework and decision-making process and therefore cannot be considered as accreditation $(202,204)$. It is incumbent on a sector-based accreditation system to strive for global coverage in order to facilitate universal participation. There are two major factors to consider when addressing universality. Firstly, there are geographical constraints and, secondly, there is the wide spectrum of development in public health education.

The vast majority of accreditation agencies are geographically constrained and reflect the underlying concepts, definitions, and working practices of their political and education systems. For public health education, this can be clearly seen. Our research found that the US-based accreditation system is confined to North American schools and programmes (chapter 3). The only example of an accredited school outside North America is the American University of Beirut which is an "implant" model. One of the main reasons for this is the particular prescription that schools of public health have to stand alone and be separate from medical universities and colleges, and must provide at least five Master-level awards (see Appendix F). In Europe, along with their implant models in former colonies, there is a history of public health education interwoven in medical settings (14). Equally, within the European region, the academic offering is not prescribed, and associations such as the European region association of schools of public health have a rather more eclectic understanding of what constitutes a "school," with examples of schools with only one academic bachelor programme (chapter 1). This means that for many countries the US model is prohibitive and thus remains, by and large, a US-based enterprise.

With regard to wider accreditation schemes across the higher education sector, we can also find that systems are locked within the borders of their sovereign nation states and their ensuing legal boundaries (chapter 3). In the European region, this has produced as many accreditation agencies as there are countries. This has led to the characterisation of a "jungle" of accreditations. During our research, we found a large variety of accreditation schemes, but not one example of where "public health education" explicitly existed within the standards or criteria (chapter 1).

In chapter 1 we found that many European national accreditation systems are considered as a form of state control $(21,29,33,34,36,157)$ and that this control also includes market control by protecting systems against alternative providers of education $(21,158)$. We can also note that the European accreditation criteria examined as part of our literature surveys in chapters 1 and 3 demonstrated the use of generic standards which can be used across all disciplines in the higher education sector. In this sense, the national systems were 
found to possess an inbuilt level of flexibility. Further questions must be raised as to how these systems approach differences in levels of development and quality. We know that governments would prefer not to close down poor quality institutions (197), which also indicates a level of flexibility concerning the inclusion of varying levels of quality. The same level of flexibility is questionable in current public health accreditation.

Our research identifies that the American public health education accreditation system was formed by an attempt to standardise education provision across many different states against a laissez-faire backdrop which propagated huge variety in the quality of public health education. To counter this variability, a system of accreditation was instigated and was based on many of the defining features of a school of public health exhibited by the Rockefeller funded schools (chapters 2 and 3). Initially an American Public Health Association (APHA) enterprise, in the latter years of the 20th century the system was incorporated into the foundation of the Council on Education for Public Health (CEPH). Subsequently, the system matured into a more rigid system operating as a gateway function for membership of the presently entitled Association of Schools and Programs of Public Health (ASPPH). We should also note that a benefit of CEPH accreditation is that it retains its linkage to state funding: "for the federal government and other public funding agencies, it serves as a basis for determining eligibility for federally funded programmes and student financial aid" (80). As the accreditation system operates in a gate-keeping capacity for ASPPH membership and federal funding, it could be argued that it is naturally inclined to adopt a pass/fail, in or out, "summative" approach characterised by control, rather than a "formative" approach which focuses on improving quality (44).

The European system of public health accreditation initially began through the desire of countries to collaborate together. It began as a formative-based PEER Review (chapters 2 and 3 ) but its maturation into an accreditation scheme also witnessed the inclusion of a summative decision-making process reflective of the American system. This approach may derive through the usage of specific criteria qualified by check points prescribed in the selfevaluation process. In this sense, the criteria operate as a sort of "checklist" in which schools and programmes are asked to provide detailed information on compliance. The ensuing site visit then has a mission to verify the data contained in the self-evaluation and to write a report on which the decision is made.

Our research found that within the European region there were many variations in public health education, from names (chapter 5) through to the understanding of public health (chapter 2), which is a different situation from that in America. In America there is much more unity beginning with standardised names for "schools" and "colleges" through to academic offerings entitled "MPHs." In some cases in the European region, our findings indicated that there was no consistency in the names of schools and programmes. More complex was the finding that even the name of a programme was not sufficient to understand its content. In chapter 2, we found that the content of a programme administered in Ukraine was public health but the degree awarded was a "Master of Management of Organizations," as the term Master of Public Health was not recognised by the state at that time. A similar issue occurred in Russia (chapter 5) which only recently 
saw the recognition of the MPH award in 2009. The process of recognition of these degrees throughout other ministries in the system, such as the Ministries of Labour and Finance (responsible for areas such as state employability of graduates and paying faculty salaries) could not be ascertained through our research in this dissertation, but it is known that even by 2013 no other Ministry in Russia (including the Ministry of Health) recognised the MPH award (190).

Our research also found that within the European region there was a large amount of heterogeneity in compliance to selected accreditation criteria (or check-lists as referenced above) (chapter 4). We found that compliance in 5 out of 7 main criteria headings (71\%) was significantly associated with the regional location of programmes, with Southern Europe displaying the least amount of compliance in all but one of the main criteria headings. For the criteria associated with quality management systems, only one quarter of programmes in the Southern region were found compliant with the accreditation criteria, and overall we found an average of only $43 \%$ compliance of programmes to accreditation criteria. Central and Eastern Europe demonstrated more compliance but still only achieved an average of $63 \%$ compliance. Such low levels of compliance would undoubtedly jeopardise the outcome of a summative-based accreditation decision.

It is debatable, therefore, whether the findings of our research would result in schools and programmes questioning their motivation to undertake a process containing a doubtful outcome. The literature concerning the improvement of education through accreditation schemes relies on schools and programmes entering the accreditation process $(17,21,22$, $24,26,193,194)$. If the accreditation systems are, for real or perceived reasons, prohibitive, then the potential for improvement will be drastically curtailed. Our research indicates that, under their present summative structures, both the American and European public health education accreditation systems would appear only to be viable for those education systems at a later or advanced stage of development or, as Temple calls it, the "luxury good" end of the market (103) .

\section{Further research}

More research on the role of decision-making thresholds needs to be conducted to understand how accreditation could be used to accept a full developmental spectrum of schools and programmes of public health across differing geographical settings. If the distinction between summative and formative approaches is located within a formal decision-making process, based upon compliance to threshold-based criteria, will it curtail the ability of accreditation to work as an improvement tool within a diverse compliant landscape as found in our research? Further research needs to understand the nature of that threshold. How does (or can) the decision-making threshold operate? Is it, for example, the case that national systems operate on a lower threshold in order to avoid wholesale closure of educational units? Are there other examples of thresholds which could be used as reference? For example, in our research we highlighted the Finnish agency FINEEC which is unique in the ENQA membership for operating a gradated or scaled decision-making process using the development termed scales of absent, emerging, developing and advanced, where accreditation is granted for all except the "absent" category (see Table $11)$. 


\section{Policy recommendations}

The main policy recommendation is directed at the emergent global accreditation system and would be to consider the introduction of a flexible decision-making process which can account for all levels of development and not just those at the higher or "luxury" end of the development spectrum. If a gradated or scaled threshold could be implemented within a global accreditation scheme, it may allow for acceptance of the spectrum of development, from burgeoning education through to providing a recognition of high quality. Such a scale may help developing schools plan or at least plot their development within the scales, but also publicly attest for providers who are "bench-marking," "advanced" or "excellent." This flexibility may encourage (or at least not discourage) initial adoption and the overall process may encourage schools to stay within the accreditation system through periodic reviews in order to be publicly and transparently attested to have improved quality. In this latter sense, such a system may induce sustainability by viewing quality improvement as a continuous (formative) process.

\section{Flexibility 2: Fitness for purpose}

During our research we found that the term "fitness for purpose" was used both within accreditation schemes and by groups of accreditation agencies such as ENQA (chapter 1). The term has been summed up thus: "'fitness for purpose' is a definition of quality that allows institutions to define their purpose in their mission and objectives, so 'quality' is demonstrated by achieving these" (42). There are, however, detractors who believe "fitness for purpose" does not induce the core concepts of "quality" (21). To a limited extent this can be entertained, as the term allows for a large amount of flexibility in actions as long as they are mentioned in the mission. With regard to the adoption of the Bologna process within the national accreditation agencies, such freedom was criticised for allowing the adoption of "individualised versions" of the Bologna process for self or nationally defined purposes (28). Our research reinforces this assertion as two central tenets of the Bologna process, ECTS (chapter 1) and exchange (chapter 4), were neither monitored by many of the national accreditation agencies nor universally adopted by programmes of public health in the region, many of whom were positively accredited by their national agencies.

In terms of public health education, such flexibility, allowed through a fitness-for-purpose approach, is imperative. Public health education has a duty to the populations they have a mandate to serve, and not all populations or disease burdens are the same. Table 9 demonstrates a range of mission statements from schools throughout the globe. Schools of public health are shown to have individualised missions, and from Table 9 we can see clear areas of remit and scope which include education, research and service functions which capture the essence of a school of public health $(92,93)$. Not all of these attributes are necessarily involved, since, for social, economic, political or cultural reasons, schools may not carry all three. This is in keeping with the lack of any universal definition of a school of public health (chapter 1). The only definition that can act as a common denominator or baseline is that the educational unit offer at least one postgraduate programme of public health $(1,2)$. However, as was highlighted in chapter 1 , even this prerequisite is questionable. 
As with a school's mission, programmes should also carry clear aims and objectives. This requires that, along with a competent core curriculum, public health programmes should focus on the priorities of the populations they serve. This will entail that a programme in Australia may focus on aboriginal alcohol consuming behaviour, whereas in Africa there may be a focus on family and reproductive health.

There are, however, reservations in using a fitness-for-purpose approach. During the OSI ASPHER program highlighted in chapter 2, several schools were advised to reflect upon and refresh their missions to incorporate actual activity (113). Our research highlighted that $94 \%$ of programmes had explicit aims in line with the mission of the parent institution. However, the research could not ascertain the nature of this linkage, nor could it attest to the validity or pertinence of the school mission or programme aims. When we look at the Ghanaian mission statement in Table 9, for example, it reads: "to train public health practitioners who will be leaders and change agents for health development in Ghana in particular and in the wider African context" (144). The only function or remit the school identifies for itself is "training." If we then explore their website we find the following text: "the School has a focus on applied research with strong multidisciplinary focus linked to key issues in Ghana and around the world. Faculty, staff and students of the various departments in the School are involved in research across traditional subject boundaries" (144). This finding demonstrates the inconsistencies between practice and mission that can occur and will invariably place a strain on the utility of a fitness-for-purpose approach using the mission statement as a focal point within accreditation.

\section{Further research}

More research needs to be conducted on how fitness for purpose is, or could be, realised within accreditation schemes and decision making for public health education. There is often a sense that schemes adopt the term whilst not putting it into practice. For example, in its school accreditation criteria, CEPH states: "each school will be evaluated by CEPH based on its self-defined mission, goals and objectives" (84) but then goes on to issue a highly prescriptive set of standards. It would be anticipated that a fitness-for-purpose approach would entail an element of weighting in decision making. If a school does not have research in its mission, how are accreditation decisions made when evaluating against research-based criteria? The CEPH criteria, however, do retain a focus on social accountability by emphasising an expectation that schools' missions will be guided by a broader mission of public health: "enhancing health in human populations, through organized community effort" (84). Such a prescription does not form part of the APHEA accreditation criteria which is incongruent to the sector that it serves. Hence, more research is required to understand how schools and programmes embrace public health in their missions.

\section{Policy Recommendation}

A fitness-for-purpose policy approach may be essential to ensure that accreditation operates based on both a "bottom-up" (local) and "top-down" (international) approach and allows for navigation through the many varying education and health systems across the globe. However, a note of caution should be sounded. The mission statement has to be up to 
date and clearly reflective of the present activities undertaken, as well as housing future aspirations. An accreditation process founded on a fitness-for-purpose approach would suffer if the evaluation was based on an out-of-date or incorrect mission. Therefore, the policy recommendation would be to include a review and a possible refresh of the mission statement as part of the reflective self-evaluation process. However, to achieve this, clear guidance may be required on how to undertake this process. Furthermore, a clear definition of public health "purpose," potentially along the lines of a social accountability model (see the section on social accountability below) needs to be proposed to provide an identifiable sector focus.

\section{Flexibility 3: The fight against stasis}

One of the criticisms of education and curricula in particular is the potential for stasis which ushers in the possibility of producing ill-equipped graduates (3). In chapter 1 we found how a curriculum in the early 20th century had been so far out of date that it disregarded a major paradigm shift in public health from Miasma theory to Bacteriology by up to 50 years (47). We also found examples which demonstrate how accreditation agencies can stultify development and innovation through restrictive criteria. Our research in chapter 1 explored the detail of an accreditation scheme from the membership of ENQA, the Serbian Commission for Accreditation and Quality Assurance (CAQA). Here we found an example of micro-managing control: "for the performance of study programme an adequate space shall be provided with at least $5 \mathrm{~m}^{2}$ net per student" (111). How does this criterion improve quality? Although it is conceivable that such a criterion would exclude alternative education providers, it also raises the possibility of obstructing internationalisation and pedagogic innovations such as e-learning. Again in chapter 5 our research found that the only examples of programmes not implementing multidisciplinary curricula were from countries whose governments restricted the ability to determine their own curricula.

In chapter 3 (Table 13) we see how the CEPH articulates its core competences in public health, and in Appendix C we can find APHEA's list which is based on work carried out on competences by the Association of Schools of Public Health in the European Region (291). If we look within these we may notice that, although broad, they may not cover aspects of public health which are specific to particular countries. Some examples of this may be, as mentioned, aboriginal alcohol consumption in Australia or disaster preparedness / management or even bio-terrorism. Furthermore, many of the competences outlined are intellectual or knowledge-based competences and do not highlight the more practical transferable or transversal competences, such as presentation skills, change management, conflict resolution or project management. To this extent an accreditation system has also to consider the wide and ever changing variety of competences that keep the skills of the public health workforce at the forefront of science and practice. The authors of the global commission on the Education of Health Professionals for the 21st Century state as a policy reform proposal: "adoption of competency-based curricula that are responsive to rapidly changing needs rather than being dominated by static coursework. Competencies should be adapted to local contexts and be determined by national stakeholders, while harnessing global knowledge and experiences" (3). Therefore, to avoid stasis an accreditation system 
needs not only to be prescriptive but also be adaptable to the changes taking place in the field which address the varying burdens of disease as well as the priority concerns and competences found globally. Furthermore, as part of the knowledge economy, public health education has to embrace innovation (134). Our research in chapter 1 highlights the extent to which social innovation can be seen to induce changes from an individual level through to system-wide changes (141) which is essential for developing the sector against an ever evolving burden of disease.

Our research produces some concerning results with regard to change and innovation. We have already seen how governments and legislation in Russia, Lithuania and Ukraine have potentially restricted and stalled the operations and innovations of emerging public health education in those countries (chapters 2 and 5). Table 20 in chapter 4 eludes to a larger geographical scope. We found that the public health accreditation criteria least complied with across the European region, international exchange and quality management systems, are considered essential for schools and programmes to learn from and integrate global and local experiences for the benefit of themselves and their workforces. Exchange was seen to benefit individuals from increasing competences and knowledge (273) but also exposure to differing organisational change models (274). Adaptation to local contexts is a central feature for quality management systems by listening to and integrating the needs of the national stakeholders (277). However, our study did find examples of alternative situations, such as in Macedonia where an outcome of international exchange was seen in the introduction of a Health Management and Leadership course which is now required for health care facility managers (chapter 2).

\section{Further research}

Much of the further research needs to focus on reflecting actual practice and this will take time. For example, in Appendix D we can find activity recently adopted by APHEA accreditation to introduce flexibility into their competency framework. Programmes now have the possibility to add the competences that they focus on and therefore not be constrained by a prescribed set. These competences can be intellectual or knowledge-based and include the opportunity to cover transferable skills. More research needs to be conducted on the range of competences housed within public health focused education. The scope of the research should be broad enough to encapsulate so-called "hybrid" public health programmes such as Environmental and Occupational Health or Health Management.

\section{Policy Recommendation}

As the global accreditation scheme continues, there should be systematic reviews of the competences employed by schools and programmes which require publishing to demonstrate the varying competences used throughout the globe. The objective would be to expose schools and programmes to the range of competences used, without having to undergo exchange which, from our research, is evidently difficult for many schools and programmes to incorporate. This does not propose the elimination of exchange, which is a valuable exercise, but simply that such exposure can help compensate if exchange is impracticable. 


\section{Flexibility 4: Lightness of approach}

Winslow's writing of the first accreditation criteria for public health education deliberately used a small amount of criteria in order to give schools time to comply (241). The first American accreditation scheme in the 1940s contained 11 criteria whilst presently there are $29(79,84)$. Within the APHEA programme accreditation used for this research, there were 61 . The methodology sections in chapters 4, 5 and 6 demonstrate our challenge to "lighten" the process by reducing this number to 23 which was considered more manageable for our research purposes. In chapter 6 our research focused upon incorporating these reduced criteria as a replacement for the self-evaluation (see Appendix E). Although the process was seen as useful in terms of improvement by both the programmes and evaluators, the conclusions were that the process of self-evaluation was deemed too valuable to be omitted. The self-evaluation process not only provides the evaluators with examples and evidence of how the criteria have been met, but also provides a tool for self-reflection. It is this internal self-evaluation which forms the linkage between external assessment and internal quality management (17) which our research identified as lacking in many programmes (chapter 4).

Therefore if the process undertaken by our research is to be pursued, it can only be done outside formal accreditation processes, of which self-evaluation is an integral part (see Table 2). Equally, if such an approach were to be used for newly established programmes, there would need to be a consideration of other areas important for early stage development seen in our research in chapter 2, such as initial licensing and local institutional support (Ukraine), initial curriculum design and governmental statute changes (Macedonia). These do not occur in accreditation, as the criteria focus on higher stages of development. Moreover, limiting or reducing the number of criteria runs the risk of producing a myopic impression of the programme or school under review and therefore would potentially limit the benefits of a formative approach. However, this does not imply that the findings of our research should be immediately discarded. As part of the research, the distribution of questions beforehand gave the programme and the interviewees time and opportunity to provide considered answers rather than reacting to unseen questions within the limited timeframe of a scheduled meeting. This became more salient during the discussions with our Russian colleagues where many did not have a full command of English. This meant that they had time to understand the questions and could prepare answers in advance which in turn was found to increase the efficiency of the meetings and the pertinence of information received.

Furthermore, our research in chapter 3 indicates that the notion to reduce the number of accreditation criteria to increase the number of applicants may be false. The original 11 criteria forwarded by Winslow resulted in the accreditation of 9 schools. When the CEPH took over responsibility for accreditation in the early 1970s the number of main criteria was 7 and saw the adoption by 19 schools $(95,248)$. By 2016, using the present 29 criteria, the number of accredited schools had risen to 59 (80). Evidently there may be other factors, such as links to federal funding or a "momentum or snowballing effect" but as the size of the self-evaluation exercise increased so did the applicants. Therefore a "light" approach 
based on a small number of criteria does not seem to be the defining feature for the uptake of accreditation by schools.

\section{Further research}

More research should be undertaken on how accreditation agencies approach questioning during the site-visits. In particular, an examination should be made of the processes and mechanisms that occur between the delivery of the self-evaluation documentation to the asking of questions during the site-visit meetings. This was not apparent during our research. In the case of APHEA, the process consists of receiving the self-evaluation documentation then conducting a video conference between the evaluator group where specific questions are raised based on the information contained in the self-evaluation documentation, along with the identification of the people those questions should be addressed. Usually this is in accordance with the people proposed in the draft site-visit schedule but can include a request to meet with additional people. Questions are then prioritised based on whether each criterion has been sufficiently answered in the documentation. Criteria which are considered to have been answered fully receive a lower priority than those criteria where the information remains unclear or in doubt. This produces a list of prioritised questions directed at identified interviewees. Incorporating the findings of our research in chapter 6 , the agency has begun to provisionally send these questions in advance to the applicant for the reasons highlighted above and in a similar fashion to those highlighted in Appendix E which is taken from our research.

\section{Policy Recommendation}

If deemed a valuable exercise by both applicant and reviewer, the distribution of specified and prioritised questions beforehand should be adopted as a formal procedure. Resulting from this adoption would be the need to evaluate and monitor the utility of the approach. For example, does it create efficiencies for the applicant and evaluator? With concern to "lightness," the adoption of this approach should also assess whether the process places the applicant more "at ease." Although tangential to the main aim of the exercise, a common trait found through anecdotal observation is that many applicants experience a high level of apprehension over the site visit. This may be for several reasons, including a sense of feeling under scrutiny. Knowing what is to be asked by the evaluators in advance may relieve this feeling, but this would need evaluating to draw any firm conclusions.

The second main statement to summarise the overall findings is:

\section{Global accreditation needs to be responsive to, as well as to promote and share, the competences required by the public health workforce to ensure the health of their populations.}

Public health education needs to be considered within the context of the wider public health system, workforce development and the health and well being of the population. We have seen in the introductory chapter that the concept of public health is in a continual state of flux. Currently public health continues to be viewed and understood differently across the globe. Even in the European region there are examples of differences, with more Western systems adopting multidisciplinary population-based approaches whilst the 
Eastern sections continue to demonstrate a San-Epid approach based on sanitary and epidemiological inspection (chapters 1,2 and 3$)(1,49,136,137)$.

The fallout from these global differences in interpretation of public health can be seen across many areas. From our literature surveys conducted in chapters 1 and 2 there is a strong sense that public health in many parts of the globe cannot be clearly identified or determined from medicine in terms of workforce and education (127). Even now, very little is known about the extent and composition of the public health workforces $(3,5,12,127$, 210) and where it is known there is evidence that the majority of those workforces have not been formally educated in public health $(10,11,13)$.

It may be taken that if a country were to educate its workforce based on its own varied interpretation of public health, an equally varied landscape of public health education would appear, with medically orientated education in one corner and a multidisciplinary education in the other $(286,298)$. However, our data do not support this. Conversely, our data in chapter 5 signify that across the European region, although there is variance in many areas, public health curricula taught across the region demonstrate a high level of uniformity and consistency in multidisciplinary approaches and this appears alongside the teaching of basic public health concepts (see in chapter 5). However, it is striking that the work of the European University Association on the autonomy of universities to determine their own curricula identified Italy, Latvia, Lithuania and Poland as the only four countries in the European Union which had to abide by government dictates on the content of their curricula (114). The countries identified in chapter 5 as having the lowest compliance scores gained for multidisciplinary curricula were from Italy, Lithuania and Poland.

The limitations of our research, however, are that the data used in chapter 5 are based on self-assessment, and without independent verification it is not possible to understand whether these are subjective judgements or even true reflections. Even if the responses gained through the research are correct it only signifies compliance within formal Master level education. If we take the extreme case of India which has four schools of public health for over a billion people (3), what impact does (or will) this formal education have on the overall workforce?

In earlier manifestations of the US-based accreditation scheme, workforce training came under the "service" function of a school (131). In later criteria, the CEPH used a separate category for "workforce development" (132). Improvements in public health education are therefore required to go further than formal education, such as MPHs, but also embrace the need for improvements in the Continuous Professional Development (CPD) of existing workforces. CPD training as part of a school's remit is a relatively recent addition (chapter 1). Traditionally, education and training have been viewed as existing separately, with "education" focused on academic or science and "training" being professionally or practice based $(128,129)$. This dichotomy between science and practice is a reflection of the historical German and British public health education models which were combined by Welch and Rose and implemented by Rockefeller as the model for US schools of public health. This model forms the basis in the interpretation of a school of public health for the 
US public health education accreditation scheme (chapters 2 and 3) (246). In chapter 6 we found that 2 of the 3 programmes reviewed were advised to offer their curricula in parts which would allow the possibility to engage in CPD training. However, the potential to integrate CPD training as part of a formal Master award may be hampered by national legislative restrictions on the construct of formal academic awards.

A potential problem arises in that, on the one hand, as mentioned above, there is very little information regarding public health workforces (chapters 1 and 2) whereas, on the other hand, there have been such wide workforce interpretations that sectors not usually associated with public health, such as the police and probation workers, have been included (125). Although this interpretation might propagate a sense of dilution or "spreading too thin," it may however be the most pertinent within a multidisciplinary approach: there may be an overlap in function between distinct professional sectors in society which, at one point or another, fall under the banner of "public health." As the WHO states, "many countries have moved from a medically dominated public health workforce to a multidisciplinary one. Given the breadth of factors with an impact on health, it is difficult to define the workforce precisely" (259). Our research indicates that the public health workforce is difficult to define and therefore it is highly conceivable that their learning needs will be equally difficult to define and this will have direct consequences on the learning provided through schools, programmes, and courses of public health. In mitigation, our research found in the case of Macedonia (chapter 2) that it is possible to identify key workforce groups with specific training needs.

\section{Further research}

Public health education is intrinsically linked to the health of the population through the workforce. It is assumed that the closer the fit between the skills and knowledge the workforce possess with the health needs of that population the greater impact the workforce can make. However, both the workforce and the understanding of public health in many countries remains unclear and potentially outmoded.

The World Health Organization EURO region is presently undertaking work on the Essential Public Health Operations (EPHOs) and these mirror other initiatives such as the World Health Organization PAHO region "Essential Public Health Functions" or in America the "Essential Public Health Services" (215). Work on the EPHOs has a clear aim to "ensure that there is a relevant and competent public health workforce sufficient for the needs of the population it is designed to serve" (299). There are evidently large gaps remaining in our understanding of what the workforce consists of in different settings and this will have implications on the range of competences it requires to undertake its jobs. More research needs to be done to understand how public health education identifies its own workforces and their learning needs and how those needs are translated into learning outcomes or competences. Furthermore, a greater understanding is required of how these processes could be improved or monitored through accreditation.

A secondary area of research needs to focus on understanding how national accreditation agencies integrate the curricula of formal public health education. We have found in this 
research that there is a large amount of homogeneity in the curricula of the Master programmes in the European region. At the same time we have also found that no single national accreditation system contains explicit standards for monitoring public health. How then do these agencies assess the quality of the public health curricula? We know, for example, that many agencies use international experts as part of their site review panels (184), but we also know there can be mismatches between the site visitor expertise and the field of study assessed $(185,186)$. Are these international experts required to give some form of curricula assessment and, if so, based on what criteria? We are also informed that only four countries in the region (Austria, Iceland, Switzerland and Cyprus) allow universities the liberty to choose their accreditation mechanisms whereas in the Netherlands only privately funded programmes can do so (114). This can be considered restrictive as the majority of countries in the region "force" their education systems to adopt their own nationally sanctioned and generic accreditation systems. How would such restrictions improve the quality of public health education? From the examples provided in chapter 5 for Italy, Lithuania and Poland, the answer is simple: they do not. As the Dean of the Faculty of Public Health in Lithuania in our research (chapter 2) states, "it is evident that this is a challenge for national and international experts and accreditation bodies to harmonize assessment criteria" (113). In a world where public health concepts are understood so variedly, it would seem imperative to ensure a baseline understanding and teaching of the core content and competences of modern public health.

A tertiary study should focus on why we found homogeneity in the public health curricula in the European region. The region is heterogeneous in a wide range of areas, so what were the processes that facilitated this homogeneity? For example, was it membership of sector associations, was it based on prevailing scientific literature, was it international exchange? Understanding this may help drive accreditation policy and standards. For example, if it was found that association membership aided this, would there be scope to include a criterion or standard on association membership as the American system once did? The same could apply if international exchange was found to be the catalyst. The results of our research indicate that some governments are restrictive, even counterproductive, to the development of the discipline but the evidence linking government operations to a lack of curricula development is lacking and therefore requires further inquiry.

\section{Policy recommendations}

There are two policy recommendations aimed at the public health accreditation system. Firstly, more dialogue needs to take place between the accreditation system and groups working on competences. Competences should not be considered as a static entity, so accreditation will need also to focus on implementing a flexible system which not only caters for the core intellectual competences but also allows for the inclusion of transferable competences and those competences which are tailored to individual populations, workforces and their workplaces. The ambition may, for example, include a system which is prescriptive over the core competences to guarantee that modern public health learning is assured, but flexible enough to ensure that learning is centred on the health of their own defined populations. 
The second policy would be to seek dialogue with existing national accreditation agencies for the adoption or sharing of sector specific curricula standards. If the further research confirms what our research has eluded to, it would appear bewildering that national agencies pay so little (transparent) attention to the detail of what is being taught and how it is being taught.

The third main statement to summarise the overall findings is:

To operate and be pertinent globally for the development and continual improvement of public health education, the accountability justification of accreditation needs to be reconsidered and refocused on international sector expertise, stakeholders, and the health of populations.

Much of the legitimacy of accreditation is drawn from its demonstration of accountability to society (37). One of the earliest notions of accountability can be found in Burton Clark's triangle of coordination focusing on the axis of the state, the market, and academics (45). However, Clark never used the word "accountability" and the term itself is a later arrival associated with the language of new public management which summoned in new societal power relationships between the state apparatus and higher education providers (100, 300). New public management emphasises cost control, transparency, market creation, and enhancement of accountability to customers for the quality of services $(107,108)$. For medical education, however, the World Federation for Medical Education is quite clear on the matter: "accreditation of medical education is normally carried out by national governments, or by national agencies receiving their authority from government" (203).

From our literature survey in chapter 1, the connotations of these new power structures for accreditation are negative: "accountability is a further obfuscation of the real purpose, which is control" (301). We may therefore consider the term "accountability" as a euphemism for control $(39,283,302,303)$ and the systems of accreditation can clearly be demonstrated to operate in this guise $(21,29,33,34,36)$. Control can take many forms (114), from influencing the behaviour of academics (110), determining institutional functioning (36) and the design of programmes (157) through to the protection of a country's education system from external competition and alternative providers $(21,158)$. Throughout the literature survey in chapter 1 there was a plethora of commentators who argued that quality improvement was integral to quality assurance $(17,21,22,24,26,193$, 194). However, and most importantly, there was only one tangible example of evidence provided for this claim as being an outcome of the self-reflective exercise contained within the self-study process (29).

The problem identified in our research is the difficulty in reconciling accountability with improvement: "accountability systems, in short, are unlikely to lead to a process of continuous quality improvement" (39) and "quality assurance processes may find that in practice they are unable to encourage improvement whilst demanding compliance" (21). Ton Vroeijenstijn summarises this through the use of the Homeric fable of Odysseus navigating his way through Scylla (improvement) and Charybdis (accountability). Deviating too much in one direction would lead to doom. The challenge, to Vroeijenstijn, is to keep 
straight and by doing so reconcile the two (17). According to the fable, Odysseus chose to hug Scylla's crag and sacrificed a few men rather than jeopardise the whole ship in Charybdis' whirlpool.

We can therefore see the symptoms consisting of an inability to reconcile accountability and improvement. The cause of this is generally financial in nature. Accreditation is used as a direct and indirect gateway to access funds from government and government sanctioned funds such as, but not limited to, the ability to accept students, research grants and student loans $(17,21,25,36,192,304,305)$. In this sense, improvement (the formative function) becomes only a side effect of the accreditation process which becomes summative in nature (39): "accreditation results in only one all-or-nothing outcome: institutions are either accredited or they are not. And because loss of accreditation is an outcome that few institutions can survive because it means that they cannot access federal funds" (304).

Our research shows that the history of the development of both public health education and accreditation is heavily rooted in the third sector outside of direct government influence (chapters 1, 2 and 3). Non-governmental organisations such as Rockefeller, the World Bank and the Open Society Foundation were instrumental in developing public health education throughout the world. These organisations in particular come from America where education remains outside federal government responsibility (chapters 2 and 3). In Europe, the absorption of education as a state function is a relatively recent addition used to reinforce the legitimacy of the burgeoning nation states from the mid to the end of the 19th century (chapter 3) (155). More recently, we find that education in Europe is becoming increasingly autonomous at an organisational level (although many restrictions remain) (114). For the future, some authors believe that higher education systems are becoming more like that in the US, with growing institutional autonomy and a shift in financing from the state to the consumer (192). This may become more acute if educational services are included in the present European and North American TTIP trade negotiations (chapter 3) (306).

In America, accreditation systems exist in the third sector (chapters 2 and 3) and globally there is an increasing move of accreditation agencies to be non-governmental or quasiautonomous non-governmental $(36,304)$. Concurrent with the development of public health education, the World Bank since the 1970s has been a driving force in the establishment of accreditation and QA agencies throughout the developing world (188). Hence one avenue available to reconcile accountability with quality improvement is to view accreditation as a third sector enterprise autonomous to governments. This is not to say governments should not or will not have authority: as long as governments control the purse strings of higher education, they will be the master of their own systems. To achieve this reconciliation, we must reconsider the three axes of the accountability triangle as proposed by Clark and Burke $(45,112)$ (chapter 1 ). Figure 10 below has adapted the accountability triangles of Clarke and Burke by replacing the three axes of state, academic concerns, and market forces with three new axes of stakeholders, social (accountability), and sector. This is reflective of the view posited by Malcolm Frazer: 
"quality in higher education is important because universities must be accountable to society, to employers, to students, and to each other. The accountability is not merely financial" (24).

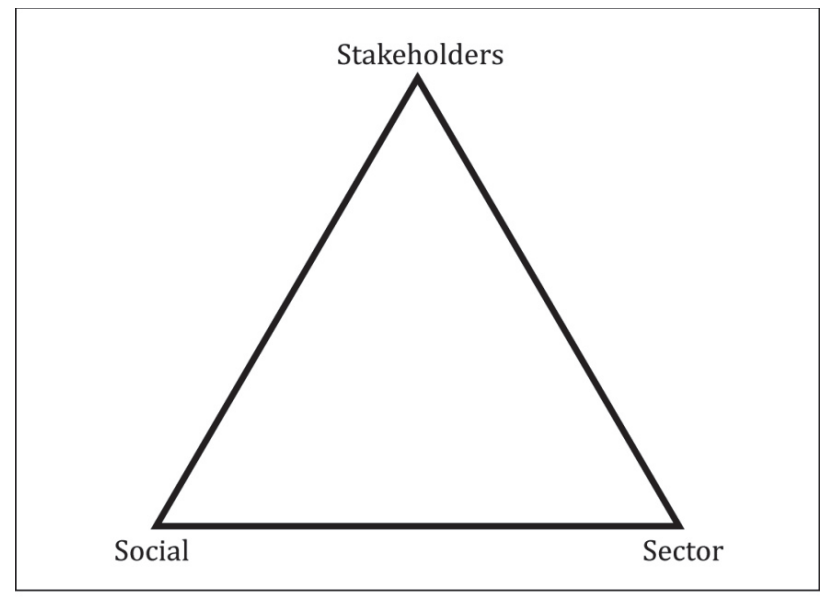

Figure 10.New accountability axes proposed for international accreditation scheme

Below we describe in more detail these three accountability axes.

\section{Accountability axis 1: Stakeholders}

Aside from their financing role, governments fall within a stakeholder category being "organizations and individuals that are involved in a specific activity because they participate in producing, consuming, managing, regulating, or evaluating the activity" (118). To this end governments occupy a position of stakeholder alongside the non-governmental sector and other agents in a system. The developmental activity financed by the Open Society Institute identified through our research in chapter 2 raises some harsh realities about the functioning of government and non-governmental sectors in developing countries:

"One of the concerns throughout the region is the desire of many graduates to work in the private NGO sector. Much of the emphasis of public health training in the western part of the European region is designed toward filling the workforce needs of the public sector rather than the private. In CEE, public salaries often are a fraction of those offered in the private sector. Hence there is a trend away from state employment. In one project country, for example, government salaries ranged from $\$ 30-\$ 100$ per month; the NGO sector was offering $\$ 600$ $\$ 1,000$ per month" (113)

This identifies two concerns. Firstly it emphasises the need to reconsider the role of the state in an international accountability framework. Although states occupy a dominant role nationally, their remit is geographically restricted to their national political boundaries. As 
we have seen, their dominance within their national systems is also variable when it comes to the employability of graduates.

This leads to the second area which focuses upon the "customer" or "client." As our research in chapter 1 highlights, since the adoption of new public management, confusion remains over who is to be considered the customer (117). We can see from the quote above and from the examples in chapter 2 that the public sector is not the only customer in many national settings. An example of a common denominator across all education systems is the student and this becomes more prominent when students have to pay for their studies. This is not a situation confined to developing countries. For example, an alumnus in the US, Trina Thompson, instigated litigation to sue her college for $\$ 72,000$ to cover the cost of her tuition fees because she could not find a job (307). However, focusing on the student as a client has led to concerns over the "commodification" of education and turning students (and their parents) into consumers $(109,283)$ which can lead to a concentration "on shortterm, narrow student satisfaction, rather than meeting the long-term needs of an entire range of stakeholders" (308). Our results in chapter 6 support this assertion as two of the three programmes, visited as part of our research, focused their feedback systems solely on student satisfaction. All of the programmes visited were recommended to consider the needs of a broader base of stakeholders.

\section{Further research:}

The model proposed here places more emphasis on the accountability of accreditation to stakeholders. There is an intuitive sense that accreditation should provide stakeholders with assurances over the quality of education. However, both between individual stakeholder groups and within individual groups of stakeholders, there may be different interpretations of what that quality should represent. For example, a student's assessment of quality may differ from that of an employer or an alumnus. Likewise, one particular student may wish to have assurances that the education would facilitate employment, whereas another student may wish for there to be sufficient facilities or more broadly the "student experience." Therefore, more research needs to be undertaken to understand how different accreditation systems have integrated different stakeholders and their levels of success. For example, the Norwegian agency NOKUT is one of the rare national accreditation agencies to use students as part of their evaluation teams but they admit that, although the overriding consensus is a positive one, "it is a shared impression of the Nordic quality assurance agencies that student participation serves better certain types of evaluations than others" (309).

\section{Policy recommendations}

There would seem to be a need to have ongoing consultation with the varying stakeholder groups to continually monitor and integrate their expectations of quality. This could range from surveys, increasing the focus on stakeholders during the self-study and site visits, through to the formal inclusion of stakeholders in the organisational structures of the accreditation agency. 


\section{Accountability axis 2: Social accountability}

One of the areas which is difficult to assimilate is the role and purpose of public health education (in the broader sense of the term). In one respect, it is responsible for academic concerns in education and research, but in another respect it forms an integral part of the health system through such areas as advisory services, technical support or providing direct interventions such as a health promotion campaign. This dichotomy is often reflected in countries by falling under the dual jurisdiction of the Ministry of Education and the Ministry of Health (chapter 2) (113).

During the first decade of the 21st century, the WHO's social accountability model advocated the need to assess the "impact" of a school's function which ushers in the possibility for a new dimension of accountability. What is the impact of education, research, and service on the health of the populations served (101)? The WHO's work on social accountability is heavily focused on traditional health services where the interaction between the health of the population and health services, such as hospitals or doctors, is perhaps clearer and more direct than the interaction of public health education. For instance, to make an impact, the educative function of a school of public health requires it to pass through a third party conduit, the workforce. Schools have a "recognised duty to prepare the workforce that society needs" (101). As mentioned above, our research concludes that in many countries the public health workforce is difficult to define and identify. However, our research, as shown in chapter 1, begins to crystallise some of the functions of a school within a social accountability model. Unlike the CEPH criteria, workforce development can co-exist with education under a broader heading of "learning." Equally, the terminology of "service" has been superseded within a discourse of knowledge economies by the term "innovation" (134). The modern conceptions of innovation embrace the older notions of service but go further by emphasising adaptability and the requirement to scan for future needs (149). The concept is also broad enough to cover innovation and impact from the individual change agent through to interactions of the organisation within the health system at large (310). This secondary concept of innovation may contain the potential to increase the impact factor of public health education, but little is known of the functioning of this concept within the context of public health education.

Further research

Social accountability remains a conceptual model primarily focused on health services. The further researching of social accountability therefore also needs to form a policy recommendation of this research. There would need to be a translation of this concept into practice within a framework of public health education and how this could be integrated within accreditation. Each of the functions of a school (including programmes and courses) would need to be considered for its ability to make an impact on the health of the population they serve. For example, learning has a direct influence on workforce development, but how does that learning develop workforces toward targeted population health needs? However, this focuses solely on the learning potential of a school which also houses research and service functions. Further research needs also to focus on understanding the impact of research within the context of a school of public health, for example, impacting on curriculum content or the wider discipline, publishing in 
international journals, providing evidence for stakeholders, identifying public health priorities, and proposing and monitoring interventions. Finally, the recent changes of "service" into "social innovation" require clarification as to how it could affect the operations and impact of public health education at an individual, organisational and system wide level. As with social accountability, the concept of "social innovation" remains theoretical, which would need to be placed within a context of practical application. Therefore, more research needs to identify where this has taken place and the levels of success.

\section{Policy recommendations}

Many of the policy recommendations for the absorption of social accountability are secondary to conducting the further research outlined above, which, of itself, is a recommendation for the policy of the global accreditation NGO. However, in the meantime, a policy will be the prospect of placing greater emphasis on the priority health concerns of the populations served and how these are addressed through education, research, and service. This may mean that evidence is required, as part of the accreditation process, of what the priority health concerns are for the populations served which, along with the mission statement, could form a focal point of the accreditation scheme under a " fitnessfor-purpose" approach (see the fitness-for-purpose section above).

\section{Accountability axis 3: Sector}

The proposed axis of "sector" in this case refers to peers from the specific discipline of public health education. As part of an accountability framework, however, we face a conundrum. On the one hand, we have professional sectors which are considered their own best judges (22), and, on the other hand, we have a potential for these judges to be in a conflict of interest: "in the age of heightened accountability, a process based on peer review looks like an inherent conflict of interest because those who judge performance are drawn from the community that is being judged" (304). However, from our conclusions in chapter 3 , the same criticism could be directed at many accreditation agencies operating either directly or indirectly as agents of their governments over their state provision of education. At this point we are reminded of Amaral and Maassen's assertion that "the balance between these potentially conflicting objectives (quality improvement and accountability) shifts towards improvement when academics have a strong voice, and towards accountability when the will of the government's predominates" (110).

More serious is that, as we have found, national accreditation agencies in Europe are not specific to the sectoral discipline and are based on elements of control rather than improvement (chapters 1, 3, and 4). If sectoral peers are not the best judges, then who are? We found in chapter 5 that the three countries not complying fully with multidisciplinary public health curricula descriptors were the same countries whose governments constricted their ability to independently determine their curricula. This would suggest that governments and their civil services are not the best judges. Perhaps independent reviewers from other sectors could be used. Again, as we found in the case of the Lithuanian accrediting agency which used a dentist to review a faculty of public health, the outcome led 
to a negative outcome which threatened the faculty's existence (113). This was in contrast to an international site visit of sectoral peers as part of the PEER Review some weeks later who viewed it positively (chapter 2). International sectoral peers may not have an in-depth knowledge of some of the difficulties involved in the varying stages of development across varying countries or the details of local government dictates, but they do understand fully the intricacies of their own sector. With regard to local circumstances, the inclusion of national sectoral peers in the site reviews would appear advantageous to give greater "localised" insight and understanding. It is this understanding from a national and international perspective which is fundamental if accreditation is to be focused on development and continual improvement rather than control. The evidence from our research in chapter 2 provides three examples of how in practice this peer support worked for the development of public health education in the CEE region using the PEER Review which went on to become the accreditation system. Writing on the development of accreditation in this region, Paul Temple opines: "the international academic audience also provides a means of accountability" (103)

\section{Further research}

There are five areas for further research concerning sectoral peer involvement. Firstly, more investigation needs to be conducted as to the construct of the reviewers. When we talk about "peers," who are we talking about? There is an overriding sense that the term refers only to academic peers. However, especially for institutional level accreditation, the applicant institution (and accreditation criteria) generally consists of more than the sum of the institution's academics. Administration, for example, is a large part of the functioning of a school. How many accreditation schemes utilise non-academic sectoral peers and what is their level of success / impact?

Secondly, something which has never been approached within any of the literature is the potential for improvement in the reviewers' own institutions. There is overwhelming anecdotal evidence that the reviewers, as part of the process, are able to self-reflect on their own programmes and institutional activities and processes. During the site visits, for example, reviewers are exposed to many approaches that are different from their own, which provides them with evidence of alternative practices. What do they do with this knowledge when they return home? The impact of accreditation in this sense is a two-way street, improving not only the applicant but also the reviewers' schools and programmes. This process has been termed "co-development" (311). More research needs to be conducted into the improvement benefits for the reviewers and their institutions and programmes.

Thirdly, related to this two-way co-development improvement process, what are the prospects to involve peers from developing schools and nations? As we have seen, summative forms of accreditation are formed by compliance to codified standards and often operate as a form of "check-list" based on the production of examples and evidence by the applicant to affirm that they meet those standards. The process itself is relatively clear and straightforward and does not mean that the reviewer needs to be from a school at an equal or higher stage of development. The training of reviewers becomes most important to 
ensure they are capable of adequately assessing whether the evidence is satisfactory and does not depend on the developmental status of their own institution. Further research needs to understand how accreditation systems compose their evaluation teams with regard to the involvement of schools in varying stages of development. Such an activity may compensate for the results of our research in chapter 5 which shows that the exchange of faculty and students is one of the three lowest areas of compliance with accreditation standards across the EHEA. Moreover, our research as part of chapter 6 clearly indicates that exchange gives faculty valuable insights into both the content and functioning of other schools and programmes around the European region. Indeed, the results from our research in chapter 2 show successes through twinning partnerships which encouraged exchange.

Having noted this, and as a fourth area for further research, it is important as part of a formative process that the evaluators are also in a position to recommend to the applicants practicable activities which may be beneficial for their future development. Hence it is important also to include evaluators from equal or more developed schools, as well as evaluators from within the applicant's own national system. Together, these groups have an understanding of the issues faced and have the possibility to recommend a range of alternative solutions or propositions for development which are feasible within the applicants' national system. This was an integral part of the PEER process (chapter 2) which, with the addition of a decision-making structure, metamorphosed into the present public health education accreditation scheme. It will be important to research not only the construct and merits of review teams but also how or if the recommendations for change were integrated and, if not, why not. Within the present public health accreditation schemes there is a criterion which asks about the changes made based on previous reviews, so evidence is already beginning to collate.

Finally, because accreditation falls within a summative process there is a tendency only to monitor compliance with prescribed standards and criteria. But what happens when the schools demonstrate practices which go beyond these prescribed standards? More research needs to be conducted on how accreditation schemes promote and share these practices which can help in the developmental process of other sectoral peers. For example, the Dutch NVAO agency has recently introduced a "good practice in internationalisation platform" section on their website (312), but this is not integral to their formal accreditation system and only focuses on the internationalisation of education.

\section{Policy recommendations}

Firstly, the public health accreditation scheme may help the development and improvement of schools by including developing schools in the evaluation teams. As this is a new venture, the recommendation would be to involve them as "observers" rather than the main team in order to monitor and evaluate their input as well as understand the learning potential of such an exercise. Secondly, the accreditation scheme should consider the appointment of sectoral peers on their review teams from the same country as the applicant. The inclusion and local knowledge of nationally based reviewers may help in assessing the practicability of the recommendations made within a local context. Finally, a system should be developed 
whereby the accreditation agency has clear policies for the recognition, promotion, and sharing of good practice found throughout the accredited schools, programmes, and courses.

\subsection{Concluding Remarks}

The answer to the research question as to whether accreditation can be used for the development and improvement of schools and programmes of public health depends on the second the part of the question which asks, if so, how? The "how" relates to two approaches of accreditation systems found throughout the globe. The predominant model used by national agencies is summative, which sees accreditation as more of a highly prescriptive control audit which tends to carry some form of punitive measure for failure. Under this auspice, the possibility for its use in development is limited. Any development or improvement would only exist as a by-product or a side effect, as it is not central to the aims of this type of activity and its decision making. Alternatively, within a formative approach, accreditation can have an influence on development and improvement. However, based on practicability, any such statement should be issued with caution. Making formative judgements about areas covered by existing national accreditation and accountability processes runs the risk of not only lacking authority but also being rendered irrelevant if they are not in-line with national accreditation and government dictates.

It could be argued that the two existing public health education accreditation agencies have tended to recreate these summative approaches. In the American system, this is understandable as they fit within a larger national system of accreditations operated by NGOs which are indirectly linked to the issue of federal funds. This is not the case for the European and now burgeoning global system. Any future use of an accreditation scheme as a development tool may need a re-thinking of its aims and mandate. Social accountability may provide for this by re-focusing accountability on the "population's health" rather than on the state apparatus which, in education terms, is covered by national accreditation systems. Under this umbrella, schools and programmes will be viewed not only for their academic or administrative processes but also for the impact they make on the health of the populations they serve. This definition may be broadened by also viewing the varying impact on the students, alumni, stakeholders, and the international community that the schools and programmes have a direct mandate to serve and who look to accreditation for assurances of quality.

The distinction between summative and formative approaches may well answer another key issue related to decision-making thresholds. At some point, accreditation will need to distinguish a level of status, legitimacy or appropriateness (39). To do this, decisions will need to be taken and most agencies contain some variant of a summative yes / no threshold. With a view to development, whose starting point could be the day of establishment, this approach may be counter-productive. A more supportive mechanism may be through a transparently gradated decision-making structure which allows for a range of decisions based on a spectrum of different developmental stages. This inclusive decision making may 
allow the canopy of accreditation to cover all developmental levels of public health education from day one through to the stage of being extremely advanced.

The historical binding of accreditation's "legitimacy" within national systems of accountability and financing alongside constricted binary-type decision thresholds answers one final important question for the development of such an accreditation system: why does it not already exist? 



\section{References}


1. Ijsselmuiden CB, Nchinda TC, Duale S, Tumwesigye NM, Serwadda D. Mapping Africa's advanced public health education capacity: the AfriHealth project. Bulletin World Health Organisation. 2007;85(12):914-22.

2. World Health Organization. World directory of schools of public health and postgraduate training programmes in public health. 1985.

3. Frenk J, Chen L, Bhutta ZA, Cohen J, Crisp N, Evans T, et al. Health professionals for a new century: transforming education to strengthen health systems in an interdependent world. Lancet. 2010;376(9756):1923-58.

4. Hart JT. The inverse care law. The Lancet. 1971;297(7696):405-12.

5. Chen L, Evans D, Evans T, Sadana R, Stilwell B, Travis P, et al. Working together for health: The world health report 2006. Geneva, Switzerland: The World Health Organization. 2006.

6. Evans D. The role of schools of public health: learning from history, looking to the future. Journal of Public Health. 2009;31(3):446-50.

7. Beaglehole R, Bonita R. Reinvigorating public health. Lancet - London. 2000;356:787-8.

8. World Health Organization GHWA. Health Workforce 2030: A global strategy on human resources for health. Geneva.2015 [Available from:

http://www.who.int/hrh/documents/strategy_brochure9-20-14.pdf] last accessed 25.03.2017

9. Gerzoff RB, Richards TB. The education of local health department top executives. Journal of Public Health Management and Practice. 1997;3(4):50-6.

10. Fee E. Divorce between theory and practice: the system of public health training in the United States. Ciencia \& saude coletiva. 2008;13(3):841-51.

11. Sadana R, Mushtaque A, Chowdhury R, Petrakova A. Strengthening public health education and training to improve global health. Bulletin of the World Health Organization. 2007;85(3):163-4.

12. Magaña-Valladares L, Nigenda-López G, Sosa-Delgado N, Ruiz-Larios JA. Public health workforce in Latin America and the Caribbean: assessment of education and labor in 17 countries. Salud pública de México. 2009;51(1):62-75.

13. Paccaud F, Weihofen A, Frank M. Public Health Workforce in Switzerland: are public health workers lacking? International Journal of Public Health. 2013.

14. Paccaud F, Weihofen A, Nocera S. Public health education in Europe: old and new challenges. Public Health Reviews. 2011;33(1):66-86.

15. de Leeuw E. European schools of public health in state of flux. The Lancet. 1995;345(8958):1158-60. 
16. Tulchinsky TH, Bickford MJ. Are Schools of Public Health Needed to Address Public Health Workforce Development in Canada for the 21 st Century? Canadian Journal of Public Health/Revue Canadienne de Sante'e Publique. 2006:248-50.

17. Vroeijenstijn AI. Improvement and Accountability: Navigating between Scylla and Charybdis. Guide for External Quality Assessment in Higher Education. Higher Education Policy Series 30: ERIC; 1995.

18. Stensaker B. Accreditation of higher education in Europe-moving towards the US model? Journal of Education Policy. 2011;26(6):757-69.

19. Welch CE, Grover PL. An overview of quality assurance. Medical Care. 1991:8-28.

20. Vlăsceanu L, Grünberg L. Quality assurance and accreditation: A glossary of basic terms and definitions. Bucharest: Unesco-Cepes,: UNESCO; 2004.

21. Harvey L, Newton J. Transforming quality evaluation: moving on. Quality assurance in higher education: Springer; 2007. p. 225-45.

22. Woodhouse D. Global trends in quality assurance. Quality Approaches in Higher Education. 2013;5(1):3-7.

23. Harcleroad FF. Accreditation--history, process, and problems: American Association for Higher Education; 1980.

24. Frazer M. Quality in higher education: an international perspective. What is quality in higher education. 1994:101-11.

25. Worthington F, Hodgson J. Academic labour and the politics of quality in higher education: a critical evaluation of the conditions of possibility of resistance. Critical Quarterly. 2005;47(1-2):96-110.

26. Eaton JS. An Overview of US Accreditation--Revised. Council for Higher Education Accreditation. 2012.

27. Wolff RA. Accountability and accreditation: Can reforms match increasing demands? Achieving Accountability in Higher Education: Balancing Public, Academic, and Market Demands San Francisco: Jossey-Bass. 2005:37-67.

28. Westerheijden DF. States and Europe and quality of higher education. Quality assurance in higher education: Springer; 2007. p. 73-95.

29. Harvey L. The power of accreditation: views of academics. Journal of Higher Education Policy and Management. 2004;26(2):207-23.

30. Stensaker B. Trance, transparency and transformation: The impact of external quality monitoring on higher education. Quality in higher education. 2003;9(2):151-9.

31. Morley L. Quality and power in higher education: McGraw-Hill Education (UK); 2003. 
32. Brennan J, Shah T. Managing quality in higher education: An international perspective on institutional assessment and change: Open University Press; 2000.

33. Harvey L, Newton J. Transforming quality evaluation. Quality in higher education. 2004;10(2):149-65.

34. Van Vught F, Westerheijden D. Towards a General Model of Quality Assessment in Higher Education. Higher Education. 1994;28(3):355-71.

35. Van Vught FA. Intrinsic and extrinsic aspects of quality assessment in higher education. Changing contexts of quality assessment Utrecht Lemma. 1994.

36. Campbell C, Rozsnyai C. Quality Assurance and the Development of Course Programmes. Papers on Higher Education. 2002.

37. Stensaker B, Harvey L. Accountability in higher education: Global perspectives on trust and power: Routledge; 2011.

38. Westerheijden DS, Bjørn. Rosa, Maria João,. Quality assurance in higher education: Trends in regulation, translation and transformation: Springer Science \& Business Media; 2007.

39. Harvey L. Analytic quality glossary 2004 [Available from: http://www.qualityresearchinternational.com/glossary/].last accessed 29.10.2015

40. Semrow JJ. Institutional assessment and evaluation for accreditation: Higher Education Program, College of Education, University of Arizona; 1977.

41. Council For Higher Education Accreditation (CHEA). Glossary of Key Terms in Quality Assurance and Accreditation 2002 [Available from: http://www.uv.es/alfaacro/documentos/documentosinteres/29.htm].last accessed 05.04.2016

42. Woodhouse D. Quality and quality assurance. Quality and internationalisation in higher education. 1999:29-44.

43. EI-Khawas E. Accreditation's role in quality assurance in the United States. Higher Education Management. 1998;10:43-56.

44. Kis V. Quality assurance in tertiary education: Current practices in OECD countries and a literature review on potential effects. Tertiary Review: A contribution to the OECD thematic review of tertiary education. 2005;14(9).

45. Clark BR. The higher education system: Academic organization in cross-national perspective: University of California Press; 1986.

46. Rosen G. A history of public health. Expanded ed. / introduction by Elizabeth Fee, biographical essay and new bibliography by Edward T. Morman. ed. Baltimore, Md. ; London: Johns Hopkins University Press; 1993. 
47. Acheson RM. The British Diploma in Public Health: birth and adolescence. In: Fee E, Acheson RM, editors. A History of education in public health : health that mocks the doctors' rules. Oxford: Oxford University Press; 1991.

48. Duffy J. The sanitarians: a history of American public health: University of Illinois Press; 1992.

49. Marks L, Hunter, D. J., Alderslade, R. Strengthening Public Health Capacity and Services in Europe: A Concept Paper: World Health Organization Regional Office for Europe; 2011 [Available from:

http://www.euro.who.int/_data/assets/pdf_file/0007/152683/e95877.pdf].last accessed 27.07.2013

50. Hill HW. The new public health: Press of the Journal-Lancet; 1913.

51. Fee E, Acheson RM. A History of education in public health: health that mocks the doctors' rules: Oxford University Press; 1991.

52. Beaglehole R, Dal Poz MR. Public health workforce: challenges and policy issues. Human resources for health. 2003;1(1):4.

53. Kickbusch I. The contribution of the World Health Organization to a new public health and health promotion. American Journal of Public Health. 2003;93(3):383-8.

54. Marx K, Engels F. The german ideology: International Publishers Co; 1970.

55. Fee E, Rosenkrantz B. Professional education for public health in the United States. A history of education in public health: health that mocks the doctors' rules: Oxford University Press; 1991.

56. Semashko NA. Health Protection in the USSR: Victor Gollancz London; 1934.

57. Lyons M. Public health in Colonial Africa: the Belgian Congo. The History of Public Health and the Modern State. 1994;26:356.

58. Curtin PD. The End of the "White Man's Grave"? Nineteenth-Century Mortality in West Africa. The Journal of Interdisciplinary History. 1990;21(1):63-88.

59. McKeown T, Lowe CR. An Introduction to Social Medicine: Blackwell Scientific Publications, Ltd; 1966.

60. Fraser D. The evolution of the British welfare state: a history of social policy since the Industrial Revolution: Palgrave Macmillan; 2009.

61. Wilkinson R, Pickett K, Cato MS. The spirit level. Why more equal societies almost always do better. Penguin, London; 2009.

62. Omran AR. The epidemiologic transition: a theory of the epidemiology of population change. 1971. The Milbank memorial fund quarterly 2005;83(4):731-57. 
63. Awofeso N. What's New About the "New Public Health"? American Journal of Public Health. 2004;94(5):705-9.

64. Wilkinson RG, Marmot MG. Social determinants of health: the solid facts: World Health Organization; 2003.

65. Sein T, Detels R, Beaglehole R, Lansang M, Gulliford M. The history and development of public health in low-and middle-income countries. Oxford textbook of public health, Volume 1: the scope of public health. 2009(Ed. 5):39-64.

66. Schell CO, Reilly M, Rosling H, Peterson S, Ekström AM. Socioeconomic determinants of infant mortality: a worldwide study of 152 low-, middle-, and high-income countries. Scandinavian journal of public health. 2007;35(3):288-97.

67. Paccaud F. Educating and training the public health workforce. The European Journal of Public Health. 2011;21(2):137.

68. Frenk J, Bobadilla JL, Lozano R, Timaeus I, Chackiel J, Ruzicka L. The epidemiological transition in Latin America. Adult Mortality in Latin America. 1996;123.

69. Agyei-Mensah S, Aikins Ad-G. Epidemiological transition and the double burden of disease in Accra, Ghana. Journal of urban health. 2010;87(5):879-97.

70. Tulchinsky TH, Varavikova EA. Addressing the epidemiologic transition in the former Soviet Union: strategies for health system and public health reform in Russia. American Journal of Public Health. 1996;86(3):313-20.

71. Childress JF, Faden RR, Gaare RD, Gostin LO, Kahn J, Bonnie RJ, et al. Public health ethics: mapping the terrain. The Journal of Law, Medicine \& Ethics. 2002;30(2):170-8.

72. Ashton J, Seymour H. The new public health : the Liverpool experience: Open University Press; 1988.

73. Tulchinsky T, Varavikova E. The new public health. 2nd ed: Academic Press; 2009.

74. Winslow C-EA. The untilled fields of public health. Science. 1920;51(1306):23-33.

75. Acheson D. Report of the Committee of Inquiry into the future development of the Public Health functions and Community Medicine. Report of the Committee of Inquiry into the future development of the Public Health functions and Community Medicine. 1988.

76. Institute of Medicine. The future of public health: National Academy Press; 1988.

77. The Royal College of Physicians of Edinburgh. Consultation held by the Nuffield Council on Bioethics on Public Health, [Available from: http://nuffieldbioethics.org/wpcontent/uploads/The-Royal-College-of-Physicians-of-Edinburgh.pdf].last accessed 30.09 .2015

78. Cole K, Sim F, Hogan H, Murray L. The evolution of public health education and training in the United Kingdom. Public Health Reviews. 2011;33(1):87-104. 
79. Shepard W, Atwater RM, Anderson GW, Bauer W, Defries RD, Godfrey Jr ES, et al. Institutions Accredited by the American Public Health Association to Give the Degree of Master of Public Health (Diploma of Public Health in Canada) for the Academic Year 19461947. American Journal of Public Health and the Nations Health. 1946;36(3):244-7.

80. Council on Education for Public Health. 2015 [Available from: http://ceph.org].last Accessed 19.08.2015

81. Fee E. Designing schools of public health for the United States. A history of education in public health: health that mocks the doctors' rules: Oxford University Press; 1991.

82. White KL. Healing the schism: epidemiology, medicine, and the public's health: Springer Science \& Business Media; 2012.

83. Eaton JS. Quality and an international higher education space. International Educator. 2005;14(5):57.

84. Council on Education for Public Health. Accreditation Criteria for Schools of Public Health 2011 [Available from: http://ceph.org/assets/SPH-Criteria-2011.pdf].last accessed 03.08.2015

85. Welch W, Rose W. Institute of Hygiene: a report to the General Education Board of Rockefeller foundation. New York: The Rockefeller Foundation. 1915.

86. Austin DM. The Flexner myth and the history of social work. The Social Service Review. 1983:357-77.

87. Kerr C. The great transformation in higher education, 1960-1980: SUNY Press; 1991.

88. Williams G. Schools of Public Health: Their Doing and Undoing. The Milbank Memorial Fund Quarterly Health and Society. 1976:489-527.

89. Terris M, editor The Profession of Public Health Conference on Education, Training, and the Future of Public Health: Conference Proceedings: March 22-24, 1987, Houston, Texas; 1991: National Academies.

90. Wylie CM. Schools of public health in 1972--ivory towers or sites of relevance? Health services reports. 1972;87(10):886.

91. James G. The future role of schools of public health. I. American Journal of Public Health and the Nations Health. 1970;60(7):1289-98.

92. Köhler L. The mission of public health during the next 25 years, A European perspective. in Public health and socio-economic changes at the dawn of the 21st century, implication on public health academic education. University of Indonesia, Jakarta, 1992.

93. Tulchinsky TH. Developing schools of public health in countries of Eastern Europe and the Commonwealth of Independent States. Public health reviews. 2001;30(1-4):179200. 
94. Association of Schools and Programs of Public Health. [Available from: http://www.aspph.org/].last accessed 29.10.2015

95. Council on Education for Public Health. Manual for accreditation of graduate schools of public health 1975. American Journal of Public Health. 1975;65(3):317-9.

96. Roshi E, Bino S, Burazeri G, Ylli A, Laaser U, Tulchinsky T, et al. Development of a master of public health programme in Tirana, Albania. Journal of Public Health.

2006;14(4):229-32.

97. The Association of Schools of Public Health in the European Region. 2015 [Available from: http://www.aspher.org/foto/EB032014/2014_MEMBERS.pdf].last accessed 03.08.2015

98. World Health Organization. Recommended requirements for schools of public health: tenth report of the Expert Committee on Professional and Technical Education of Medical and Auxiliary Personnel [meeting held in Geneva from 12 to 16 December 1960]. 1961.

99. Stebbins EL. Contribution of the Graduate School of Public Health-Plans for the Future. American Journal of Public Health and the Nations Health. 1957;47(12):1508-12.

100. Sursock A. Accountability in Western Europe: Shifting quality assurance paradigms. Accountability in higher education: Global perspectives on trust and power. 2011:111-32.

101. Boelen C. Towards Unity for Health, Challenges and Opportunities for partnership in health development. 2000. World Health Organization: Geneva. 2000.

102. Boelen C, Heck J. Defining and measuring the social accountability of medical schools [Available from:

http://apps.who.int/iris/bitstream/10665/59441/1/WHO_HRH_95.7.pdf].last accessed 03.11 .2015

103. Temple P. Accountability in Eastern Europe: Becoming like Everywhere Else? Accountability in higher education: Global perspectives on trust and power. 2011.

104. Moscati R. University governance in changing European systems of higher education. European Higher Education at the Crossroads: Springer; 2012. p. 599-611.

105. Amaral A, Tavares 0, Santos C. Higher education reforms in Europe: A comparative perspective of new legal frameworks in Europe. European Higher Education at the Crossroads: Springer; 2012. p. 655-73.

106. Neave GR, Van Vught F. Prometheus bound: The changing relationship between government and higher education in Western Europe: Pergamon; 1991.

107. Tolofari S. New public management and education. Policy futures in education. 2005;3(1):75-89.

108. Power M. The audit society: Rituals of verification: Oxford University Press; 1999. 
109. Ferlie E, Musselin C, Andresani G. The steering of higher education systems: A public management perspective. Higher education,. 2008;56(3):325-48.

110. Amaral A, Maassen P. Preface to Quality assurance in higher education: Trends in regulation, translation and transformation: Springer Science \& Business Media; 2006.

111. Commission for Accreditation and Quality Assurance. National council of higher education. Serbia. Rules And Regulations of Accreditation Standards and Procedures for Higher Education Institutions and their Study Programs 2006 [Available from:

http://www.kapk.org/images/stories/pravilnici/2-Standards_of_accrd.pdf].last accessed 09.12 .2015

112. Burke JC. Achieving accountability in higher education: Balancing public, academic, and market demands. San Francisco: Jossey-Bass; 2005.

113. Goodman J, Overall J, Tulchinsky TH. Public Health Workforce Capacity Building: Lessons Learned from "Quality Development of Public Health Teaching Programmes in Central and Eastern Europe." Brussels, Belgium: Association of Schools of Public Health in the European Region (ASPHER); 2008.

114. Estermann T, Nokkala T, Steinel M. University autonomy in Europe II. The Scorecard Brussels: European University Association. 2011.

115. Vidovich L, Slee R, editors. The unsteady ascendancy of market accountability in Australian and English higher education. Australian Association for Research in Education Conference; 2000.

116. Corbett DC. Australian public sector management: Allen \& Unwin; 1996.

117. Ball SJ, Vincent C, Radnor H. Into confusion: LEAs, accountability and democracy. Journal of Education Policy. 1997;12(3):147-63.

118. Novick LF, Mays GP. Public health administration: principles for population-based management: Jones \& Bartlett Learning; 2005.

119. Gebbie KM, Rosenstock L, Hernandez LM. Who will keep the public healthy? : educating public health professionals for the 21st Century. Washington, D.C.: National Academy of Sciences; 2003.

120. Troupin JL. Schools of public health in the USA and Canada.(Year ending June 1970). American Journal of Public Health and the Nations Health. 1970;60(12):2395-9.

121. Todd G. Health Professions Education Partnership Act of 1998. AANA journal. 1998;66(3):229.

122. Association of Schools and Programs of Public Health (ASPPH). Financial Report Washington, DC: Association of Schools and Programs of Public Health; 2013 [Available from: http://depts.washington.edu/sphnet/wp-content/uploads/2013/06/ASPH-

Financial-Data-Report-2012_locked.xlsx].last accessed 08.12.2017 
123. Boelen C, Woollard B. Social accountability and accreditation: a new frontier for educational institutions. Medical Education. 2009;43(9):887-94.

124. Gebbie K, Merrill J, Tilson HH. The public health workforce. Health Affairs. 2002;21(6):57-67.

125. Sim F, Schiller G, Walters R. Public Health Workforce Planning for London. Mapping the public health function in London. A report to the Directorate of Health and Social Care London. London: DHSC; 2002.

126. Tilson H, Gebbie KM. The public health workforce. Annual Review of Public Health. 2004;25:341-56.

127. Petrakova A, Sadana R. Problems and progress in public health education. Bulletin of the World Health Organization. 2007;85(12):963-5.

128. Cole K, Sim F, Hogan H. The evolution of public health education and training in the United Kingdom. Public Health Reviews. 2011;33(1):87-104.

129. Birt CA, Foldspang A. The developing role of systems of competences in public health education and practice. Public Health Reviews. 2011;33(1):134-47.

130. Tight M. Key concepts in adult education and training: Psychology Press; 2002.

131. Council on Education for Public Health. Accreditation Criteria Graduate Schools of Public Health. 2002 [Available from:

http://web1.sph.emory.edu/ACCREDIT/SPHWEB.so2.pdf].last accessed 29.10.2015

132. Council on Education for Public Health. Accreditation Criteria Public Health Programs 2014 [Available from: http://ceph.org/assets/PHP-Criteria-2011.pdf].last accessed 18.03.2015

133. Communication From The Commission. Mobilising the brainpower of Europe: enabling universities to make their full contribution to the Lisbon Strategy. Brussels: European Commission. 2005.

134. Maassen P, Stensaker B. The knowledge triangle, European higher education policy logics and policy implications. Higher Education,. 2011;61(6):757-69.

135. World Health Organization. Transforming and scaling up health professionals' education and training: World Health Organization guidelines 2013: World Health Organization; 2013.

136. Adany R, Villerusa A, Bislimovska J, Kulzhanov M. Public health education in Central and Eastern Europe, and Central Asia. Public Health Reviews. 2011;33:105-33.

137. Djibuti M, Gotsadze G, Mataradze G, Menabde G. Human resources for health challenges of public health system reform in Georgia. Human resources for health. 2008;6(1):8. 
138. Noya. Antonella. Transforming innovation to address social challenges: An International Perspective Paris, France: OECD; 2009 [Available from: http://www.oecd.org/sti/inno/44076387.pdf].last accessed 03.12.2015

139. Phills JA, Deiglmeier K, Miller DT. Rediscovering social innovation. Stanford Social Innovation Review. 2008;6(4):34-43.

140. Cohen WM, Levinthal DA. Absorptive capacity: a new perspective on learning and innovation. Administrative science quarterly. 1990:128-52.

141. Westley F, Antadze N. Making a difference: strategies for scaling social innovation for greater impact. The Innovation Journal: The Public Sector Innovation Journal. 2010; 15(2).

142. Harvard T.H. Chan School of Public Health. Mission 2015 [Available from: http://www.hsph.harvard.edu/about/mission/].last accessed 02.12.2015

143. London School of Hygiene and Tropical Medicine. Mission 2015 [Available from: http://www.lshtm.ac.uk/aboutus/introducing/mission/].last accessed 02.12.2015

144. University of Ghana. School of Public Health. Ghana. Mission 2015 [Available from: http://sph.ug.edu.gh/index1.php?linkid=370].last accessed 02.06.2016

145. Faculty of Health Sciences. University of Pretoria. South Africa. Mission 2015 [Available from: http://www.up.ac.za/en/faculty-of-health-sciences/article/30863/visionmission].last accessed 02.12.2015

146. School of Public Health. University of Hong Kong. Mission 2015 [Available from: http://sph.hku.hk/en/about-us/mission].last accessed 02.12.2015

147. The James P Grant School of Public Health D, Bangladesh. Mission 2015 [Available from: http://sph.bracu.ac.bd/index.php/overview/abouttheschool1].last accessed 02.12 .2015

148. Escola Nacional de Saude Publica Sergio Arouca at the Oswaldo Cruz Foundation. Rio de Janeiro. Brazil. Mission 2015 [Available from:

http://portal.fiocruz.br/en/content/institutional-profile].last accessed 02.12.2015

149. Abernathy WJ, Clark KB. Innovation: Mapping the winds of creative destruction. Research policy. 1985;14(1):3-22.

150. Evans P. Accreditation in the United States: Achieving Quality in Education. Third European Symposium; Zurich. 2000.

151. Zumeta W. Accountability and the private sector: State and federal perspectives. JC Burke and Associates, Achieving Accountability in Higher Education San Francisco, Calif: Jossey-Bass. 2004:25-54.

152. Maassen PA. Quality in European higher education: recent trends and their historical roots. European Journal of Education. 1997:111-27. 
153. Jarvis DS. Regulating higher education: Quality assurance and neo-liberal managerialism in higher education-A critical introduction. Policy and Society. 2014;33(3):155-66.

154. Trow M. On the accountability of higher education in the United States. Inside academia. 1996:227-68.

155. Ramirez FO, Boli J. The political construction of mass schooling: European origins and worldwide institutionalization. Sociology of education. 1987:2-17.

156. Schwarz S, Westerheijden DF. Accreditation and evaluation in the European higher education area: Springer; 2004.

157. Skolnik ML. Quality assurance in higher education as a political process. Higher Education Management and Policy. 2010;22(1):67-86.

158. Westerheijden DF. Ex oriente lux?: national and multiple accreditation in Europe after the fall of the Wall and after Bologna. Quality in Higher Education. 2001;7(1):65-75.

159. Gornitzka Å. Bologna in Context: a horizontal perspective on the dynamics of governance sites for a Europe of Knowledge. European Journal of Education. 2010;45(4):535-48.

160. ENQA. European standard and guidelines. 2nd ed. Helsinki: ENQA; 2007 [Available from: http://www.enqa.eu/wp-content/uploads/2013/06/ESG_3edition-2.pdf].last accessed 02.10.2015

161. Kohoutek J. Quality assurance in higher education: a contentious yet intriguing policy issue. Implementation of Standards and Guidelines for Quality Assurance in Higher Education of Central and East-European Countries-Agenda Ahead. Bucharest: UNESCO; 2009. p. 21-50.

162. Public Accreditation Agency for Higher Education. Accreditation of Second Cycle Study Programs, Tirana2012 [Available from:

http://www.albranking.com/web/dokumente/en/3..pdf].last accessed 25.06.2013

163. Die Agentur für Qualitätssicherung und Akkreditierung Austria (AQ Austria). Accreditation \& Certification of Study Programmes and Joint Programmes, 2010 [Available from: http://www.aqa.ac.at/download.552.guideline-programme-accreditiation-general2010-06.pdf].last accessed 25.06.2013

164. Agence pour l'evaluation de la qualite de l'enseignement Superieur - AEQES. AEQES Reference Framework. Compilation and assessment guide 2012 [Available from:

http://www.aeqes.be/documents/Guide\%20experts\%20EN.pdf].last accessed 25.06.2013

165. National Evaluation and Accreditation Agency of Bulgaria. Criteria System for Programme Accreditation of Professional Fields and Majors From the Regulated Professions, 2010 [Available from:

http://www.neaa.government.bg/images/Criteria_EN/Kriterialna_sistema_za_PA_eng.pdf]. last accessed 06.10.2015 
166. Agencija za znanost i visoko obrazovanje (azvo). Criteria for the assessment of quality of higher education institutions within universities 2013 [Available from: http://www.azvo.hr/images/stories/vrednovanja/reakreditacija_vu/Criteria_universities. doc].last accessed 16.05.2013

167. Akreditační komise Ceska Republika (ACCR). Accreditation Commission standards for assessing applications for the granting, extension and renewal of accreditation for study programmes and fields of study, 2009 [Available from:

http://www.msmt.cz/uploads/soubory/akak/anglicka_verze/standards_ac_for_assesing_a pplications/standards_for_study_programmes_12_2009.doc].last accessed 06.10.2015

168. Danmarks Akkrediteringsinstitution (ACE Denmark). On Application for Accreditation and Approval of Existing University Study Programmes, 2011 [Available from:

http://acedenmark.eu/fileadmin/user_upload/dokumenter/Akkreditering_dokumenter/V ejledninger/EN_Vejledning_eksisterende_uddannelser_2012_English.pdf].last accessed 26.05.2013

169. Eesti Kõrg- ja Kutsehariduse Kvaliteediagentuur (EKKA - Estonia). Quality Assessment of Study Programme Groups in the First and Second Cycles of Higher Education, 2012 [Available from:

http://www.ekka.archimedes.ee/files/OKH_kord_07.08.2012_Eng-2.pdf].last accessed 26.05.2013

170. The Finnish Higher Education Evaluation Council. Audit manual for the quality systems of higher education institutions 2011-2017 2012 [Available from: http://karvi.fi/app/uploads/2014/09/KKA_1512.pdf].last accessed 06.10.2015

171. Agence d'évaluation de la recherche et de l'enseignement supérieur - AERES France. Evaluation of master's degrees. Group B. (2012 - 2015) 2010 [Available from: http://www.aeres-evaluation.com/content/download/14707/238363/file/3-ENGLISHPlan_dossier-Master-S3-VB-150310.pdf].last accessed 26.05.2013

172. Der Akkreditierungsrat. Rules for the Accreditation of Study Programmes and for System Accredita-tion 2013 [Available from:

http://www.akkreditierungsrat.de/fileadmin/Seiteninhalte/Beschluesse_AR/englisch/201 0_12_Rules_Study_Programmes_System_Accreditation.pdf].last accessed 26.05.2013

173. Hungarian Accreditation Committee (HAC). Standards and Criteria for Master Programs and Ex Post Accreditation of Institutions and Programs , 2012 [Available from: http://www.mab.hu/web/doc/hac/regulations/Accr_criteria_101012.pdf].last accessed 06.10 .2015

174. De Nederlands-Vlaamse Accreditatieorganisatie (NVAO). Assessment frameworks for the higher education accreditation system Programme assessment (extensive) 2011 [Available from:

http://www.nvao.net/page/downloads/DEFINITIEVE_KADERS_OPLEIDINGSBEOORDELIN G_UITGEBREID_22_november_2011_English.pdf].last accessed 24.03.2014 
175. Agenţia Română de Asigurare a Calităţii în Învăţământul Superior - Romanian Agency for Quality Assurance in Higher Education (ARACIS). Methodology for External Evaluation, Standards, Standards of Reference, and List of Performance Indicators of The Romanian Agency for Quality Assurance in Higher Education, 2006 [Available from: http://www.aracis.ro/fileadmin/ARACIS/Proceduri/Methodology_for_External_Evaluation. pdf].last accessed 06.10.2015

176. La Agencia Nacional de Evaluación de la Calidad y Acreditación (ANECA). SelfAssessment Guide (Abstract) Accreditation of Recognized Bachelor, Master and Doctorate Programmes , 2012 [Available from:

http://www.aneca.es/eng/content/download/13054/161864/file/Selfassessment\%20gui de_abstract.pdf].last accessed 06.10.2015

177. The Quality Assurance Agency for Higher Education. The UK Quality Code for Higher Education 2006 [Available from: http://www.qaa.ac.uk/assuring-standards-andquality/the-quality-code].last accessed 06.10.2015

178. Frazer M. Quality assurance in higher education. In: Craft A, editor. Quality assurance in higher education Proceedings of an International Conference: The Falmer Press; 1992. p. 9-25.

179. Chernay G. Accreditation and the Role of the Council on Postsecondary Accreditation. Washington, DC.: ERIC; 1990.

180. Sursock A. Towards accreditation schemes for higher education in Europe. CRE Project, co-funded by the SOCRATES Programme. Final project report.; 2001.

181. The Quality Assurance Agency for Higher Education. Higher education credit framework for England: Guidance on academic credit arrangements in higher education in England. Gloucester, UK.2008 [Available from:

http://www.qaa.ac.uk/en/Publications/Documents/Academic-Credit-Framework.pdf].last accessed 08.09.2015

182. Crosier D, Purser L, Smidt H. Trends V: Universities shaping the European higher education area: European University Association Brussels; 2007.

183. Westerheijden DF, Stensaker B, Rosa MJ, Corbett A. Next Generations, Catwalks, Random Walks and Arms Races: conceptualising the development of quality assurance schemes. European journal of education. 2014;49(3):421-34.

184. Vroeijenstijn T, editor Similarities and differences in accreditation. International Workshop of The Netherlands Accreditation Organization, NAO, Hague; 2003.

185. Brennan J, Shah T. Quality assessment and institutional change: Experiences from 14 countries. High Educ. 2000;40(3):331-49.

186. Cox J. Many Voices, One Song: The Role of Discipline-Based Europe-Wide Evaluation Tools in Emphasising Enhancement and Promoting the Modernisation Agenda of the EHEA. European Higher Education at the Crossroads: Springer; 2012. p. 287-301. 
187. World Bank. Priorities and strategies for education: a World Bank review: World Bank; 1995.

188. World Bank, DC. Higher Education: The Lessons of Experience. Development in Practice Series: ERIC Clearinghouse; 1994.

189. Salmi J. Constructing knowledge societies: New challenges for tertiary education. Washington, DC: World Bank. 2002.

190. Goodman. J, Müller-Nordhorn. J, Cavallo. F, Kalediene. R, Kuiper. T. Toward Equity in the Quality of European Public Health Education. Results, discussion and recommendations from the "Public health Education Reform For Equity in Quality of Training" (PERFEQT) project. Brussels, Belgium: The Association of Schools of Public Health in the European Region; 2013.

191. Grundy F, Mackintosh JM. The teaching of hygiene and public health in Europe; a review of trends in undergraduate and post-graduate education in nineteen countries. Monograph Series, World Health Organization. 1957(34):9-231.

192. Ewell P. The 'Quality Game': External review and institutional reaction over three decades in the United States. Quality Assurance in Higher Education: Springer; 2007. p. 119-53.

193. Melia T, Green D. Inspecting quality in the classroom: an HMI perspective. What is quality in higher education. 1994:38-45.

194. Thune C. The alliance of accountability and improvement: The Danish experience. Quality in higher education. 1996;2(1):21-32.

195. Williams P. Anyone for enhancement. Higher Quality. 2002;11(1):1.

196. Newton J. Is quality assurance leading to enhancement? : European University Association; 2012 [Available from: http://www.eua.be/Libraries/publications-homepagelist/How_does_quality_assurance_make_a_differenceEQAF2012.pdf?sfvrsn=2].last accessed 02.09.2015

197. Middlehurst R, Woodhouse D. Coherent systems for external quality assurance. Quality in Higher Education. 1995;1(3):257-68.

198. Saarinen T. Systematic Higher Education Assessment and Departmental Impacts: translating the effort to meet the need. Quality in higher education. 1995;1(3):223-34.

199. Hamm. M S. Quality Improvement Initiatives in Accreditation: Private Sector Examples and Key Lessons for Public Health, : Michael Hamm \& Associates,; 2007 [Available from: http://www.phaboard.org/wpcontent/uploads/QIInitiativesinAccreditation.pdf].last accessed 13.11.2015

200. Senge PM. The fifth discipline: The art and practice of the learning organization. New York: Currency Doubleday. 1990. 
201. Sursock A. Reflection from the higher education institutions' point of view: Accreditation and quality culture. Estonia2002 [Available from: http://www.aic.lv/bolona/Bologna/contrib/EUA/accredi_andQC.pdf].last accessed 15.10 .2015

202. World Federation of Medical Education (WFME). Postgraduate Medical Education Global Standards for Quality Improvement, Ferney-Voltaire, France \& Copenhagen, Denmark,: WFME; 2015 [Available from: http://wfme.org/standards/pgme/97-final-2015revision-of-postgraduate-medical-education-standards/file].last accessed 16.11.2015

203. World Federation of Medical Education. Accreditaiton 2015 [Available from: http://wfme.org/accreditation].last accessed 16.11.2015

204. Bury J, Gliber M. Quality Improvement and Accreditation of training programmes in Public Health. Lyon: Fondation Mérieux.; 2001.

205. Otok R, Levin I, Sitko S, Flahault A. European Accreditation of Public Health Education. Public Health Reviews. 2011;33(1):30-8.

206. Narayan T WM, Ghebrehiwet,. NGO coalitions for global health promotion. [Available from: http://www.phmovement.org/pha2/issues/documents/

NGOCOALITIONSFORGLOBALHEALTHPROMOTION.doc].last accessed 02.05.2011

207. Laaser U EL. Threats to global health and opportunities for change: a new global health. Public Health Reviews. 2010;32(1):54.

208. Fosdick. Raymond B. Adventure in giving; the story of the General Education Board, a foundation established by John D. Rockefeller. New York: Harper \& Row; 1962.

209. Avicenna Directories. Global directories of education institutions for health professions - a partnership of the World Health Organization and the University of Copenhagen [Available from: http://avicenna.ku.dk ].last accessed 18.05.2011

210. Beaglehole R, Sanders D, Poz M. The public health workforce in sub-Saharan Africa: challenges and opportunities. Ethnicity and Disease. 2003;13(2; SUPP/2):S2-24.

211. Pan American Health Organization. Public health in the Americas: conceptual renewal, performance assessment, and bases for action Washington: PAHO WHO; 2002 [Available from:

http://iris.paho.org/xmlui/bitstream/handle/123456789/2748/9275115893.pdf?sequenc $\mathrm{e}=1$ \&isAllowed=y].last accessed 08.09.2016

212. Bailey RJ, Dal Poz M. Building the public health workforce to achieve health-related development goals: moving forward in collaboration. Journal of public health policy. 2010;31(4):494-7.

213. Ramagen C RJ. The essential public health strategies as a strategy for improving overall health systems performance: trends and challenges since the Public Health in America initiative, 2007-2009: Washington, DC: PAHO/WHO; 2008 [Available from: http://www.paho.org/english/DPM/SHD/HR/EPHF_2000-2007.pdf].last accesed 18.05.2011 
214. The Pan-American Health Organization/World Health Organization (PAHO/ WHO). What are the EPHF? [Available from:

http://www.paho.org/english/dpm/shd/hp/EPHF.htm ].last accessed 18.05.2011

215. Centers for Disease Control and Prevention. National public health performance standards program: orientation to the essential public health services. [Available from: http://www.cdc.gov/nphpsp/documents/EssentialServicesPresentation.pdf].last accessed 18.05.2011

216. Calhoun JG, Ramiah K, Weist EM, Shortell SM. Development of a core competency model for the master of public health degree. American Journal of Public Health. 2008;98(9):1598-607.

217. Birt CA, Foldspang A. Public health capacity building-not only the property of the medical profession. The European Journal of Public Health. 2009;19(3):232-5.

218. World Federation of Public Health Associations (WFPHA). [Available from: http://www.wfpha.org/working-groups.html\#phed ].last accessed 27.05.2011

219. Council on Education for Public Health. [Available from: http://www.ceph.org].last accessed 02.05.2016

220. Agency For Public Health Education Accreditation. Website Brussels: APHEA; 2016 [Available from: www.aphea.net].last accessed 08.07.2016

221. American Public Health Association. Bridging the gap in public health capacity in Africa: experiences from public health schools without walls (PHSWOW) in Uganda.: APHA 135th Annual Meeting and Expo.; 2007 [Available from:

http://apha.confex.com/apha/135am/techprogram/paper_163935.htm].last accessed 18.05.2011

222. Rubina IG, Cassell,. Public Health Workforce Development. Emerging Infectious Disease journal. 2004;10(11):2051.

223. World Health Organization. Public health schools: six portraits: Bulletin World Health Organization. (85):907-9.; 2007 [Available from:

http://www.who.int/bulletin/volumes/85/12/07-021207/en/].last accessed 03.05.2016

224. Mushtaque A, Chowdhury R, editors. A new school of public health in Bangladesh. Global Forum update on research for health; 2005.

225. The Atlantic Philanthropies. [Available from:

http://www.atlanticphilanthropies.org].last accessed 05.05.2016

226. Public Health Foundation Of India - UK Consortium. PHFI-UKC Capacity Building Programme. [Available from: http://wtp-india-ukc.org/faculty-exchange-visits.php].last accessed 05.05.2016

227. European Commission. The Bologna Process and the European Higher Education Area. [Available from: http://ec.europa.eu/education/policy/higher-education/bolognaprocess_en.htm].last accessed 05.05.2016 
228. Tulchinsky TH, Varavikova EA. What is the" new public health"? Public Health Reviews. 2010;32(1):25.

229. Grosse-Tebbe. S, Cicevalieva. S, Bacanovic. A, Gjorgjev. D, Sulevski. Z. The former Yugoslav Republic of Macedonia: Health system review: The European Observatory on Health Systems and Policies; 2006 [Available from:

http://www.euro.who.int/_data/assets/pdf_file/0020/79004/E89275.pdf].last accessed 08.09 .2016

230. Gotsadze G, Chikovani I, Goguadze K, Balabanova D, McKee M. Reforming sanitaryepidemiological service in Central and Eastern Europe and the former Soviet Union: an exploratory study. BMC Public Health. 2010;10(1):1.

231. Association of Schools of Public Health in the European Region. ASPHER working group on accreditation in public health education. 2009 [Available from:

http://www.aspher.org/index.php?site=accreditation_in_ph_education ].last accessed 18.05.2011

232. Association of Schools of Public Health in the European Region. European Accreditation of Public Health project (ph-ACCR). 2007 [Available from: http://www.aspher.org/index.php?site=acc\&PHPSESSID=078658532d444116e5929f096d 8e5853].last accessed 18.05.2011

233. Association of Schools of Public Health in the European Region. Press release: agency for public health education accreditation in the European region. 2011 [Available from: http://www.aspher.org/pliki/pdf/aphea_press_release.pdf ].last accessed 18.05.2011

234. Karadzinska-Bislimovska J, Tozija F. New Public Health education in the Republic of Macedonia: expectations, experiences and perspectives. Journal of Public Health. 2006;14(4):217-23.

235. Flexner A. Medical education in the United States and Canada. From the Carnegie Foundation for the Advancement of Teaching, Bulletin Number Four, . Bulletin World Health Organisation. 2010;80(7):594-602.

236. Flexner A. I Remember: The Autobiography of Abraham Flexner: Simon and Schuster; 1940.

237. Fee E. The education of public health professionals in the 20th century. Institute of Medicine Gebbie KM, Rosenstock L, Hernandez LM, editors Who will keep the public healthy? 1987:222-61.

238. Abbott AC, Boyd M, Bristol LD, Brown WH, Geiger JC, Greeley SA, et al. Standardization of Public Health Training: Report of the Committee of Sixteen. American Journal of Public Health. 1921;11(4):371-5.

239. Editorial. The Medical Diploma Scandal. American Journal of Public Health. 1924;14(2):141-2.

240. Accreditation of Schools of Public Health. American Journal of Public Health and the Nations Health. 1945;35(9):953-5. 
241. Shepard WP. The professionalization of public health. American Journal of Public Health 1948;38:145-53.

242. Winslow C-EA. The accreditation of North American schools of public health: American Public Health Association; 1953.

243. Association News. American Journal of Public Health. 1974;64(9):853-933.

244. Criteria and guidelines for accrediting Schools of Public Health. American Journal of Public Health and the Nations Health. 1966;56(8):1308-18.

245. Altbach PG, Knight J. The internationalization of higher education: Motivations and realities. Journal of studies in international education. 2007;11(3-4):290-305.

246. Fee E. The WelchRose Report: blueprint for public health education in: The WelchRose Report: A public health classic, a publication by the Delta Omega Alpha Chapter to mark the 75th anniversary of the founding of the Johns Hopkins University School of Hygiene and Public Health, 1916 1992. Baltimore: Delta Omega Honorary Public Health Society. 1992:1.

247. Rosenstock L, Helsing K, Rimer B. Public health education in the United States: then and now. Public Health Reviews. 2011;33(1):39-65.

248. Matthews MR. Some trends in schools of public health. American Journal of Public Health. 1975;65(3):291-2.

249. Sommer A. Toward a better educated public health workforce. American Journal of Public Health. 2000;90(8):1194-5.

250. Hämäläinen K, Haakstad J, Kangasniemi J, Lindeberg T, Sjölund M. Quality assurance in the Nordic higher education: European Network for Quality Assurence in Higher Education; 2001.

251. Colomer C, Lindstrom B, O'Dwyer A. European training in public health A practical experience. The European Journal of Public Health. 1995;5(2):113-5.

252. Kohler L, Eklund L. BRIMHEALTH. A successful experience in Nordic-Baltic cooperation in public health training. European Journal of Public Health. 2002;12(2):152-4.

253. Eskin F, Davies A. Steps towards the development of European standards for public health training. European Journal of Public Health. 1991;1(2):110-2.

254. Winslow C-EA. The Evolution and Significance of the Modern Public Health Campaign. New Haven (CT): Yale University Press; 1923.

255. Köhler L, Bury J, de Leeuw E, Vaughan P. Proposals for collaboration in European public health training. European Journal of Public Health. 1996;6(1):70-2.

256. Bury J, Köhler L, de Leeuw E, Vaughan P. The future of ASPHER collaboration in European public health training. Zeitschrift für Gesundheitswissenschaften= Journal of public health. 1994;2(2):119-30. 
257. Cavallo F, Rimpela A, Normand C, Bury J. Public health training in Europe. Development of European masters degrees in public health. European Journal of Public Health. 2001;11(2):171-3.

258. Overall JW, Goodman J. The role of non-governmental organizations in development of schools of public health: an example from Eastern Europe and Central Asia. Public Health Reviews. 2011;33(1):168-89.

259. World Health Organization. European action plan for strengthening public health capacities and services 2012 [Available from: http://www.euro.who.int/_data/assets/pdf_file/0005/171770/RC62wd12rev1Eng.pdf?ua=1].last accessed 08.09.2016

260. Bjegovic-Mikanovic V, Vukovic D, Otok R, Czabanowska K, Laaser U. Education and training of public health professionals in the European Region: variation and convergence. International Journal of Public Health. 2012.

261. Chauvigné C, Ottenwaelter M. Accreditation Of Public Health Training Programs In Europe: Mapping And Analysis Of Quality Assurance And Accreditation Systems In Public Health Education. Rennes, France: Working Package 2 Report, Leonardo Da Vinci Programme; 2006 08.09.2013.

262. Goodman J, Simmons N. ASPHER PEER review: a discussion of its role in the joint Open Society Institute (OSI)--Association of Schools of Public Health in the European Region (ASPHER) program. Public Health Reviews. 2002;30(1-4):51-67.

263. The European Association for Public Administration Accreditation. [Available from: http://www.eapaa.org/index.php/accreditation/criteria].last accessed 27.07.2013

264. World Federation for Medical Education (WFME). Postgraduate Medical Education WFME Global Standards for Quality Improvement, Ferney-Voltaire, France \& Copenhagen, Denmark,: WFME; 2014 [Available from: http://www.wfme.org/accreditation].last accessed 27.07.2013

265. Center of Accreditation and Quality Assurance of the Swiss Universities. Guidelines of the Swiss University Conference for Academic Accreditation in Switzerland (Accreditation Guidelines) 2007 [Available from:

http://www.oaq.ch/pub/en/documents/Akkr-07-RL-eng_VO.pdf].last accessed 27.07.2013

266. European Foundation for Management Development (EFMD). EFMD Programme Accreditation System (EPAS) Standards \& Criteria Brussels2012 [Available from: http://www.efmd.org/index.php/accreditation-main/epas/epas-guides].last accessed 27.07.2013

267. European Association for Quality Assurance in Higher Education. Standards and Guidelines for Quality Assurance in the European Higher Education Area. 3rd Edition. Helsinki2015 [Available from: http://www.enqa.eu/wpcontent/uploads/2013/06/ESG_3edition-2.pdf].last accessed 27.07.2013 
268. European Quality Improvement System. EQUIS Standars \& Criteria. 2012 [Available from: https://www.efmd.org/accreditation-main/equis/equis-guides].last accessed 27.07.2013

269. The Quality Assurance Agency for Higher Education. Guidelines for preparing programme specifications Mansfield, UK.2006 [Available from:

http://www.qaa.ac.uk/Publications/InformationAndGuidance/Documents/guidelines06.p df].last accessed 27.07.2013

270. United Nations. Population Division. Dept of Economic and Social Affairs. Classification of countries by major area and region of the world. 2009 [Available from: http://esa.un.org/unpd/wup/CD-

ROM_2009/WPP2009_DEFINITION_OF_MAJOR_AREAS_AND_REGIONS.pdf].last accessed 27.07.2013

271. Prague Declaration. Toward the European Higher Education Area, communiqué of the meeting of European ministers in charge of higher education in Prague on 19 May 2001 [Available from:

http://www.ehea.info/Uploads/Declarations/PRAGUE_COMMUNIQUE.pdf].last accessed 02.05 .2015

272. Knight J. The changing landscape of higher education internationalisation - for better or worse? Perspectives: Policy and Practice in Higher Education. 2013;17(3):84-90.

273. Bucharest Communiqué. Making the most of our potential: Consolidating the European Higher Education Area 2012 [Available from:

http://www.ehea.info/uploads/(1)/bucharest\%20communique\%202012(1).pdf].last accessed 02.05.2015

274. Knight J. Internationalisationof higher education; a conceptual framework. Internationalisation of Higher Education in Asia Pacific Countries, Amsterdam: EAIE/IDP. 1997.

275. O'Donnell A. Promoting Student Mobility and Exchange in Hungary: Central European University; 2009 [Available from:

http://www.etd.ceu.hu/2009/odonnell_aileen.pdf].last accessed 08.09.2016

276. Commission E. Erasmus Plus Programme Guide. Version 2 (2015): 23/10/2014

Brussels, Belgium2014 [Available from: http://ec.europa.eu/programmes/erasmusplus/documents/erasmus-plus-programme-guide_en.pdf].last accessed 06.11.2014

277. Reavill LR. Quality assessment, total quality management and the stakeholders in the UK higher education system. Managing Service Quality. 1998;8(1):55-63.

278. McKee M, Jacobson B. Public health in Europe. Lancet. 2000;356(9230):665-70.

279. Glass RI. The SANEPID Service in the USSR. Public Health Reports. 1976;91(2):154-8.

280. The Future of the Public's Health in the 21st Century: The National Academies Press; 2003. 
281. Barnard K, Köhler L. Creating a good learning environment-a review of issues facing schools of public health. Training in Public Health Strategies to Achieve Competences Training and Research in Public Health Dialogue. 1994.

282. Crozier F, Curvale B, Dearlove R, Helle E, Hénard F. Terminology of Quality Assurance: Towards Shared European Values? ENQA Occasional Papers 12: ERIC; 2006.

283. Hoecht A. Quality Assurance in UK Higher Education: Issues of Trust, Control, Professional Autonomy and Accountability. Higher Education,. 2006;51(4):541-63.

284. Martin M, Stella A. External Quality Assurance in Higher Education: Making Choices. Fundamentals of Educational Planning 85: ERIC; 2007.

285. Lichtveld MY, Cioffi JP. Public health workforce development: progress, challenges, and opportunities. Journal of Public Health Management and Practice. 2003;9(6):443-50.

286. Navarro V. European schools of public health. The Lancet. 1995;345(8963):1511.

287. White M, Bojan F, Watt I, McKee M. Hungary: A new public health. The Lancet. 1993;341(8836):43-4.

288. Evans D. The role of schools of public health: learning from history, looking to the future. J Public Health (Oxf). 2009;31(3):446-50.

289. McKee M, Clarke A, Kornitzer M, Gheyssens H, Krasnik A, Brand H, et al. Public Health Medicine Training in the European Community: is there scope for harmonization? The European Journal of Public Health. 1992;2(1):45-53.

290. Goodman. J, Muckelbauer R, Muller-Nordhorn J, Cavallo F, Kalediene R, Kuiper T, et al. European accreditation and the future public health workforce. European Journal of public health. 2015.

291. Birt C, Foldspang A. European Core Competences for MPH Education (ECCMPHE) Brussels, Belgium: Association of Schools of Public Health in the European Region (ASPHER); 2011 [Available from: http://www.aphea.net/docs/research/ECCMPHE1.pdf].last accessed 08.09.2016

292. McKee M. Cochrane on Communism: the influence of ideology on the search for evidence. International journal of epidemiology. 2007;36(2):269-73.

293. Frenk J. The new public health. Annual Review of Public Health. 1993;14:469-90.

294. McKee M, White M, Bojan F, Ostbye T. Development of public health training in Hungary--an exercise in international co-operation. Journal of public health medicine. 1995;17(4):438-44.

295. Ladurner J, Gerger M, Holland W, Mossialos E, Merkur S, Stewart S, et al. Public Health in Austria: An analysis of the status of public health: World Health Organization; 2011. 
296. World Health Organization. Global health risks: mortality and burden of disease attributable to selected major risks: World Health Organization; 2009.

297. Smith RD, Coast J. Antimicrobial resistance: a global response. Bulletin of the World Health Organization. 2002;80(2):126-33.

298. Williamson S. Conceptualising geographies of health knowledge: the emergence of new education spaces for public health. Health \& Place. 2004;10(4):299-310.

299. World Health Organisation. The 10 Essential Public Health Operations Copehagen2016 [Available from: http://www.euro.who.int/en/health-topics/Healthsystems/public-health-services/policy/the-10-essential-public-health-operations].last accessed 06.05.2016

300. Stensaker B, Harvey L. Accountability: Understanding and Challenges. In Accountability in Higher Education: Global Perspective on Trust and Power,. 2011.

301. Harvey L. Quality assurance in higher education: some international trends. Higher Education Conference; 22-23 January 2002.; Oslo,2002.

302. Kogan M, Hanney S. Reforming higher education: Jessica Kingsley Publishers; 2000.

303. Walford $\mathrm{G}$. The changing relationship between government and higher education in Britain. G Neave and FA v Vught (Eds), Prometheus Bound: The Changing Relationship Between Government and Higher Education in Western Europe. 1991:165-84.

304. Ewell P. Transforming institutional accreditation in US higher education 2015 [Available from: http://nchems.org/documents/GatesAccreditationWhitePaper.pdf].last accessed 08.09.2016

305. Gaston PL. Higher education accreditation: How it's changing, why it must: Stylus Publishing, LLC.; 2013.

306. European University Association. Transatlantic Trade and Investment Partnership (TTIP) Update no. 4, July 20152015 [Available from:

file:///E:/A1\%20DOCS/PHD2/A1\%20Public\%20health/TTIP\%20_Update\%20no.\%204_\% 20jul15.pdf].last accessed 04.08.2015

307. CNN. Alumna sues college because she hasn't found a job [Available from: http://edition.cnn.com/2009/US/08/03/new.york.jobless.graduate/].last accessed 06.11 .2015

308. Bay D, Daniel H. The student is not the customer-An alternative perspective. Journal of Marketing for Higher Education. 2001;11(1):1-19.

309. Froestad W, Bakken P. Student involvement in quality assessments of higher education in the Nordic countries Helsinki: Nordic Quality Assurance Network in Higher Education; 2004 [2009]. Available from:

http://www.nokut.no/documents/noqa/reports/student $\% 20$ involvement $\% 20 \mathrm{in} \% 20$ quali ty $\% 20$ assessments $\% 20$ of $\% 20$ higher $\% 20$ education $\% 20$ in $\% 20$ the $\% 20$ nordic $\% 20$ countries .pdf].last accessed 08.09.2016 
310. Dees JG. The meaning of social entrepreneurship: Kauffman Center for Entrepreneurial Leadership; 1998 [Available from:

http://www.redalmarza.cl/ing/pdf/TheMeaningofsocialEntrepreneurship.pdf].last accessed 08.09.2016

311. Crisp N. Turning the world upside down: the search for global health in the 21st century: CRC Press; 2010.

312. The Accreditation Organisation of the Netherlands and Flanders (NVAO). Good Practices in Internationalisation Platform 2016 [Available from: http://gpip.nvao.net/].last accessed 15.07.2016

313. World Health Organisation. Global strategy on human resources for health: Workforce 2030 Geneva, Switzerland.2016 [Available from:

http://www.who.int/hrh/resources/global_strategyHRH.pdf?ua=1].last accessed 15.09.2016 
Appendices 

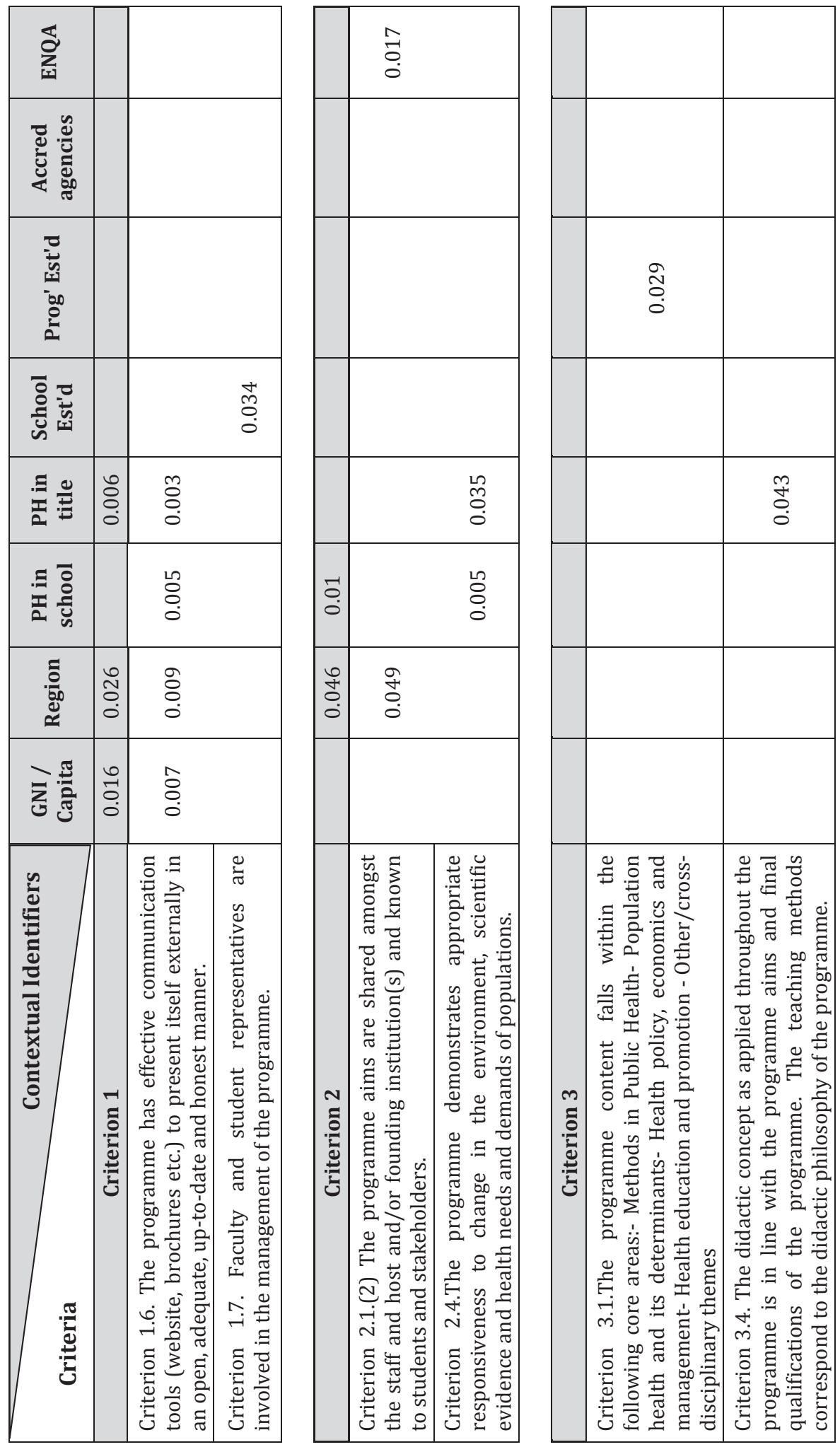

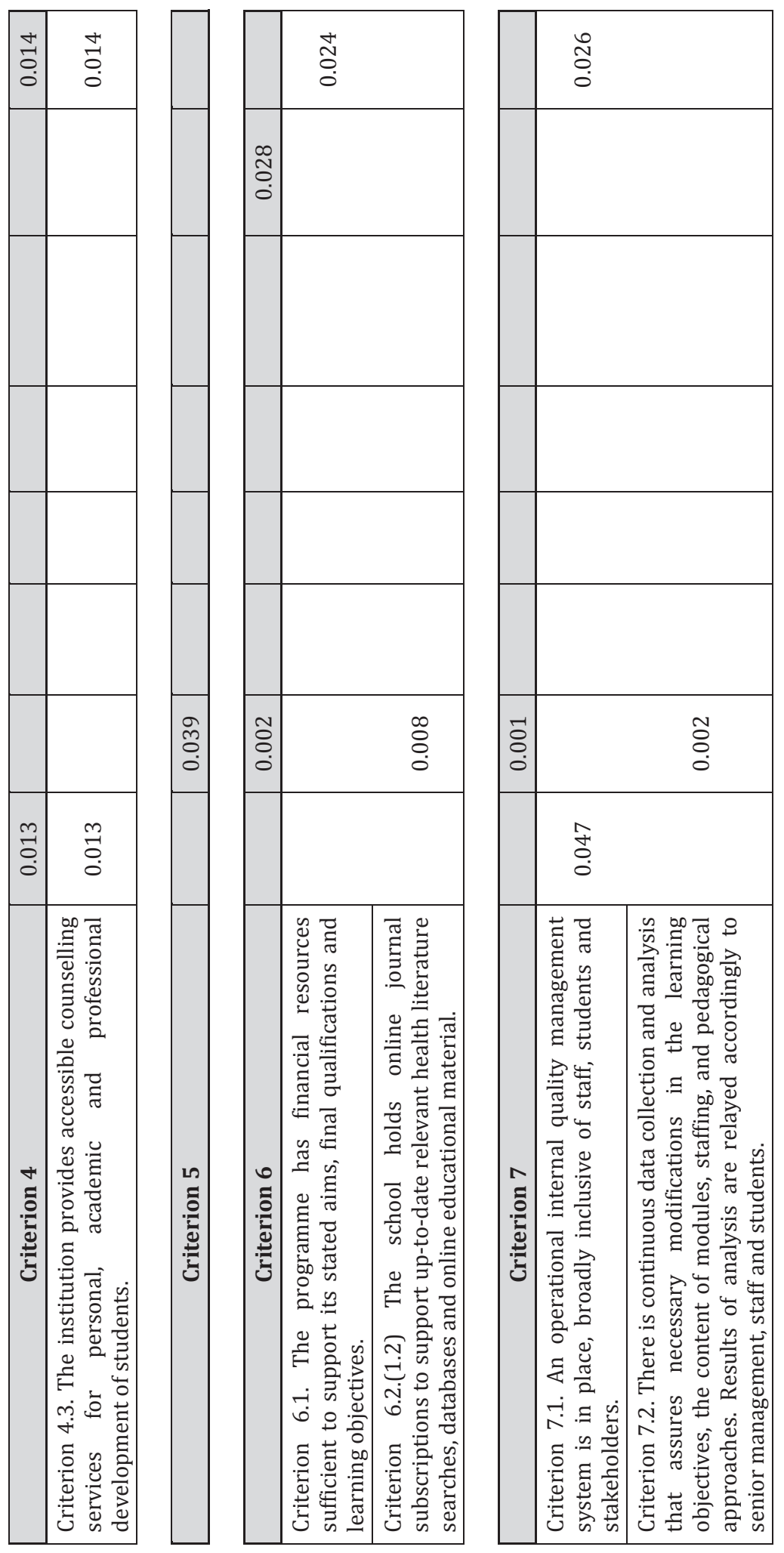


\section{Appendix B. Distributed Questionnaire for chapters 4 and 5}

Dear ASPHER member,

Recently ASPHER received co-funding to conduct a research project focusing upon the status of schools in the European Higher Education Area (EHEA) in relation to the standards outlined in the new accreditation system implemented by APHEA (Agency for Public Health Education Accreditation). The remit of the project is outlined in the box below and in addition, as a membership organisation, we would also like to enquire about any areas in which we can service your needs in the future.

We understand that your time is limited and hence we have designed this questionnaire to take a maximum of 15 minutes to complete. We cannot stress enough how important your responses are, not just for this research but also for the overall development of Public Health Education in the European Region. We very much would appreciate if you could spend a small part of your day to help.

\section{Public health Education Reform For Equity in Quality of Training: "PERFEQT"}

The GOAL of the project is to help higher education systems and institutions of public health across the EHEA to identify and compare their respective strengths and understand the gaps which require assistance in developing toward European quality standards. In so doing the AIM will be to propose a series of measures to improve and reform the quality assurance and transparency of training throughout the EHEA as well understand the challenges and timeframes involved in implementing EHEA wide reform toward accreditation of Master level programmes of public health. The METHODOLOGY is to combine a questionnaire, institutional site visits and focus group discussions

\section{PART A. Introductory Questions}

1. School name (will not shared and only used by secretariat to verify response rate and follow-up)

\section{2 . Country}

\section{School established in}

4. Programme* name

5. Programme established in

6. Number of MPH or MPH Type* programmes in your country

\begin{tabular}{|c|c|c|c|c|}
\hline$\square$ & $\square$ & $\square$ & $\square$ & $\square$ \\
1 & 2 & 3 & 4 & 5 \\
\hline $\begin{array}{c}\square \\
6 \text { to } 10\end{array}$ & $\begin{array}{c}\square \\
11 \text { to } 20\end{array}$ & $\begin{array}{c}\square \\
21 \text { or } \\
\text { more }\end{array}$ & $\begin{array}{c}\square \\
\text { Don't } \\
\text { know }\end{array}$ & \\
\hline
\end{tabular}


7. In your country, is there a formal body responsible for licensing of new programmes.

If yes please tell us the name of that body:

YES NO

8. In your country, is there a formal body responsible for issuing accreditation of existing programmes.

YES NO

If yes please tell us the name of that body if different from above:

NOTES ON definitions:

Programme / MPH / MPH type Include all programmes which follow on at least from a first cycle degree education with a focus on public health, which are generally considered "master" level.

Faculty is used to denote academic staff.

\section{PART B. Accreditation Needs}

For all questions in this section the response sought was the following:

1. We comply

2. We don't yet comply but we are in the process of trying to reach this level

3. We don't comply

\section{Criterion I: Governance and Organisation of the Programme}

The governance, organisational structure and processes are appropriate to fulfilling the aim and objectives of the programme, and consistent with the policies and requirements of the host institution.

Criterion 1.1. The parent institution is legally recognised / accredited by national educational authorities and allowed to deliver the Master programme and issue degrees.

Criterion 1.2. The programme administration and faculty shall have clearly defined rights and responsibilities concerning programme governance and academic policies appropriate to fulfilling the aim of the programme.

Criterion 1.3.There is a competent academically qualified person (or group) responsible for the coordination of the programme.

Criterion 1.4. The programme has effective communication tools (website, brochures etc.) to present itself externally in an open, adequate, up-to-date and honest manner.

Criterion 1.5. Faculty and student representatives are formally involved in the management of the programme.

\section{Criterion 2: Aims and Objectives of the Public Health Programme}

The programme has a clearly formulated programme aim or set of programme aims, conducive to the development of final qualifications (competences) in public health and which are responsive to changing environment, evidence, health needs and demands of populations.

Criterion 2.1. The programme has explicit programme aims in line with the mission of the institution.

Criterion 2.2. The programme aims are shared amongst the staff.

Criterion 2.3. The final qualifications and learning objectives correspond to general, internationally accepted descriptions of the qualifications of an academic Master programme.

Criterion 2.4.The programme is designed to respond to changes in the environment, scientific evidence and health needs and demands of populations. 


\section{Criterion 3: The Curriculum}

The curriculum, learning objectives, educational methodology, assessment procedures and outcomes are consistent with the programme aims and final qualifications of the public health programme.

Criterion 3.1.The programme content all of the following core areas: Press here for description (Please press here to see full descriptors - Appendix C)

1. Methods in Public Health

2. Population health and its determinants

3. Health policy, economics and management

4. Health education and promotion

5. Other/cross-disciplinary themes

Criterion 3.2. The core components of the curriculum provide a thorough teaching of the basic concepts, theories and methods of public health.

Criterion 3.3. The didactic concept as applied throughout the programme is in line with the programme aims and final qualifications of the programme. The teaching methods correspond to the didactic philosophy of the programme.

Criterion 3.4. Students are assessed in an adequate, meaningful and insightful manner by means of evaluations, tests and examinations, to determine whether the learning objectives or parts thereof have been achieved.

Criterion 3.5. The credit system allocated to the programme is expressed in ECTS

Criterion 3.6. International exchange of staff and students is facilitated.

\section{Criterion 4: Students and Graduates}

The programme has policies and procedures on student recruitment, enrolment, support and follow-up which are assessed and revised regularly.

Criterion 4.1. The programme has clearly defined admission criteria and recruiting policies coherent with the aim and objectives of the programme.

Criterion 4.2. The institution provides accessible counselling services for personal, academic and professional development of students.

\section{Criterion 5: Human Resources and Staffing}

The profile of teaching and support staff is appropriate to the provision of the stated programme aim and final qualifications of the programme and its continuous development. The tenure, promotion and recruitment policy of the programme is consistent with the institutional recruitment regulations and procedures and with the aim and objectives of the programme.

Criterion 5.1. There is a central core of academically qualified teaching staff dedicated to the programme. (issue with web survey - a repetition of criteria 1.1 was included)

Criterion 5.2. The workload of teaching staff is balanced between teaching (including curriculum and material development and student guidance), administration, research and service.

\section{Criterion 6: Supportive Services, Budgeting and Facilities}

The accommodation, budget and facilities are adequate to realise the programme aims, final qualifications and learning objectives in line with the educational methodology in an effective and efficient way.

Criterion 6.1. The programme has financial resources sufficient to support its stated aims, final qualifications and learning objectives.

Criterion 6.2. Library learning resources are provided for students and staff with sufficient access to these resources.

Criterion 6.3. The school holds online journal subscriptions to support up-to-date relevant health 
literature searches, databases and online educational material.

\section{Criterion 7: Internal Quality Management}

There is an internal system for assuring quality and supporting policy development, decisions, and actions.

Criterion 7.1. An operational internal quality management system is in place, broadly inclusive of staff, students and stakeholders.

Criterion 7.2. There is continuous data collection and analysis that assures necessary modifications in the learning objectives, the content of modules, staffing, and pedagogical

approaches. Results of analysis are relayed accordingly to senior management, staff and students. 
Appendix C. Core areas and descriptors - questionnaire web pop-up window

\begin{tabular}{|c|c|}
\hline CORE SUBJECT AREAS & CURRICULUM COMPETENCES \& LEARNING AREAS \\
\hline A. Introduction & Introduction and/or essentials in public health \\
\hline B. Methods in public health & $\begin{array}{l}\text { B1. Epidemiological methods, } \\
\text { B2. Biostatistical methods, } \\
\text { B3. Qualitative research methods, } \\
\text { B4. Survey methods }\end{array}$ \\
\hline $\begin{array}{l}\text { C. Population health and its } \\
\text { determinants }\end{array}$ & $\begin{array}{l}\text { C1. Environmental sciences (including physical, chemical and } \\
\text { biological factors), } \\
\text { C2. Communicable disease } \\
\text { C3. Non- communicable disease, } \\
\text { C4. Occupational health, } \\
\text { C5. Social and behavioural sciences, } \\
\text { C6. Health risk assessment, } \\
\text { C7. Health inequalities along social gradient }\end{array}$ \\
\hline $\begin{array}{l}\text { D. Health policy, economics, } \\
\text { and management }\end{array}$ & $\begin{array}{l}\text { D1. Economics, } \\
\text { D2. Healthcare systems planning, } \\
\text { D3. Organisation and management, } \\
\text { D4. Health policy, } \\
\text { D5. Financing health services, } \\
\text { D6. Health curriculum evaluation, } \\
\text { D7. Health targets }\end{array}$ \\
\hline $\begin{array}{l}\text { E. Health education and } \\
\text { promotion }\end{array}$ & $\begin{array}{l}\text { E1. Health education, } \\
\text { E2. Health promotion, } \\
\text { E3. Health protection and regulation, } \\
\text { E4. Disease prevention }\end{array}$ \\
\hline $\begin{array}{l}\text { F. Other/Cross-disciplinary } \\
\text { themes (mandatory and/or } \\
\text { elective courses) }\end{array}$ & $\begin{array}{l}\text { F1. Biology for public health, } \\
\text { F2. Law, } \\
\text { F3. Ethics, } \\
\text { F4. Ageing, } \\
\text { F5. Nutrition, } \\
\text { F6. Maternal and child health, } \\
\text { F7. Mental health, } \\
\text { F8. Demography, } \\
\text { F9. IT use, } \\
\text { F10. Health informatics, } \\
\text { F11. Leadership and decision- making, } \\
\text { F12. Social psychology, } \\
\text { F13. Global public health, } \\
\text { F14. Marketing, } \\
\text { F15. Communication and advocacy, } \\
\text { F16. Health anthropology, } \\
\text { F17. Human rights, } \\
\text { F18. Curriculum planning and development, } \\
\text { F19. Public health genomics, } \\
\text { F20. Technology assessment }\end{array}$ \\
\hline $\begin{array}{l}\text { G. Integrating Experience, } \\
\text { practicum/Internship/ final } \\
\text { project /thesis/ } \\
\text { dissertation/exam } \\
\text { /memoire }\end{array}$ & G1. Supervised by faculty (full time and/or adjunct) \\
\hline
\end{tabular}


Appendix D. Additional competences and learning areas request

\begin{tabular}{|l|l|}
\hline $\begin{array}{l}\text { X. Other / additional } \\
\text { competences and learning } \\
\text { areas }\end{array}$ & $\begin{array}{l}\text { The list above is drawn (found in Appendix } C \text { ) from previous work in } \\
\text { ASPHER. To keep our processes pertinent we ask you to include here } \\
\text { any competences that you believe are missing from the list but which } \\
\text { are used by yourselves. These can be discipline related or "soft" / } \\
\text { transversal skills for example, problem solving, conflict resolution } \\
\text { etc. They can apply to all curriculum/module and integrating } \\
\text { experience elements. }\end{array}$ \\
$\begin{array}{l}\text { Please try to use concise terms which will be universally understood } \\
\text { and code them up using X.(plus a number) in the same way as above } \\
\text { so the reviewers can clearly see these as self-generated. Place the list } \\
\text { in this box and reference within the table in Appendix A. Applicants } \\
\text { are advised to refer to the European Core Competences for MPH } \\
\text { Education booklet found here. }\end{array}$ \\
\hline
\end{tabular}



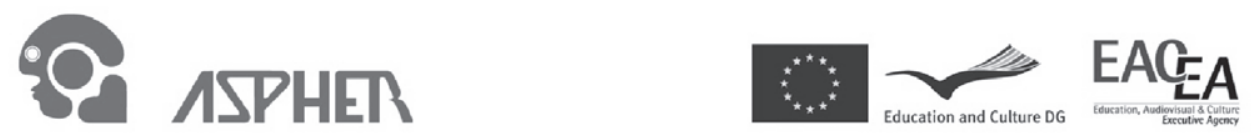

Public health Education Reform For Equity in Quality of Training: "PERFEQT"

Project co-funded by the Lifelong Learning Programme

\section{PROTOCOLS FOR SITE VISITS}

Qualitative site visit has four principal objectives

1. To understand any areas of the school needs collegial assistance with

2. To understand the willingness to undergo accreditation and what areas to focus upon

3. To understand the motivation for undertaking, or alternatively, not undertaking accreditation

4. To understand ways in which your school could help other schools.

"This is not an accreditation visit but should be seen more as a quality enhancement tool. The majority of recommendations made throughout this visit will be based upon the evidence provided from the meetings conducted with the relevant people."

This document establishes a baseline set of questions to be asked during the visit. Interviews will normally involve further questions depending on the answers provided to these questions. Please distribute this document to the relevant people in your organisation at least one week in advance of the visit so they can prepare for their meetings. The following people should receive a copy beforehand to prepare:

1. Dean / Director

2. Programme coordinator or group

3. Faculty Representative in formal school body

4. Teaching faculty

5. Librarian
6. Computer staff

7. Students

8. Student Representative in formal school body

9. Stakeholders - especially employers

10. Quality management section if applicable 


\section{CONTENTS}

CRITERIA USED IN THIS REVIEW …………………………………………………………………... 164

INFORMATION ON YOUR PROGRAMME AND SCHOOL ………………………………………........... 166

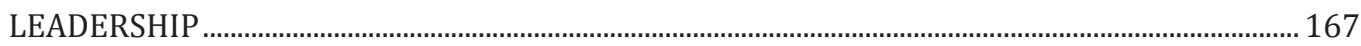

PROGRAMME COORDINATOR / GROUP.......................................................................................... 167

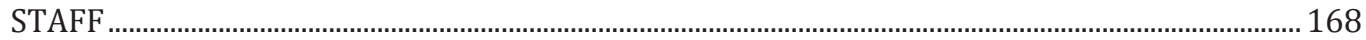

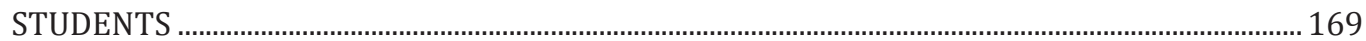

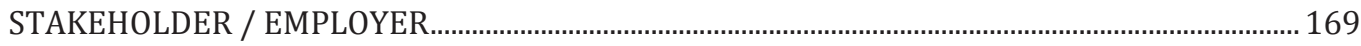

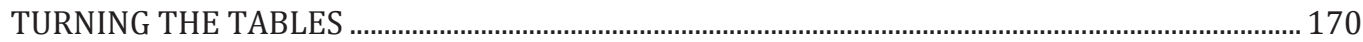

FEEDBACK SESSION PROTOCOL ……………………………………………………………………... 170

TENTATIVE REVIEW SCHEDULE........................................................................................................ 171 


\section{CRITERIA USED IN THIS REVIEW}

Criterion 1.1. The parent institution is legally recognised / accredited by national educational authorities and allowed to deliver the Master programme (see introduction) and issue degrees.

Criterion 1.2. The programme administration and faculty shall have clearly defined rights and responsibilities concerning programme governance and academic policies appropriate to fulfilling the aim of the programme.

Criterion 1.4.There is a competent academically qualified person (or group) responsible for the coordination of the programme.

Criterion 1.6. The programme has effective communication tools (website, brochures etc.) to present itself externally in an open, adequate, up-to-date and honest manner.

Criterion 1.7. Faculty and student representatives are formally involved in the management of the programme.

Criterion 2.1.(1) The programme has explicit programme aims in line with the mission of the institution.

Criterion 2.1.(2) The programme aims are shared amongst the staff.

Criterion 2.3.(1)The final qualifications and learning objectives correspond to general, internationally accepted descriptions of the qualifications of an academic (second cycle) Master programme.

Criterion 2.4.The programme is designed to respond to changes in the environment, scientific evidence and health needs and demands of populations.

Criterion 3.1.The programme content all of the following core areas:

1. Methods in Public Health

2. Population health and its determinants

3. Health policy, economics and management

4. Health education and promotion

5. Other/cross-disciplinary themes

Criterion 3.3. The core components of the curriculum provide a thorough teaching of the basic concepts, theories and methods of public health.

Criterion 3.4. The didactic concept as applied throughout the programme is in line with the programme aims and final qualifications of the programme. The teaching methods correspond to the didactic philosophy of the programme.

Criterion 3.5. Students are assessed in an adequate, meaningful and insightful manner by means of evaluations, tests and examinations, to determine whether the learning objectives or parts thereof have been achieved.

Criterion 3.7. The credit system allocated to the programme is expressed in ECTS

Criterion 3.9. International exchange of staff and students is facilitated.

Criterion 4.1.(1) The programme has clearly defined admission criteria and recruiting policies coherent with the aim and objectives of the programme.

Criterion 4.3. The institution provides accessible counselling services for personal, academic and professional development of students. 
Criterion 5.1.(1) There is a central core of academically qualified teaching staff dedicated to the programme.

Criterion 5.1.(9) The workload of teaching staff is adequately balanced between teaching (including curriculum and material development and student guidance), administration, research and service.

Criterion 6.1. The programme has financial resources sufficient to support its stated aims, final qualifications and learning objectives.

Criterion 6.2.(1) Library learning resources are provided for students and staff with sufficient access to these resources.

Criterion 6.2.(2) The school holds online journal subscriptions to support up-to-date relevant health literature searches, databases and online educational material.

Criterion 7.1. An operational internal quality management system (IQMS) is in place, broadly inclusive of staff, students and stakeholders.

Criterion 7.2. There is continuous data collection and analysis that assures necessary modifications in the learning objectives, the content of modules, staffing, and pedagogical approaches. Results of analysis are relayed accordingly to senior management, staff and students. 


\section{INFORMATION ON YOUR PROGRAMME AND SCHOOL}

In keeping with standard practice the team will require to know something of your school and programme before they arrive as well as having information on-site. Please find below details of the information we would like to receive in English language beforehand as well as information provided on-site. If the information requested is available on your website (in English) then please indicate this along with a web address. Of course, if you are able to provide all the details requested by email beforehand all the better.

\begin{tabular}{|c|c|c|}
\hline INFORMATION REQUIRED & $\begin{array}{c}\text { Sent } \\
\text { beforehand }\end{array}$ & $\begin{array}{c}\text { Available } \\
\text { on-site }\end{array}$ \\
\hline $\begin{array}{l}\text { 1. What is the exact title of the degree in national language / } \\
\text { in English }\end{array}$ & $\checkmark$ & \\
\hline $\begin{array}{l}\text { 2. What body holds the authority for degree awarding } \\
\text { powers }\end{array}$ & $\checkmark$ & \\
\hline 3. Date of national licensing - For how long and by whom? & $\checkmark$ & \\
\hline $\begin{array}{l}\text { 4. Date of national accreditation - For how long and by } \\
\text { whom? }\end{array}$ & $\checkmark$ & \\
\hline $\begin{array}{l}\text { 5. Organogram including: } \\
\text { a. governing bodies, } \\
\text { b. committees, } \\
\text { c. Roles and responsibilities } \\
\text { d. To include internal and external if unit is not stand } \\
\text { alone }\end{array}$ & $\checkmark$ & \\
\hline $\begin{array}{l}\text { 6. Promotional and information material including: } \\
\text { a. Website (web URL - website address) } \\
\text { b. brochures, publicity material }\end{array}$ & $\checkmark$ & $\checkmark$ \\
\hline 7. Mission statement & $\checkmark$ & \\
\hline 8. Programme aims & $\checkmark$ & \\
\hline $\begin{array}{l}\text { 9. Curriculum outline including modules and credit } \\
\text { allocation including core and elective elements. }\end{array}$ & $\checkmark$ & \\
\hline $\begin{array}{l}\text { 10. Assessment: Impression from a sample of exam or other } \\
\text { assessment questions }\end{array}$ & & $\checkmark$ \\
\hline $\begin{array}{l}\text { 11. Documents and/or description of the school admission } \\
\text { policies }\end{array}$ & & $\checkmark$ \\
\hline $\begin{array}{l}\text { 12. Brief description of counselling services for personal, } \\
\text { academic and professional development of students. }\end{array}$ & & $\checkmark$ \\
\hline $\begin{array}{l}\text { 13. How many full-time members are directly working for the } \\
\text { programme? }\end{array}$ & & $\checkmark$ \\
\hline $\begin{array}{l}\text { 14. What is the profile of the faculty in terms of expertise, } \\
\text { academic qualification, teamwork- and organisational } \\
\text { experience etc.? }\end{array}$ & & $\checkmark$ \\
\hline $\begin{array}{l}\text { 15. Percentage of teaching carried out by different } \\
\text { departments within the programme? }\end{array}$ & & $\checkmark$ \\
\hline $\begin{array}{l}\text { 16. Is there an internal quality management system (IQMS)? If } \\
\text { yes, what is the name of this unit and who are the } \\
\text { members? }\end{array}$ & & $\checkmark$ \\
\hline
\end{tabular}




\section{LEADERSHIP}

\begin{tabular}{|c|c|}
\hline \multicolumn{2}{|l|}{ DIRECTOR } \\
\hline Criterion 1.7. & $\begin{array}{l}\text { 1. Please describe the faculty / student / stakeholder / } \\
\text { employer participation and roles in governance, as well as in } \\
\text { formal academic organisations }\end{array}$ \\
\hline Criterion 2.1.(1) & $\begin{array}{l}\text { 1. Why was the programme initiated? } \\
\text { 2. How are staff and students made aware of the aims of the } \\
\text { programme }\end{array}$ \\
\hline
\end{tabular}

\begin{tabular}{|c|c|}
\hline \multicolumn{2}{|c|}{ DIRECTOR/MANAGEMENT } \\
\hline Criterion 3.4. & $\begin{array}{l}\text { 1. Does the programme use staff from various disciplines and } \\
\text { professions relevant to public health? } \\
\text { 2. Are there formal policies for the training processes used? }\end{array}$ \\
\hline Criterion 3.9. & $\begin{array}{l}\text { 1. Is there international exchange of faculty? } \\
\text { - If so please give details and how the policies at the school } \\
\text { / programme facilitate this. } \\
\text { 2. Number of faculty members working abroad for purposes } \\
\text { connected with the program. }\end{array}$ \\
\hline Criterion 5.1.(1) & $\begin{array}{l}\text { 1. What is the student-staff ratio within the programme per } \\
\text { academic year? }\end{array}$ \\
\hline Criterion 6.1. & $\begin{array}{l}\text { 1. Where do your main sources of income for the programme } \\
\text { derive? } \\
\text { 2. Are these sufficient and constant enough to be able to plan } \\
\text { over a five year period? }\end{array}$ \\
\hline Criterion 7.2. & $\begin{array}{l}\text { 1. Are there any examples of changes made as a direct result by } \\
\text { the operations of the internal quality management system } \\
\text { (IQMS)? }\end{array}$ \\
\hline
\end{tabular}

PROGRAMME COORDINATOR / GROUP

\begin{tabular}{|c|c|}
\hline Criterion 1.4. & $\begin{array}{l}\text { 1. Please could you describe your function as programme } \\
\text { director / coordinator }\end{array}$ \\
\hline Criterion 2.4. & $\begin{array}{l}\text { 1. How does the programme ensure that staff are aware of the } \\
\text { latest developments in their field? }\end{array}$ \\
\hline Criterion 3.4. & 1. What type of training processes are used in the programme? \\
\hline Criterion 3.5. & $\begin{array}{l}\text { 1. What are the procedures used to monitor and assess student } \\
\text { progress in achieving the learning objectives? } \\
\text { 2. What are the appeal mechanisms for assessment? } \\
\text { 3. Are tests, evaluations and examinations organised and } \\
\text { supervised by a Committee of Examination? }\end{array}$ \\
\hline Criterion 4.3. & $\begin{array}{l}\text { 1. What Information is given to the students about career } \\
\text { developments and available positions in the public and } \\
\text { private sector? }\end{array}$ \\
\hline Criterion 7.2. & $\begin{array}{l}\text { 1. Who does the IQMS formally report to? } \\
\text { 2. How does the IQMS function in terms of changes to the } \\
\text { programme? } \\
\text { 3. What and how are internal and external stakeholders } \\
\text { included in the operations of the IQMS? }\end{array}$ \\
\hline
\end{tabular}




\section{STAFF}

FACULTY REPRESENTATIVE

\begin{tabular}{l|l} 
Criterion 1.7. & 1. Please describe your role in governance/membership of formal
\end{tabular} academic bodies connected with the programme

\begin{tabular}{|c|c|}
\hline \multicolumn{2}{|l|}{ FACULTY } \\
\hline Criterion 2.1.(2) & $\begin{array}{l}\text { 1. What are the programme aims? } \\
\text { 2. How are you made aware of them }\end{array}$ \\
\hline Criterion 2.4. & $\begin{array}{l}\text { 1. How are you made aware of the latest developments in your } \\
\text { field? }\end{array}$ \\
\hline Criterion 5.1.(1) & $\begin{array}{l}\text { 1. Do you feel that your overall knowledge and skills are enough to } \\
\text { cover everything you have been asked to cover and are there } \\
\text { opportunities for you to develop those skills or knowledge? }\end{array}$ \\
\hline Criterion 5.1.(9) & $\begin{array}{l}\text { 1. Do you feel your work distribution is balanced in terms of } \\
\text { teaching, research and administration? }\end{array}$ \\
\hline Criterion 7.1. & $\begin{array}{l}\text { 1. How are you as a member of faculty included in internal quality } \\
\text { systems of the school? } \\
\text { 2. Do you feel that your input is sufficiently represented through } \\
\text { this system? } \\
\text { 3. Are you provided with feedback by the IQMS? }\end{array}$ \\
\hline
\end{tabular}

\begin{tabular}{|l|l|}
\hline LIBRARIANS & 1. \\
\hline Criterion 6.2.(1) & \multicolumn{2}{|l|}{ individuals by the library facilities? } \\
& 2. Are there guidelines for users available? \\
& 3. What are the opening times of the library? \\
& 4. Are there any areas you would to change or improve? \\
\hline
\end{tabular}

\section{COMPUTER DEPARTMENT / LIBRARIANS}

\begin{tabular}{|l|l}
\hline Criterion 6.2.(2) & 1 . What policies are in place to acquire online subscriptions?
\end{tabular}

2. What access to online subscriptions is given to the students, can they for example, gain access from home?

3. Do you consider the facilities sufficient for the required usage of students?

5. Are there any areas you would to change or improve? 


\section{STUDENTS}

\begin{tabular}{|l|l|}
\hline \multicolumn{2}{|l|}{ STUDENT REPRESENTATIVE IN GOVERNANCE } \\
\hline Criterion 1.7. & $\begin{array}{l}\text { 1. } \\
\text { Please describe your role in governance/membership of } \\
\text { formal academic bodies connected with the programme }\end{array}$ \\
\hline
\end{tabular}

\begin{tabular}{|c|c|}
\hline \multicolumn{2}{|l|}{ STUDENTS } \\
\hline Criterion 2.4. & $\begin{array}{l}\text { 1. How much do you feel the programme provides you with - } \\
\text { the latest developments in scientific evidence and } \\
\text { - up-to-date techniques for responding to the population's } \\
\text { health needs and demands }\end{array}$ \\
\hline Criterion 6.2.(1) & $\begin{array}{l}\text { 1. How often do you use the library? } \\
\text { 2. Are the resources available in the library sufficient to support } \\
\text { your studies? }\end{array}$ \\
\hline Criterion 6.2.(2) & $\begin{array}{l}\text { 1. Do you feel that there are sufficient online material and } \\
\text { subscriptions available to support your studies? }\end{array}$ \\
\hline Criterion 7.2. & $\begin{array}{l}\text { 1. Have you as a student ever been asked for your feedback on: } \\
\text { - The content of training research } \\
\text { - the didactic method of training } \\
\text { - assessments } \\
\text { 2. Do you feel that your input is sufficiently represented or } \\
\text { 3. Are you provided with feedback by the IQMS? }\end{array}$ \\
\hline
\end{tabular}

\section{STAKEHOLDER / EMPLOYER}

\begin{tabular}{|c|c|}
\hline Criterion 1.7. & $\begin{array}{l}\text { 1. (if included) Please describe your role in } \\
\text { governance/membership of formal academic bodies } \\
\text { connected with the programme }\end{array}$ \\
\hline Criterion 2.4. & $\begin{array}{l}\text { 1. To what extent does the programme meet your needs in } \\
\text { terms of : } \\
\text { - Staffing } \\
\quad \circ \text { new \& } \\
\circ \text { existing } \\
\text { - Technical assistance } \\
\text { 2. What other areas does (or does not) the programme meet } \\
\text { your needs? }\end{array}$ \\
\hline Criterion 7.1. & $\begin{array}{l}\text { 1. Have you ever been involved or asked for your views and } \\
\text { comments about the quality or relevance of the programme } \\
\text { or students? } \\
\text { 2. If so, were you given any feedback of your input? } \\
\text { 3. If not, are there any areas in which you feel the quality or } \\
\text { relevance of the programme and students might improve? }\end{array}$ \\
\hline
\end{tabular}




\section{TURNING THE TABLES}

What areas would you like to see ASPHER and its constituent members be of assistance or help to you and your school?

What areas do you feel your school could be of assistance to other schools?

\section{FEEDBACK SESSION PROTOCOL}

Criterion I: Governance and Organisation of the Programme

strengths

comments and recommendations

$$
\bullet
$$

Criterion II: aims and objectives of the public health programme

\begin{tabular}{|l|l|}
\hline strengths & comments and recommendations \\
\hline$\bullet$ & $\bullet$ \\
\hline
\end{tabular}

Criterion III: The Curriculum

\begin{tabular}{|l|l|}
\hline strengths & comments and recommendations \\
\hline$\bullet$ & $\bullet$ \\
\hline
\end{tabular}

Criterion IV: Students and Graduates

\begin{tabular}{|l|l|}
\hline strengths & comments and recommendations \\
\hline$\bullet$ & $\bullet$ \\
\hline
\end{tabular}

Criterion V: Human Resources and Staffing

\begin{tabular}{|l|l|}
\hline strengths & comments and recommendations \\
\hline$\bullet$ & $\bullet$ \\
\hline
\end{tabular}

Criterion VI: Supportive Services, Budgeting and Facilities

\begin{tabular}{|l|l|}
\hline strengths & comments and recommendations \\
\hline$\bullet$ & $\bullet$ \\
\hline
\end{tabular}

Criterion VII: Internal Quality Management

\begin{tabular}{|l|l|}
\hline strengths & comments and recommendations \\
\hline$\bullet$ & $\bullet$ \\
\hline
\end{tabular}




\section{TENTATIVE REVIEW SCHEDULE}

Please find below a general outline of the meetings the review team would like to conduct and with whom. These times can be altered to suit your schedules and will be discussed with you and finalised in advance of the arrival of the international team.

Day 0.

Day 1.

\begin{tabular}{|l|c|l|}
\hline Date/time & Criteria & Description / Participants \\
\hline 8.30 am & & Pick-up from hotel \\
\hline $09.00-09.30$ & & Briefing - Director, Programme co-ordinator / group \\
\hline $09.30-11.30$ & $1,2,3,5,6,7$ & Director \\
\hline $11.30-12.30$ & 6 & Librarian and computer staff (including tour of facilities) \\
\hline $12.30-13.30$ & & Lunch \\
\hline $13.30-17.30$ & $1,2,3,4,5,7$ & Programme co-ordinator / group \\
\hline 17.30 & & Return to Hotel \\
\hline Evening & & Social Event (Optional) \\
\hline
\end{tabular}

Day 2.

\begin{tabular}{|l|c|l|}
\hline Date/time & Criteria & Description / Participants \\
\hline $8.30 \mathrm{am}$ & & Pick-up from hotel \\
\hline $09.00-12.00$ & $1,2,3,5,7$ & Faculty (including faculty representatives in governance) \\
\hline $12.00-13.00$ & & Lunch \\
\hline $13.00-15.00$ & $1,2,7$ & Stakeholders \\
\hline $15.00-17.00$ & $1,2,3,4,6,7$ & Students (including student representatives in governance) \\
\hline 17.00 & & Return to Hotel \\
\hline
\end{tabular}

Day 3.

\begin{tabular}{|l|l|l|}
\hline Date/time & Criteria & Description / Participants \\
\hline $09.00-13.00$ & & Working session experts \\
\hline 13.30 & & Pick-up from hotel \\
\hline $14.00-15.30$ & & Feedback Session to all participants \\
\hline 16.00 & & Return to Hotel \\
\hline
\end{tabular}

Day 4.

Departure of team 
Appendix F. Key differences between APHEA and CEPH.

\begin{tabular}{|c|c|c|}
\hline $\begin{array}{c}\text { AREAS OF } \\
\text { DIFFERENCE }\end{array}$ & APHEA & CEPH \\
\hline Structural location & Non-determined & Strict separation from medical schools \\
\hline Offerings & Institutions, Masters and CPD & Institutions, PhD, Masters and Bachelor \\
\hline Content (schools) & $\begin{array}{l}\text { Basic of } 1 \mathrm{MPH} \text { type and } 2 \text { CPD or } 2 \\
\mathrm{MPH}\end{array}$ & $\begin{array}{l}\text { - } 5 \text { Compulsory MPH specialisations: } \\
\text { - } \quad \text { biostatistics, } \\
\text { - } \quad \text { epidemiology, } \\
\text { - } \quad \text { environmental health sciences, } \\
\text { - } \quad \text { health services administration } \\
\text { - } \quad \text { social and behavioral sciences } \\
\text { - Compulsory } 3 \text { doctoral degrees. }\end{array}$ \\
\hline $\begin{array}{l}\text { Content } \\
\text { (programmes) }\end{array}$ & $\begin{array}{l}\text { - Introduction } \\
\text { - } \quad \text { Methods in public health } \\
\text { - } \text { Population health and its } \\
\text { determinants } \\
\text { - Health policy, economics, and } \\
\text { management } \\
\text { - Health education and } \\
\text { promotion } \\
\text { - } \text { Other/Cross-disciplinary } \\
\text { themes } \\
\text { Other (self-defined) }\end{array}$ & $\begin{array}{l}\text { - } \quad \text { biostatistics, } \\
\text { - } \quad \text { epidemiology, } \\
\text { - } \quad \text { environmental health sciences, } \\
\text { - } \text { health services administration } \\
\text { - } \quad \text { social and behavioral sciences }\end{array}$ \\
\hline Faculty (schools) & Non-determined & Minimum of 5 faculty per specialisation \\
\hline Length of study & Dependent on national legislation & 2 year Masters \\
\hline $\begin{array}{l}\text { Length of } \\
\text { accreditation }\end{array}$ & 6 years & 7 years \\
\hline Cost (schools) & $\begin{array}{l}\text { Min } \$ 23,189 . \text { Max } \$ 29,513 \text { (Based } \\
\text { on national GNI/capita) }\end{array}$ & $\begin{array}{l}\text { US } \$ 53,530 . \text { Non US } \$ 57,350 \text { (minimum } \\
\text { amounts) }\end{array}$ \\
\hline $\begin{array}{l}\text { Cost } \\
\text { (programmes) }\end{array}$ & Min $\$ 12,648$. Max $\$ 18,973$ & $\begin{array}{l}\text { US } \$ 28,425 \text {. Non US } \$ 32,825 \text { (minimum } \\
\text { amounts) }\end{array}$ \\
\hline
\end{tabular}

It should also be highlighted that the APHEA institutional and Programme criteria are not identical. The CEPH criteria have striven for similitude. However, this has caused anomalous criteria such as the following by simply replacing the term "school" with "program":

(School Criteria) 2.14. Distance Education or Executive Degree Programs. If the school offers degree programs using formats or methods other than students attending regular on-site course sessions

(Programme Criteria) 2.12 Distance Education or Executive Degree Programs. If the programme offers degree programs using formats or methods other than students attending regular on-site course sessions 


\section{Summary}

"The foundation for a strong and effective health workforce, able to respond to the 21st century priorities, requires matching effectively the supply and skills of health workers to population needs, now and in the future."

World Health Organization (313)

The development of a strong and effective public health workforce requires widespread availability and access to high quality appropriate public health education and training. The situation at present can be characterised by an "inverse care law" (4), with those countries in most need of international support in the development of their public health education and training systems receiving the least support $(5,6)$. Alternatively, in the developed areas of the globe many (unfortunately the majority of) public health professionals already in the public health workforce do not possess even a basic education in public health (9-13).

One approach, amongst many, to address this situation is the development of an accreditation scheme capable of providing stewardship in public health education ("public health education" refers to schools, programmes and courses of public health). Over the last decades a variety of different approaches have been suggested for accreditation to shape and steer the development, content and focus of schools, programmes and courses of public health $(3,5,123,313)$. All of these have had one honourable goal in mind: the production of a professional workforce focused on population health needs. However, there are problems. Over half of the countries around the world do not have coherent higher education accreditation systems (135) and where they do exist, many are used as a form of governmental control rather than for development $(21,29,33,34)$. The situation, especially for accreditation in the European Region, is one characterised at a national level through the use of generic education standards rather than standards focused on public health education and, as a result, these standards can be applied equally to a school of public health as they can to a school of aesthetics. The efficacy of these national accreditation systems in steering public health education towards preparing a competent public health workforce is therefore highly questionable.

This leads to the central research question:

\section{Can accreditation be used for the development and improvement of public health education and, if so, how?}


There are only two agencies in the world focused on the accreditation of public health education, The Council on Education for Public Health (CEPH) in the United States and the Agency for Public Health Education Accreditation (APHEA). APHEA began life in 2011 focused on the European region. In 2015 the agency adopted a global remit to answer calls from schools, programmes and courses wishing for accreditation but unable to undertake the American system due to its prescriptive nature based around a model of public health education seldom found outside of America. Apart from these two organisations there has been no other example found of an agency using standards or criteria focused on public health education.

This dissertation focuses on how accreditation may be used globally to embrace the desire from many quarters for accreditation schemes to help instigate, improve and attest quality in public health education and training. Such a scheme would need to be flexible enough to embrace the range of development from nascent schools, programmes and courses through to those who are "world leading." Furthermore, such a system would also require flexibility to be effective and practicable within the varying systems and societies of the planet.

The introductory chapter 1 of the dissertation provides a cross-cutting literature survey based around the main themes associated with public health education accreditation. The attempt is to analyse the literature and the disparate areas of accreditation, public health, public health education and the development and delivery of education within different societies. The research found that accreditation began in earnest in America during the mid 20 th century as a response to a lack of standardisation engendered through a governmental and economic "laissez-faire" approach to education. Alternatively, the research identifies that the first systems in Europe began in the Central and Eastern region in the 1990s and were focused on control. The Western European region developed their accreditation systems some years later and these were a product of the changing relationship between the state and the education sector under the banner of accountability. These systems were also seen as a form of control based notably on "value for money" for funds received from government. Although cross national systems had been proposed the only tangible result was the establishment of membership organisations such as the European Association for Quality Assurance in Higher Education (ENQA) or the European Quality Assurance register (EQAR). These groups did not seek standardisation of processes or standards and the result is that each country of the European region continued to operate their own unique frameworks. Examples can be found from progressive systems designed to help develop internal quality systems through to systems focused solely on the control and check-listing of the minutiae.

The range in the approaches to accreditation and quality assurance is mirrored by different approaches and understanding of public health throughout the world. In the "developing" countries there continues to be a tendency to view public health as a medical specialisation which, although seen as out-dated, did provide some of the basic building blocks toward the modern approaches to public health. The accompanying education for public health in these countries therefore runs a risk of lacking some of the elements seen within modern systems such as cross / inter or multi - disciplinary approaches including, among many, health 
promotion and the control of non-communicable disease. But even in the more developed countries studies continue to demonstrate that much of their public health workforces do not possess even a basic formal education in public health (10-13). This places even more focus on the value and role of continuous professional development or short training. Therefore the purpose of accreditation in public health education has to encompass a wider range of education as well as training within varying institutional environments. To incorporate this range of training, along with the huge variation found nationally at every social, economic, political, cultural level, accreditation will need to be flexible. This is one of the key terms adopted by C-E.A. Winslow when he devised the first ever accreditation criteria for public health education in 1940s America.

The development of public health accreditation sits within a context of developmental activity conducted by the third sector or NGO sector which has been and continues to be highly influential for the development of public health education. Chapter 2 examines the range of developmental activity associated with the third sector in the global development and improvement of public health education. The chapter then focuses specifically on the use of the precursor to European accreditation (Public health Education European Review or PEER review) in the development and improvement of schools and programmes of public health in the Central and Eastern European region by an European $\mathrm{NGO}^{4}$ at the turn of the 21st century. In 2011 the European accreditation agency APHEA, a NGO, was established based upon the foundations of the previous PEER Review whilst incorporating additional decision-making structures.

The American system of public health education accreditation (CEPH) began around 65 years prior to the European system (APHEA) and both can be seen as a result of collaboration and liberalisation in the education sector (Chapter 3). In the American system the collaboration was part of a growing federal system in which the state played a minor role. Problems arose when this governmental light touch (liberalisation) created a fertile ground for the growth in disreputable education which abhorred people like Abraham Flexner who, in 1910, called for the closure of 120 of America's 155 medical schools (87). Flexner was prominent in the Rockefeller Foundation (a NGO) which from 1916 established the parameters for US based schools of public health still used today by CEPH, most notably through a separation of medical schools from schools of public health. This system is unique to the US and does not apply globally and therefore the CEPH accreditation remains prohibitive to the majority of the planet.

In Chapter 3 we found that the Rockefeller Foundation, acting on the Welch-Rose report (85), adopted a model based on a combination of German and British practices. However, collaboration in 20th Century Europe (particularly between these two countries) did not progress as smoothly as it did in America. From the mid to late 19th century education in Europe became a central element for defining and legitimising the nation state which would become grounds for separation rather than collaboration. Post second world war European progress provided a catalyst for greater inter-nation collaboration which had, as a consequence, sowed the seeds of the European regional accreditation system. However, the

${ }^{4}$ The Association of Schools of Public Health in the European Region (ASPHER) 
notion of the "nation state" continues to play a divisive and protectionist role through national accreditation agencies. European accreditation is defined by each individual national state having their own particular accreditation system and as a result there are a myriad (sometimes referred to as a "jungle") of differing accreditation systems. It is unclear if the primary responsibility of these systems is to protect academic quality or to protect the individual nation state's education system against competitive threats associated with economic liberalisation $(21,158)$. In either case, the vast majority of established accreditation systems in Europe focus on the control of education in a generic form and are not focused on individual sectors such as public health education. Thus the ability to improve public health education (as with other academic sectors) along with a potentially vested interest in protecting a country's education system in face of global competition is brought into question.

As with the introduction of accreditation systems, the development of public health education has taken place at different times and different places throughout the European region (chapter 1). In chapters 4 and 5 we examined whether this differing development over the region had led to a variation in compliance to the European regional public health accreditation criteria and the ensuing implications for the sector and accreditation. We investigated the level of compliance to the European public health education (programme) accreditation criteria and examined, first of all, the areas of least compliance or divergence (chapter 4) and, secondly, the areas of greatest compliance or convergence (chapter 5).

Chapter 4 indicates that between programmes there are variations in the compliance to criteria but these were significantly related to the programmes' geographical location rather than being dependent on other variables such as date of establishment. The two least compliant criteria were found to be internal quality management systems and exchange of students and faculty. These particular criteria stress the importance of programmes and schools of public health to learn from within and outside of their national systems with the aim of improving the competences of their respective public health workforces. As an independent commission commented in 2011, "competences should be adapted to local contexts and be determined by national stakeholders, while harnessing global knowledge and experiences" (3).

The results regarding exchange from chapter 4 also bring into question the role of national governments and their accreditation agencies in the monitoring and implementation of the Bologna process of which exchange is a central feature. This result complements the findings from chapter 1 which found that many national accreditation agencies did not monitor European transferable credits which is another central tenet of the Bologna process which European governments have signed. Together, these findings substantiate the claim that countries integrate "individualised versions" of Bologna for self or nationally defined purposes (28)

Turning the tables, in chapter 5, we examined the areas of highest compliance to the accreditation criteria. Here we found that the teaching and implementation of multidisciplinary curricula content had near universal compliance across the region. There 
were only three programmes not complying fully to multidisciplinary public health education and these came from three of the four countries where the setting of curricula content was determined by government dictates (114). As mentioned throughout the dissertation and most notably in chapter 1, national accreditation agencies in the European region do not contain systematic criteria for the review of public health curricula. This raises wider questions over who is the best judge of quality in particular academic and professional sectors.

Chapter 6 highlighted research aimed at incorporating the formative approach of the previous PEER Review and an investigation as to whether the accreditation process workload could be lightened by reducing the number of criteria and replacing the selfevaluation through a series of directed interviews. Three programmes in varying degrees of development in different areas of the European region formed the test sample. The findings reinforced the findings of the previous chapters in terms of programmes displaying a mixture of homogenous and heterogeneous attributes. The conclusions drawn from this chapter were that if accreditation is to be used for improvement it would need to be more flexible to incorporate the spectrum of development found within programmes. Furthermore, the chapter reinforces the need to include self-evaluation as an integral process within the accreditation process. This is to provide both schools and programmes with an alternative framework for introspection (200). The self-evaluation process also provides a sufficiently detailed view of the programme or school as part of the site review and decision-making process. As such the self-evaluation provides "the hinge linking the external and internal quality assessment" (17).

Chapter 7 concludes that historical accreditation processes which, for the majority of schemes are geographically locked, are based around control (summative approach) using varying pass / fail decision-making thresholds. These systems are designed to ensure accountability (most notably financial) in which a binary threshold is perhaps inevitable. Development or improvement can be viewed only as an add-on or side effect of these processes. Even with international accreditation the tendency has been to either to operate as some form of gate-keeping to a selective club or the facilitation of government funds. In these cases the accreditation processes once again operate on a pass/fail summative variant.

The conclusions are that to include improvement in its remit, accreditation will need to operate formatively across the developmental spectrum from steering and stewarding nascent education through to the attestation of quality in advanced education. To achieve this it needs to be flexible and inclusive. At national levels it is prohibited in this approach due to its links with state funds which necessitate it to be summative. This linkage is one of the foundations of accountability which provides nation-based accreditation systems with their legitimacy. However, accountability can be viewed outside of financial accountability. The chapter concludes that for the production of a competent and effective public health workforce, accreditation needs to reconsider accountability based around the impact made toward the needs of stakeholders, the sector of public health education and the health priorities of the societies and populations they serve. 
The central research question:

Can accreditation be used for the development and improvement of public health education and if so, how?

The research question answered in short by this dissertation:

The problem with public health and its education is that it is still emerging and developing in many parts of the world whereas in other parts there are highly developed systems in place. Therefore if accreditation is to help education systems develop and improve all these different levels of development would need to be included in the accreditation processes. In order to achieve this accreditation will need to be more flexible, based on a formative approach to quality and focused on improving the health, knowledge and skills of the populations that public health education serves and are accountable to. 


\section{Curriculum Vitae}

Julien Goodman was born in Leicester, the United Kingdom, in 1970. He received an initial degree in politics from the University of Huddersfield, receiving a first for his research. After receiving his Masters award in Criminology from the University of Cambridge, he worked in British and European politics as a communications director and press agent. In 2001 he began his work in public health when he joined the Association of Schools of Public Health in the European Region (ASPHER) based in Paris, France. His responsibilities in this post centred on running a multi-country Soros funded project for the establishment and development of schools and programmes of public health in the Central and Eastern European region (including the Caucus and Central Asian regions). He also devised and ran faculty training workshops with the National Institutes of Health, Bethesda, Washington. After ASPHER, Julien joined the Liverpool School of Tropical Medicine where he worked with the development of public health education in the MENA region, focusing mainly in Syria and Saudi Arabia. In 2012 Julien returned to ASPHER to run a multi-country research project funded by the European Union entitled "Public Health Education Reform for Equity in Quality of Training." At the end of 2013 he was elected the Director of the Agency for Public Health Education Accreditation (APHEA) based in Brussels. 


\section{Acknowledgements}

I would like to begin by expressing my sincere gratitude to my supervisor, Professor Wim Groot, for his continuous support of my $\mathrm{PhD}$ study over the previous seven years. His guidance and insight have supported me throughout the research and the writing of this thesis. I will be forever grateful for this support.

In addition to my supervisor, I would acknowledge and thank the assessment committee, Professor Kristof De Witte, Professor Harm Hospers, Professor Henriëtte Maassen van den Brink, Professor Selena Gray and Professor Theodore Tulchinsky for their careful reading and insightful comments which have resulted in the improvement of the thesis as a body of work.

My sincere appreciation and acknowledgement also goes to the co-authors of the work contained in the thesis, Professor Judith Overall, Professor Jacqueline Müller-Nordhorn, Professor Franco Cavallo, Professor Ramune Kalediene, Dr Rebecca Muckelbauer, Mr Tom Kuiper and Mr Robert Otok.

Furthermore, I would also like to acknowledge with appreciation the input from the friends and colleagues involved in the projects mentioned throughout this thesis who have had a profound impact on my knowledge and thinking.

I would also like to acknowledge and thank Mr Mark Davies for his keen eyes, dedication and interest in proofreading the manuscript, ensuring that grammatical and spelling errors did not evade dettection.

More generally, I would like to express my sincere appreciation and acknowledgement to Universiteit Maastricht, the Government of the Netherlands and ultimately the Dutch taxpayer who have, in my view, installed a leading system of education in the world in which I am truly grateful for being allowed to participate.

Finally, I would like to thank my wife for her unwavering support to me and our young family during the years of writing this thesis which included resettling in two different countries and giving birth to two beautiful children. 
